\title{
FOLIA
}

\section{STYLOMMATOPHORAN SLUGS OF CHINA (GASTROPODA: PULMONATA) - PRODROMUS}

\author{
ANDRZEJ WIKTOR ${ }^{1}$, CHEN DE-NIU ${ }^{2}$, WU MING ${ }^{2}$ \\ ${ }^{1}$ Museum of Natural History, Wrocław University, Sienkiewicza 21, 50-335 Wrocław, Poland \\ (e-mail: awiktor@biol.uni.wroc.pl) \\ ${ }^{2}$ Institute of Zoology, Chinese Academy of Sciences, Zoological Museum, 19 Zonguacun Lu, Hainan, \\ Beijing, China (e-mail: wum@panda.ioz.ac.cn)
}

ABSTRACT: The paper is the first attempt at a revision of the stylommatophoran slugs of mainland China, based on our own, previously unpublished, material, on examination of the available types, and on scarce literature data. Subgenus Neoanadenus and the following species have been described as new to science: Anadenus (Anadenus) parvipenis, A. (A.) yangtzeensis, A. (A.) yunnanensis, A. (Neoanadenus) gonggashanensis. The following synonymies have been proposed: Philomycus laoshanensis Chen et Gao = Philomycus bilineatum (Benson), Deroceras (Agriolimax) bilineatus Chen = Lehmannia valentiana (Férussac), Deroceras (A.) melasma Chen, $\mathrm{Xu}$ et Liu = Limax (Limacus) flavus L. Besides, ?Arion subfuscus (Draparnaud), Meghimatium bilineatum (Benson), M. cf. pictum (Stoliczka), M. rugosum Chen et Gao, Anadenus (A.) sechuenensis Collinge, ?A. (A.) sinensis Möllendorff, Lehmannia valentiana (Férussac), Limax flavus Linnaeus, Deroceras (D.) altaicum (Simroth) and $D$. (D.) laeve (Müller) have been recorded from China. Earlier records of Deroceras agreste (Linnaeus) and Eumilax brandti (Martens) have not been confirmed and must have resulted from misidentification. An identification key, taxonomic data, diagnoses of family- to species-group taxa, descriptions of external morphology and diagnostic anatomical characters, remarks on bionomics and distribution original drawings of the external appearance and internal organs, maps and lists of localities and references are provided.

KEY WORDS: Gastropoda, Pulmonata, terrestrial slugs, Arionoidea, Limacoidea, China, taxonomy, morphology, distribution, key

\begin{abstract}
摘 要
本文基于对已收集标本、以往描述及对作者所能搜集文献的研 究基础上, 对中国大陆地区柄眼目的蛞蝓种类进行了初次的厘定。 文中提出了一个新亚属 Neoanadenus 并描述了 3 个新种, 即 Anadenus (Anadenus) parvipenis, A. (A.) yangtzeensis, A. (A.) yunnanensis 和 A. (Neoanadenus) gonggashanensis。种名 Deroceras (Agriolimax) bilineatus Chen (= Lehmannia valentiana (Férussac) 和 Deroceras (A.) melasma Chen, Xu et Liu (= Limax (Limacus) flavus $\mathrm{L}$.) 为新异名。迄本研究止, 目前中国已知的柄眼目蛞崳区系包括?Arion subfuscus (Draparnaud), Meghimatium bilineatum (Benson), M. cf. pictum (Stoliczka), M. rugosum Chen et Gao, Anadenus (A.) sechuenensis Collinge, ?A. (A.) sinensis Möllendorff, Lehmannia valentiana (Férussac), Limax flavus Linnaeus, Deroceras (D.) altaicum (Simroth), D. (D.) laeve (Müller) 及上述的新种。因以前错误鉴定 故, 曾在文献中记录的 Deroceras agreste (Linnaeus) 和 Eumilax brandti (Martens) 在本研究中未被确认。

本文给出了目前已知的中国柄眼目蛞蝓的物种检索表、按分类 系统顺序排列的从科到种的鉴别特征、对外部形态及内部解剖的鉴 别特征描述、生态学记述和分布地点名录, 并绘有外形图、内部器 官图及物种分布图, 文后列出了参考文献。
\end{abstract}




\section{INTRODUCTION}

Information on the occurrence of Arionoidea and Limacoidea in China is extraordinarily poor considering the size and ecological diversity of the country. Neither is it easy to gather the pertinent literature, as these taxa have not been systematically investigated and merely single mentions of slugs appeared in print now and then, mostly in the 19th century. It was only recently that CHEN DE-NIU paid more attention to the subject.

The material at our disposal (3,731 specimens in total) is deposited at the Institute of Zoology, Academia Sinica, Beijing (=Peking) and nearly the whole of it was collected by CHEN DE-NIU himself within the last years.

Our paper, pertaining to this collection, is obviously far from complete. It should rather be regarded as a prodromus which would provide a basis for further, detailed studies on the slugs of China. Its aim is also to facilitate identification of species that have already been found to occur in this area.

The paper includes a short diagnosis of each taxon discussed, with a view to aiding identification of still undiscovered slugs and classifying them among an appropriate group while more material is being collected. A considerable part of foreign species currently recorded from China have been introduced there due to human activity, slugs being apparently particularly prone to introduction. The constantly increasing international contacts and transport of merchandise may in future contribute to intensification of this process.

The names of provinces and their geographic location are marked on Map 1. The scale bars at figures correspond to $1 \mathrm{~mm}$. Nearly all figures have been drawn with a camera lucida by ANDRZEJ WIKTOR. The distribution data have been supplied by WU MING.

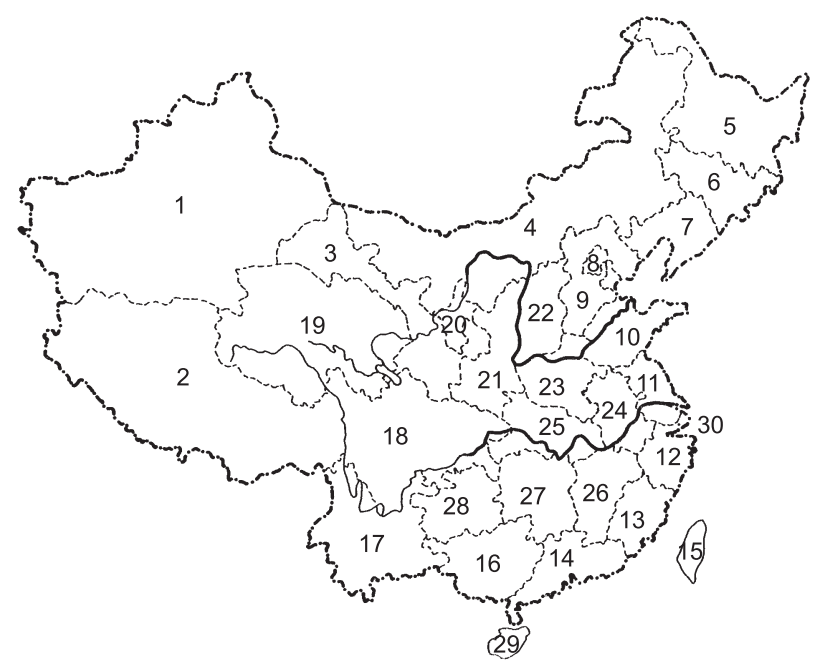

Map 1. Provinces of China: 1. Xinjiang Uygur Zizhiqu; 2. Xizang Zizhiqu (Tibet); 3. Gansu Prov.; 4. Nei Mongol Zizhiqu; 5. Heilongjiang Prov.; 6. Jilin Prov.; 7. Liaoning Prov.; 8. Beijing; 9. Hebei Prov.; 10. Shandong Prov.; 11. Jiangsu Prov.; 12. Zhejiang Prov.; 13. Fujian Prov.; 14. Guangdong Prov.; 15. Taiwan Prov.; 16. Guangxi Prov.; 17. Yunnan Prov.; 18. Sichuan Prov.; 19. Qinghai Prov.; 20. Ningxia Huizu Zizhiqu; 21. Shaanxi Prov.; 22. Shanxi Prov.; 23. Henan Prov.; 24. Anhui Prov.; 25. Hubei Prov.; 26. Jiangxi Prov.; 27. Hunan Prov.; 28. Guizhou Prov.; 29. Hainan Prov.; 30. Shanghai

The following abbreviations of repositories have been used in the text:

ZIAS - Institute of Zoology, Academia Sinica (Beijing)

NMHW - Museum of Natural History (Wrocław)

NHM - The Natural History Museum (London)

ZIN - Zoological Institute, Russian Academy of Sciences (Sankt Petersburg).

\section{SYSTEMATIC LIST OF STYLOMMATOPHORAN SLUG TAXA OF CHINA}

Arionoidea Gray, 1840

Arionidae Gray, 1840

?Arion sibiricus Simroth, 1901

?Arion subfuscus (Draparnaud, 1805)

Philomycidae Gray, 1847

Meghimatium bilineatum (Benson, 1842)

Meghimatium cf. pictum (Stoliczka, 1873)

Meghimatium rugosum (Chen et Gao, 1982)

Anadenidae Pilsbry, 1948

Anadenus (?Anadenus) dautzenbergi Collinge, 1900 after COLLINGE 1900

Anadenus (Anadenus) parvipenis n. sp. Anadenus (Anadenus) sechuenensis Collinge, 1899
Anadenus (?Anadenus) sinensis Möllendorff, 1899

Anadenus (Anadenus) yangtzeensis n. sp.

Anadenus (Anadenus) yunnanensis $\mathrm{n} . \mathrm{sp}$.

Anadenus (Neoanadenus n. subgen.) gonggashanensis n. sp.

Limacoidea Rafinesque, 1815

Limacidae Rafinesque, 1815

Lehmannia valentiana (Férussac, 1823)

Limax (Limacus) flavus Linnaeus, 1758

Agriolimacidae Wagner, 1935

Deroceras altaicum (Simroth, 1886)

Deroceras laeve (O.F. Müller, 1774) 


\section{IDENTIFICATION KEY TO THE SLUGS OF CHINA}

1(7) - Mantle covers nearly whole body. Inside mantle no shell or calcareous crystals.

2(3) - Body strongly flattened or vermiform. Pneumostome invisible, located in a slit beneath mantle margin. Sole narrow, considerably narrower than the rest of body (Caution! The family is not discussed in this paper; its few representatives occur in southern China).

Veronicellidae

3(2) - Body narrow. Back rounded. Anteriorly on the right side of mantle a well-visible pneumostome. Sole roughly as wide as the rest of body or wider.

Philomycidae p. 9 , Fig. 1

4(5) - Sexually mature slugs very large, total body length after preservation up to $131 \mathrm{~mm}$. Penis vermiform, strongly elongated. Atrium small and narrow.

\section{Meghimatium rugosum}

p. 13, Figs 18-20

5 (4) - Sexually mature slugs up to ca. $50 \mathrm{~mm}$ long. Penis vermiform, convoluted, twisted or folded in two. Atrium ovate.

Meghimatium bilineatum p. 10, Figs 11-13

6(5) - Sexually mature slugs up to ca. $35 \mathrm{~mm}$ long. Penis clavate, arcuately bent. Atrium barrel-shaped.

\section{Meghimatium pictum}

p. 12, Figs $14-17$

7(1) - Mantle covers at most half of body. Inside mantle a flat shell or loose calcareous crystals.

$8(21)$ - Pneumostome located in anterior half of mantle. Posterior body end rounded. Sole not divided by longitudinal grooves.

9(12) - Inside mantle calcareous crystals which can be loose or glued together. On posterior body end, above foot, a caudal gland. Body unicolour or with distinct lateral stripes. Penis absent. A tapering convoluted epiphallus opens directly to atrium. Oviduct large with a ligula inside and provided with its own retractor.

Arionidae

p. 6 , Fig. 1

10(11) - Coloration dark, brown-blackish, upper sole margin transversely striated (Caution! The species is expected to occur in $\mathrm{N}$ China).

Arion sibiricus p. 7, Figs $2-5$

11(10) - A slug very similar to the preceding one; orange or russet brown, with or without brown lateral stripes, in the latter case back is brownish grey and sides light; sole margin delicately striated.

Arion subfuscus p. 8, Figs $6-10$
12(9) - Inside mantle a thin flat shell. No caudal gland. Body unicolor or with irregular lateral streaks (not stripes) on mantle; on body sides beyond mantle a series of spots usually nearly vertically arranged. Penis cylindrical or clavate with a strong retractor. Epiphallus long, coiled in a skein, apically opening to penis.

Anadenidae

p. 14 , Fig. 1

13(14) - Laterally in anterior section of penis a sac-like structure which opens to penis through a narrow duct directed posterad.

subgenus Neoanadenus

p. 21

Anadenus (Neoanadenus) gonggashanensis

p. 21, Figs $41-46$

14(13) - No additional sac-like structures on the side of penis.

subgenus Anadenus s. str. p. 15

15(16) - A very large slug, after preservation at least $93 \mathrm{~mm}$ long. Back covered with very well-pronounced wrinkles, even up to $17 \mathrm{~mm}$ long and ca. $3.5 \mathrm{~mm}$ wide, which are strongly convex and nearly triangular in cross-section. Body uniformly black. Epiphallus thin and short.

Anadenus (Anadenus) yunnanensis p. 20, Figs 37-40

16(15) - A smaller slug, after preservation up to ca. 70 $\mathrm{mm}$ long. Wrinkles on back indistinct: several millimetres long, flattened or semicircular in cross-section. 17(18) - Penis small, clavate, with a ligula inside. Spermatheca duct strongly distended, clavate, roughly twice longer than penis. Epiphallus thick compared to penis, and about a dozen times longer. Penial retractor narrow. Body length after preservation up to ca. $41 \mathrm{~mm}$. General coloration of preserved slugs olive brown; on this background black or blackish irregular lateral streaks on mantle. On body sides beyond mantle the spots form lateral streaks. Besides, on back, sides and sole unevenly distributed, fine, black, round dot-like spots.

Anadenus (Anadenus) parvipenis p. 15, Figs 21-25

18(17) - Penis large, of different shape. Spermatheca duct not distended or the distension less conspicuous and smaller than penis.

19(20) - Penis clavate, posteriorly distended, with no ligula but with a granular-surfaced papilla in its distended section. Penial retractor wide. Epiphallus long (ca. 3 times longer than penis) and thick. Spermatheca duct not distended. Body length after preservation up to ca. $69 \mathrm{~mm}$. Coloration olive brown with darker spots and lateral streaks.

Anadenus (Anadenus) sechuenensis p. 17, Figs 26-28 
20(19) - Penis anteriorly distended, gradually narrowing posterad, apically equipped with a short appendix or at least a blind lateral pocket. Epiphallus thin and relatively short (ca. twice as long as penis). Inside penis a huge ligula. Spermatheca duct anteriorly inconspicuously distended. Body length of preserved slugs up to ca. $63 \mathrm{~mm}$. General body coloration brown with a reddish tint; on this background in some specimens few black dots ca. 0.5 $\mathrm{mm}$ in diameter. Besides, some specimens have blackish streaks on mantle, and laterally on the rest of body irregular spots arranged in one row.

Anadenus (Anadenus) yangtzeensis p. 18, Figs 29-36

21(8) - Pneumostome located clearly in mantle posterior half. Posterior body end pointed. Sole divided in 3 zones by longitudinal grooves.

22(25) - Mantle covers at least $1 / 3$ body length. Sole lateral zones with transverse wrinkles, the wrinkles in the median zone form a widely gaping V-letter. Alimentary canal coiled in two loops, the second reaching more posterad.

Agriolimacidae p. 28 , Fig. 1

23(24) - Rectal caecum present. Penis short, ovate or hook-like bent, its posterior end equipped with a digital penial gland. Stimulator inside penis in the shape of an elongate fold. Body section behind mantle covered by a darker reticulate pattern.

Deroceras (Deroceras) altaicum p. 29, Figs 52-54
24(23) - Rectal caecum absent. Penis - when present - vermiform, usually bent or twisted, its posterior section behind retractor insertion in the form of a long blind process. On the tip of the process single papillae may occur. Stimulator in the shape of a conical papilla (Caution! In some specimens penis is partly or completely reduced!). Body part behind mantle unicoloured.

Deroceras (Deroceras) laeve p. 31, Figs 55-57

25(22) - Mantle smaller than $1 / 3$ body length. All three zones of sole covered exclusively by transverse wrinkles. Alimentary canal coils in three loops, the first one reaching the most posterad.

Limacidae

p. 25 , Fig. 1

26(27) - Penis short, clavate, its posterior end equipped with a lobular penial gland. Dark stripes distributed laterally on mantle and partly also in posterior body section.

\section{Lehmannia valentiana} p. 25 , Figs $47-48$ 27(26) - Penis vermiform, with no penial gland. Body covered by alternating darker and lighter spots.

Limax (Limacus) flavus

p. 27, Figs 49-51

\section{SYSTEMATIC REVIEW}

\section{SUPERFAMILY ARIONOIDEA GRAY, 1840}

References: HESSE 1926: 58; PILSBRY 1948: 660; RIEDEL \& WIKTOR 1974: 85; LIKHAREV \& WIKTOR 1980: 386.

These slugs probably share a common ancestor with Endodontidae, with which they are associated by many authors. The present short diagnosis pertains only to slug species classified with Arionoidea, although the superfamily is variously treated by malacologists, who often include there also snails. The slugs included here are polyphagous or phytophagous. Their shell, partly or completely reduced, is buried in the mantle. The surface of the latter is finely granular. Pneumostome antemedially situated. Sole not divided by longitudinal grooves. Jaw usually odontognathic, marginal radular teeth wide, with numerous cusps set directly on them. Kidney encircling heart; the heart axis tilted to the left relative to the body axis. Spermatophore-producing epiphallus present. The superfamily discussed includes the following families (many authors regard them as subfamiles): Philomycidae, Arionidae, Anadenidae, Ariolimacidae, Oopeltidae and semi-slugs Binneyinae. Only the first three are represented in China.

\section{Family Arionidae Gray, 1840 (Fig. 1)}

Arionidae GRAY, in TURTON 1840: 104.

Mantle oval, limited to anterior body section. Pneumostome clearly antemedial. Posterior body section rounded, provided with an inconspicuous caudal gland. Back convex. Shell reduced to loose crystals buried in mantle, in some species assuming the form of a thick plate with indistinct growth lines. Alimentary canal strongly twisted, composed of two loops, the first of them extending more posterad. Ommatophore retractors of the right and left side with independent, posterior, insertions. Epiphallus long. Inside atrium or terminal section of oviduct a ligula. Spermatophore elongated, vermiform, with 


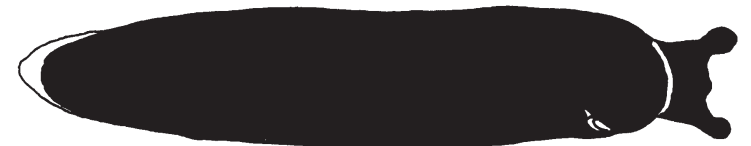

PHILOMYCIDAE

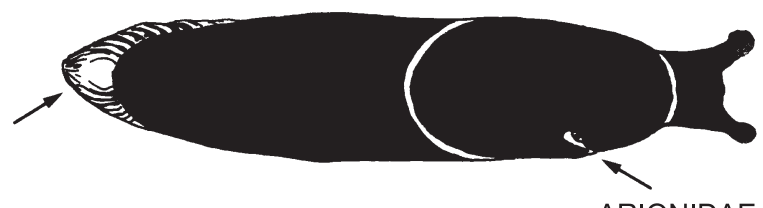

ARIONIDAE

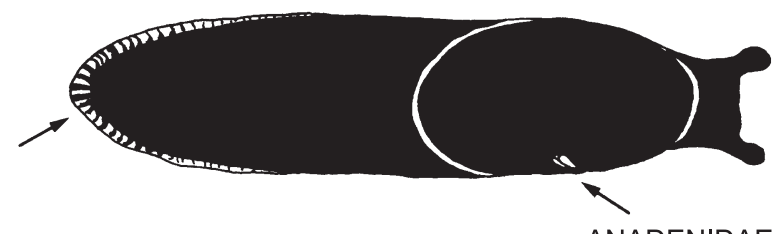

ANADENIDAE
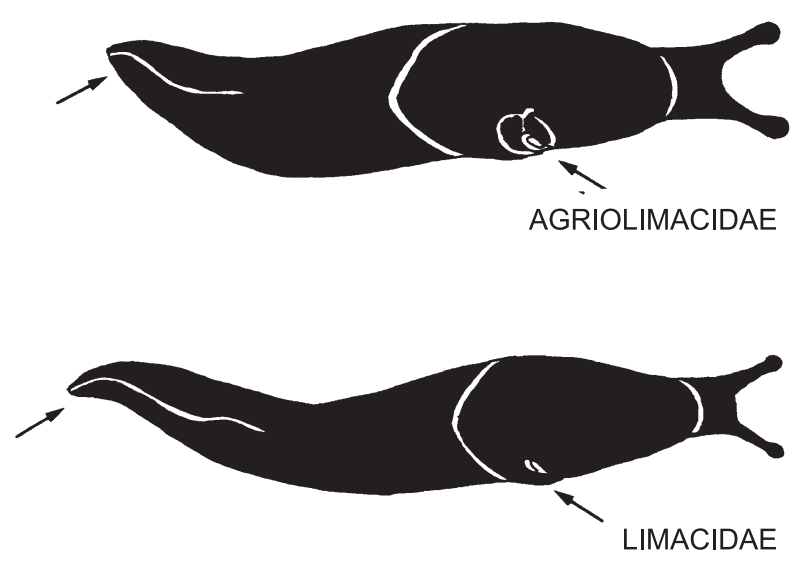

Fig. 1. Typical external appearance of stylommatophoran slugs occurring in China (orig.)

a lateral notched crest. The natural distribution range covers the northern part of Africa and nearly entire Europe (especially Iberian Peninsula), where most species occur. The family includes three genera: Arion Férussac, 1819, Geomalacus Allman, 1843 and Letourneuxia Bourguignat, 1886. Only two species (both members of the genus Arion) have colonized Asia.

\section{Genus Arion Férussac, 1819}

Arion FÉRUSSAC 1819: 50. Species typica: Arion empiricorum Férussac, 1819 [= Arion rufus (Linnaeus, 1758) or Arion ater (Linnaeus, 1758)].

References: HESSE 1926: 63; LIKHAREV \& WIKTOR 1980: 387; BACKELJAU \& BRUYN 1990: 35.
In its external appearance it does not clearly differ from other arionid genera. Inside mantle loose crystals instead of shell. Epiphallus long, loosely convoluted and gently, without a clear delimitation, passing into vas deferens at one side and into penis at the other. Oviduct mostly with a narrow posterior and a broad and well-muscled anterior section. Spermatheca, clearly delimited from its duct, connected with atrium. The main branch of strong retractor inserted to the thicker part of oviduct and to spermatheca duct. Atrium of varied shape, usually short. The genus inhabits the whole distribution area of the family Arionidae.

\section{?Arion sibiricus Simroth, 1901}

(a species not recorded from China so far but most likely to occur in this country)

Arion sibiricus SIMROTH 1901: 53, Pl. 2: Figs 1-6. Locus typicus: Irkutsk (Russia). Lectotypus: ZIN.

References: LIKHAREV \& WIKTOR 1980: 400, Figs 552-558.

Body length 20-30 mm, width 7-9 mm, mantle length 8-11 mm. Back almost black. Body wrinkles conspicuous, 14-18 of them between the median line of back and pneumostome. On sides darker stripes; between them and the darker back lighter streaks (Figs 2-3). Sides below the dark stripes orange-yellow, though the dark pigment remains visible in some of the skin grooves. Some specimens additionally have their sides dark-dotted. Such dots are also present on the sole upper margin. Sole pale but in very dark specimens its fringes may be darker.

Genitalia (Figs 4-5). Very similar to those of A. subfuscus, differing in being more robust, i.e. epiphallus, oviduct and spermatheca duct shorter and thicker.

Distribution. Poorly known; recorded exclusively from Asia, occurring in Russia in the region of the upper Abakan River, the environs of Irkutsk, in Yakutia, Primorskiy Kray and south of Khabarovsk, in the mid and southern basin of the Amur River, and in Sakhalin.

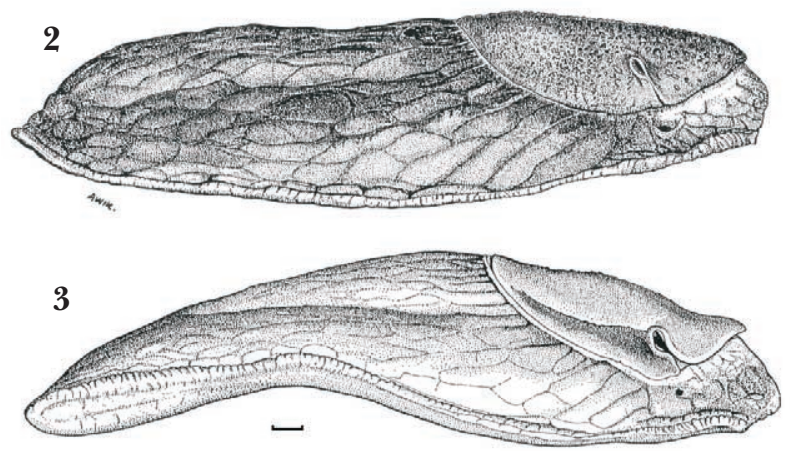

Figs 2-3. Arion sibiricus Simroth, 1901 - lateral view of two specimens from Russia (after LIKHAREV \& WIKTOR 1980) 


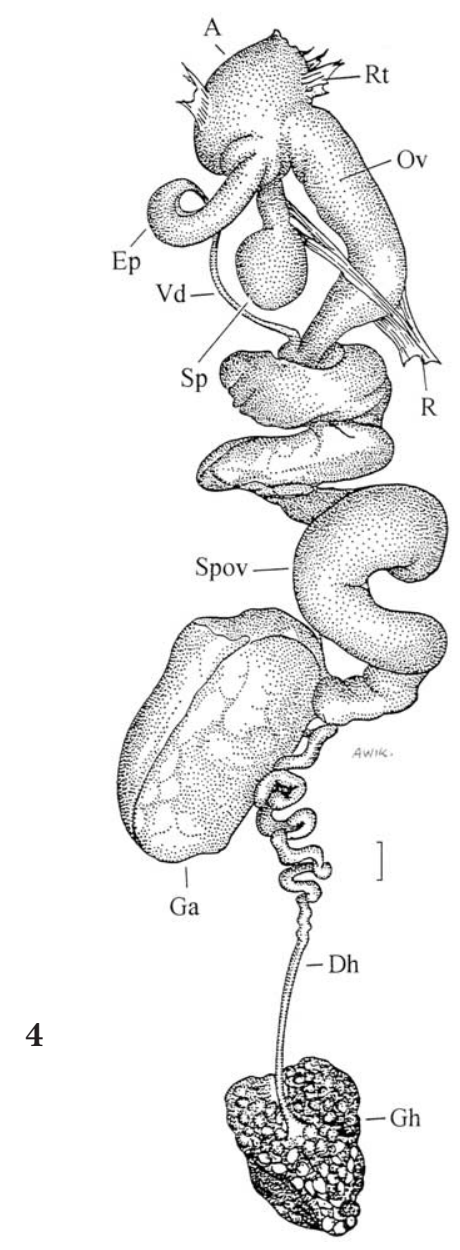

Comments. Based on the material at our disposal, we have not unequivocally ascertained the occurrence of this species in China. The hitherto known localities in Russia indicate that the slug may occur also in northern China. Single juvenile Arion specimens recorded from this country undoubtedly belong to one of the two species: either $A$. sibiricus or A. subfuscus (see below).

The species discussed is closely related to A. subfuscus. Considering both their mutual resemblance and distribution, they seem to have resulted from splitting of a single species when the distribution area was divided during the Ice Ages; the ranges of the resulting species extended after the ice-sheet had receded. Their present distribution areas probably do not overlap. Nevertheless, the number of localities of A. sibiricus and A. subfuscus and the distance between them, the unknown morphological variability ranges of the two slugs and the lack of molecular data on their relationship permit only conjectures, impending unequivocal clarification of their specific status.

\section{?Arion subfuscus (Draparnaud, 1805)}

Limax subfuscus DRAPARNAUD 1805: 125, Pl. 9: Fig. 3. Terra typica: France. Typus: probably does not exist.
5

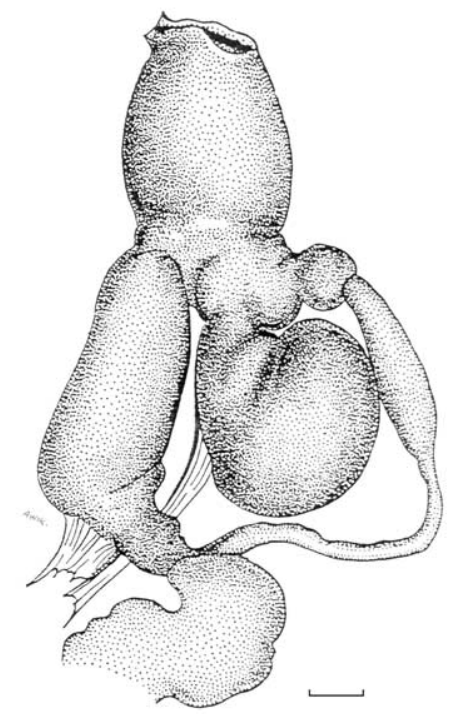

Figs 4-5. Arion sibiricus Simroth, 1901 - reproductive organs of two specimens from Russia (after LIKHAREV \& WIKTOR 1980). A - atrium, Dh - ductus hermaphroditicus, Ep epiphallus, $\mathrm{Ga}$ - glandula albuminalis, Gh - glandula hermaphroditica, Ov - oviductus, R - musculus retractor genitalis, Rt - retentor, Sp - spermatheca, Spov spermoviductus, $\mathrm{Vd}$ - vas deferens

Synonyms: ?Limax fuscus O. F. Müller, 1774; Arion ethymeanus Florence, 1836; Arion cinctus Dumont et Mortillet, 1857; ?Arion olivaceus Kotula, 1884 (for more detailed data on synonymy see HESSE 1926).

References: QUICK 1960: 133, Figs 6D, F, G, Pl. 1: Figs 1-2; LIKHAREV \& WIKTOR 1980: 396, Figs 548-553.

Externally, the slug is similar to A. sibiricus, but lighter in colour. Measurements: body length up to 40 $\mathrm{mm}$, mantle length up to $12 \mathrm{~mm}$, body width up to 11 $\mathrm{mm}$. The number of wrinkles between the median line of back and pneumostome equals 19-20. Body coloration varied: various shades of brown (not black), russet, orange or olive. On sides most frequently (but not always) distinct darker stripes. Likewise, there are darker stripes on mantle. Another stripe runs above pneumostome but the dark pigment is concentrated also below it, at its rear producing a characteristic dark triangle. Sole creamy. An orange mucus is secreted on irritation, especially by juvenile specimens (Figs 6-8).

Genitalia (Figs 9-10) differ from those of A. sibiricus in their more slender shape. A relatively long vas deferens gradually broadens into an increasingly wider epiphallus. The latter organ joins atrium close to the opening of spermatheca duct, where it forms a ring-shaped structure. Posterior oviduct section narrow, anterior one clearly broader, long and fleshy. Spermatheca oval or spherical. Spermatheca duct long, at least twice longer than spermatheca. Atrium short, oval. Genital retractor attached to oviduct 


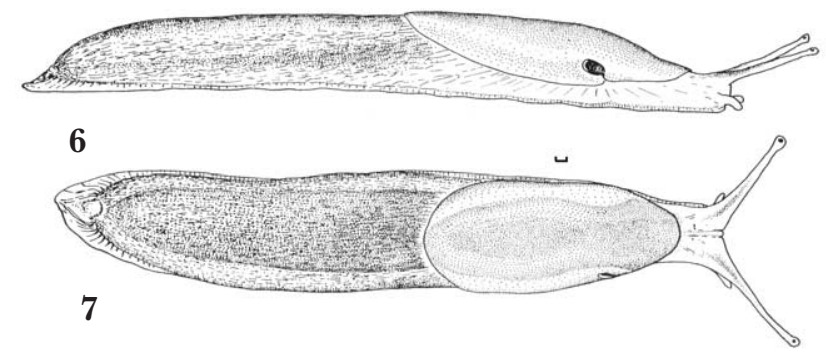

Figs 6-7. Arion subfuscus (Draparnaud, 1805) - a specimen from Poland, dorsal and lateral view (after WIKTOR 1973)

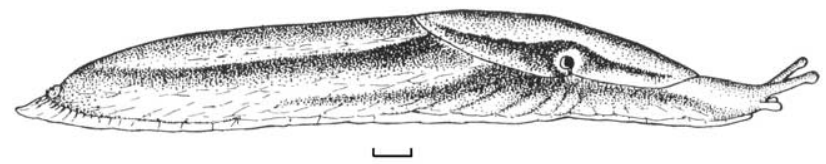

Fig. 8. Juvenile Arion subfuscus - lateral view of a specimen from Poland (after WIKTOR 1973)

where the latter distends; a small muscle strand inserts to spermatheca duct near spermatheca.

Material examined (juvenile specimens) (Map 2): Nei Mongol: Baihe, Erlian, 1979-VI-23, 2 spec., leg. Chen DE-NIU; Jilin Prov.: Qidahoe, Jiahoe County, 1980-VI-5, 1 spec., leg. CHEN DE-NIU; Yunnan Prov.: Zhongdian County, 4,200 m a.s.l., 1981-VII-26, 1 spec., leg. CHEN DE-NIU.

Distribution. The distribution area covers nearly whole Europe, except for its southern fringes. In the east the range extends beyond the Ural Mts. In China (Map 2) known only from isolated localities; no former records from Asia.

Comments. We had at our disposal only four juvenile specimens collected in China. In appearance, they resemble the species discussed. If this slug proves to be neither A. subfuscus nor A. sibiricus, its occurrence

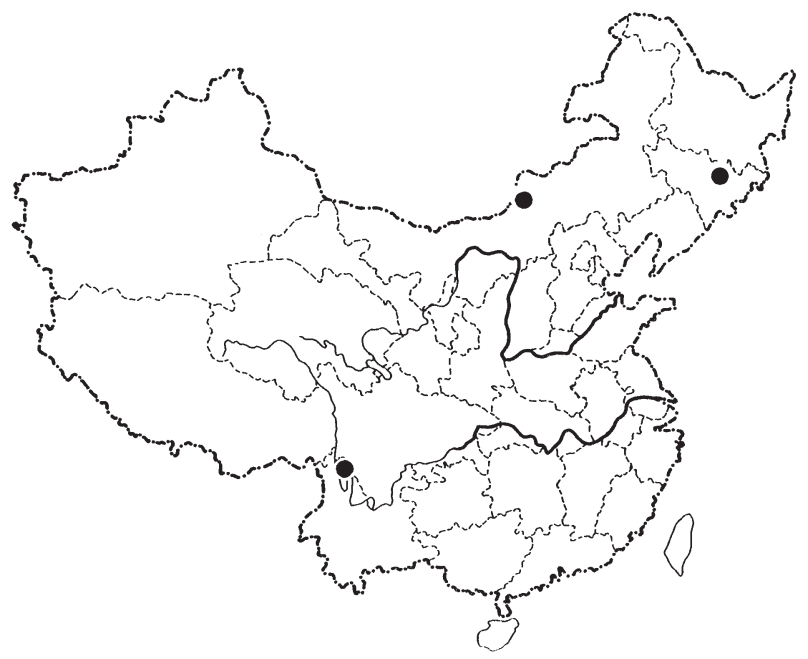

Map 2. Localities of Arion subfuscus (Draparnaud, 1805) in China

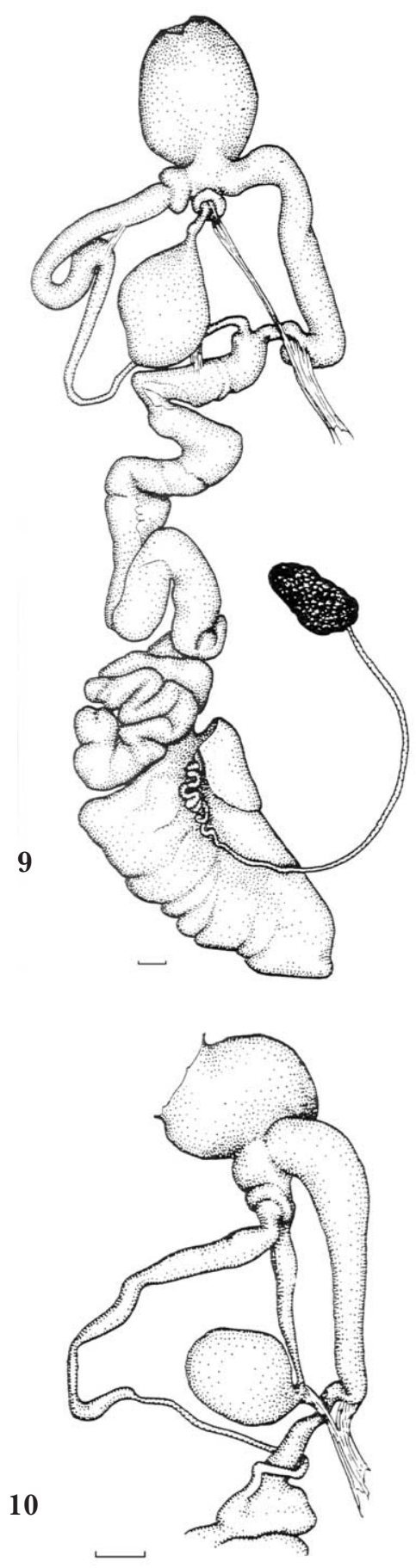

Figs 9-10. Reproductive organs of Arion subfuscus (Draparnaud, 1805) - various specimens from Poland (after WIKTOR 1973)

will have to be accounted for by introduction. See also comments to A. sibiricus.

\section{Family Philomycidae Gray, 1847 (Fig. 1)}

Philomycidae GRAY 1847: 170 (as subfamily Philomycini).

References: HOFFMANN 1924: 363; LIKHAREV \& WIKTOR 1980: 380. 
Body strongly elongated, semi-cylindrical, attaining a length up to $130 \mathrm{~mm}$. Mantle covers almost the whole body, on sides nearly reaching sole margin. It is accreted lengthwise to the rest of the body, its margins cannot be bent aside. When the slug is active, its head and posterior end of foot protrude from beneath the mantle. Mantle surface smooth. Pneumostome located in the anterior section, at ca. 1/8 body length. Posterior body end rounded, caudal gland lacking. Sole inconspicuously wider than the rest of the body, not divided by longitudinal grooves. No shell; inside mantle a fluid-filled cavity. Alimentary system composed of two loops, the first one being longer, both somewhat twisted around the body axis. Retractors of the right and left side of the body have independent insertions posteriorly. Heart tilted left by $45^{\circ}$ relative to the long body axis. Vas deferens long. Penis welldeveloped, epiphallus absent; in Asian species other accessory organs lacking as well. Spermatheca comparatively small, its duct large and thick-walled. Inside atrium a tongue-shaped ligula. The family is distributed in eastern and south-eastern Asia (see notes on Meghimatium below) as well as in North and Central America, where it reaches Colombia in the south. Only one genus, namely Meghimatium Hasselt, 1823, is known to occur in Asia; in America the family is represented by the genera Philomycus Rafinesque, 1820 and Pallifera Morse, 1864. In total, the family Philomycidae comprises ca. 20 species, only three of which have been recorded from China.

\section{Genus Meghimatium van Hasselt, 1823}

Meghimatium VAN HASSELT 1823: 232. Species typica: Meghimatium striatum van Hasselt, 1823.

Incilaria BENSON 1842: 486. Species typica: Incilaria bilineata Benson, 1842.

Contrary to the other two philomycid genera, Meghimatium occurs in Asia. Besides, it differs from the two American genera, i.e. Philomycus and Pallifera, in the lack of external glandular layer around atrium. Meghimatium differs from the externally similar Philomycus, in the absence of a special organ comprising a calcified dart-like stimulator. The distribution range of the genus extends over a vast area of eastern and southern Asia along with adjacent islands, from Russian Khabarovsk in the north and through Korea, Japan, China and India up to Borneo, Sumatra, Java, Celebes (=Sulawesi) and the Philippines.

Comments. A great number of species-level taxa have been described and later revised by HOFFMANN (1924). It seems, however, that this is still only a long list of synonyms actually representing a mere four (or just a few more) species, three of which occur in China and the fourth, namely Meghimatium striatum Van Hasselt, 1823, recorded from Japan, Java, Sumatra and Celebes.

\section{Meghimatium bilineatum (Benson, 1842)}

Incilaria bilineata BENSON 1842: 486. Terra typica: Chusan (China). Types: probably not preserved.

Synonyms: Philomycus australis Bergh, 1870; Philomycus campestris Godwin-Austen, 1876; Philomycus confusus Cockerell, 1890; Philomycus monticulus Godwin-Austen, 1876; Philomycus formosensis Cockerell, 1890; ?Philomycus chinensis Cockerell, 1890 - juv.; ?Philomycus taivanensis Simroth, 1890 juv.; ?Philomycus doderleini Simroth, 1902; Philomycus viperinus Simroth, 1902; Philomycus fruhstorferi Collinge, 1901 (for more detailed bibliographic data see HOFFMANN (1924) and also Comments).

?Philomycus laoshanensis CHEN \& GAO 1985: 24. Locus typicus: Laoshan, Shandong Prov., China. Holotypus: ZIAS. Syn. nov.

References: SIMROTH 1901: 63; LIKHAREV \& WIKTOR 1980: 382; CHEN \& GAO 1985: 24; CHEN \& GAO 1988: 63; CHEN et al. 1995: 402.

Body length (after preservation) up to ca. $50 \mathrm{~mm}$. General body coloration of alcohol-preserved specimens creamy, brownish or reddish; on this background a pattern of brown-black spots of varied intensity. The spots form the darkest concentrations and two lateral streaks of frayed edges. Sometimes the streaks constitute nearly regular stripes. Besides, both on back and below the lateral streaks/stripes there are irregular series of spots, often connected with one another (Figs 11-12). Most frequently a concentration of spots which merge in a kind of frayed dorsal streak is visible medially on back. The dark pattern varies, especially between populations. Specimens having almost exclusively three streaks (without spots between them) or uniformly light are also found. Juveniles usually have a darker, i.e. more intense and distinct, pattern. Sole unicolour: creamy.

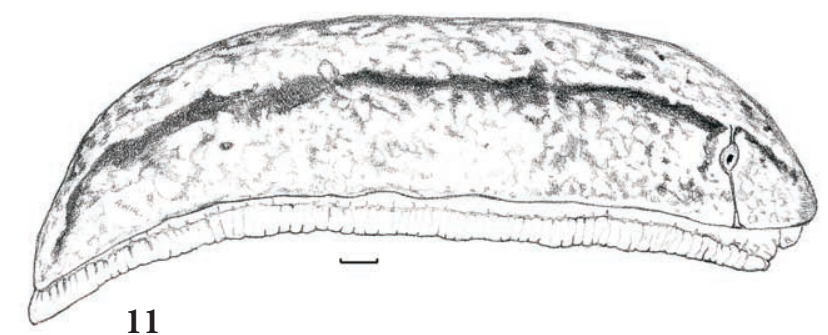

11

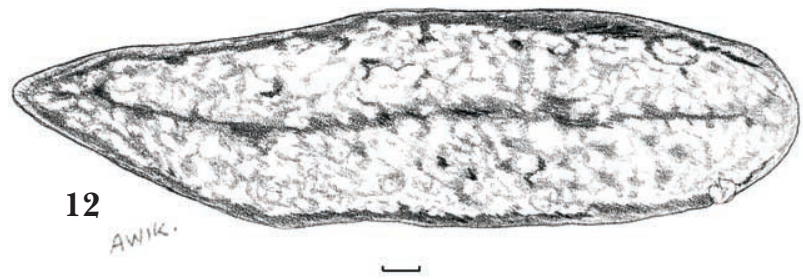

Figs 11-12. Meghimatium bilineatum (Benson, 1842) - lateral and dorsal view of a specimen from Chengxiang (Guanxi Prov.) (orig.) 
Genitalia (Fig. 13). A thin and long vas deferens opens apically. Penis worm-like elongated, folded in two, often coiled, roughly twice as long as atrium. Penial retractor asymmetrically attached to posterior end of penis. Spermatheca ovate or spherical. Atrium large, ovate.

Habitat. The species is found on humid moss under shrubs, occasionally on bare rocks after showers.

Material examined. Jilin Prov.: Tumengling, 1980-VII-5, 1 spec., leg. CHEN DE-NIU; Zhejiang Prov.: Gaoting, Daishan County, 1978-V-31, 40 spec., leg. Chen DE-NIU; Xiaopumen, Daishan County, 1978-VI-3, 5 spec., leg. Chen De-NIU; Haiyou, Sanmen County, 1978-VI-11, 21 spec., leg. CHEN DE-NIU; Niutoushan, Changxing County, 1978-V-24, 16 spec.; West Tianmu, Lin'an County, 1979-VI-11, 2 spec.; Hangzhou, 1978-V-20, 27 spec., leg. CHEN DE-NIU; Tonglu County, 1978-VII-7, 5 spec.; Hubei Prov.: Zhoutang, Yuquancun, Dangyang County, 1985-VII-31, 1 spec.; Dayan, Changyang County, 1984-V-21, 2 spec., leg. CHEN DE-NIU; Sanyang, Xingshan County, 1984-VII-23, 2 spec.; Zhenzi, Xingshan County, 1984-VII-13, 3 spec.; Sitangping,

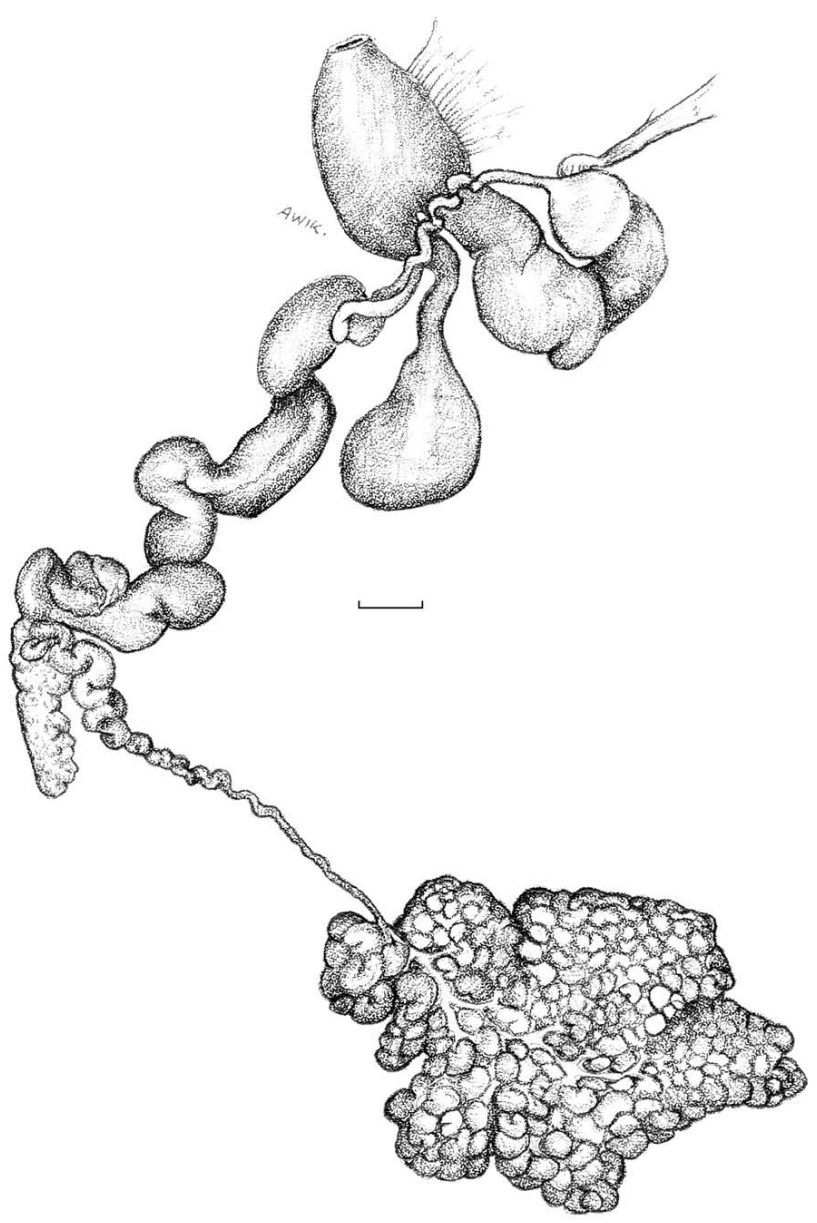

Fig. 13. Reproductive organs of Meghimatium bilineatum (Benson, 1842) - the same specimen as in Figs 11-12 (orig.)
Yangliu, Badong County, 1984-VII-2, 4 spec.; Dangyangxiang, Maopingqu, Jianshi County, 1989-VII-18, 3 spec., leg. CHEN DE-NIU; Sichuan Prov.: Bailu, Wuxi County, 1 spec.; Luojiayan, Jinxiqu, Qianjiang County, 1989-VII-24, 1 spec.; Shitixiang, Xiushan County, 1986-VI-21, 22 spec., leg. CHEN DE-NIU; Mingshan, Fengdu County, 1985-IX-23, 4 spec.; Shibaozhai, Zhong County, in the mountains, 1985-X-3, 1 spec., leg. CHEN DE-NIU; Yanzigou, E slope of Gonggashan, Luding County, 1982-IX-17, 2 spec., leg. Chen De-niU; Moxi, E slope of Gonggashan Mt., Luding County, 1982-IX-14, 6 spec., leg. CHEN DE-NIU; Lumbering Station, E slope of Gonggashan Mt., Luding County, 1982-IX-15, 6 spec., leg. CHen DE-NIU; Fenjiangqiao, Ya'an County, 1964-VII, 1 spec.; Caopingshan, Ya'an County, 1964-VII, 1 spec.; Baoguosi, Emei Mts., 1964-VIII-3, 3 spec.; Jiu Laodong, Emei Mts., 1964-VIII-8, 3 spec.; Cuipingshan, Yibin, 1964-VI-18, 12 spec., 1964-VI-18, 1 spec., 1964-VI-11, 1 spec.; Martyr Cemetery, Liangshan, 1964-VII, 1 spec.; Guizhou Prov.: Yangguan, Guiyang, 1998-V, 25 spec.; Yunnan Prov.: Town of Dali County, 1981-VII-3, 1 spec., leg. Chen De-NiU; Xishan, Qiongzushi, Kunming, 1985-VI-8, 1 spec., leg. CHEN DE-NIU.

Distribution. In China (Map 3) the species occurs mainly in the mid and lower Yangtse basin. Because of the scarcity of data on the slugs in NE China, it is difficult to judge whether the occurrence of M. bilineatum in Jilin Prov., the only northern locality, indicates introduction due to human activity or represents its natural distribution. COLLINGE (1899) recorded the species from Chekiang, YEN (1937) from Shanghai. It is difficult to draw the whole distribution range precisely without prior verification of the numerous synonyms and many very old records of the species. The present state of knowledge indicates that M. bilineatum

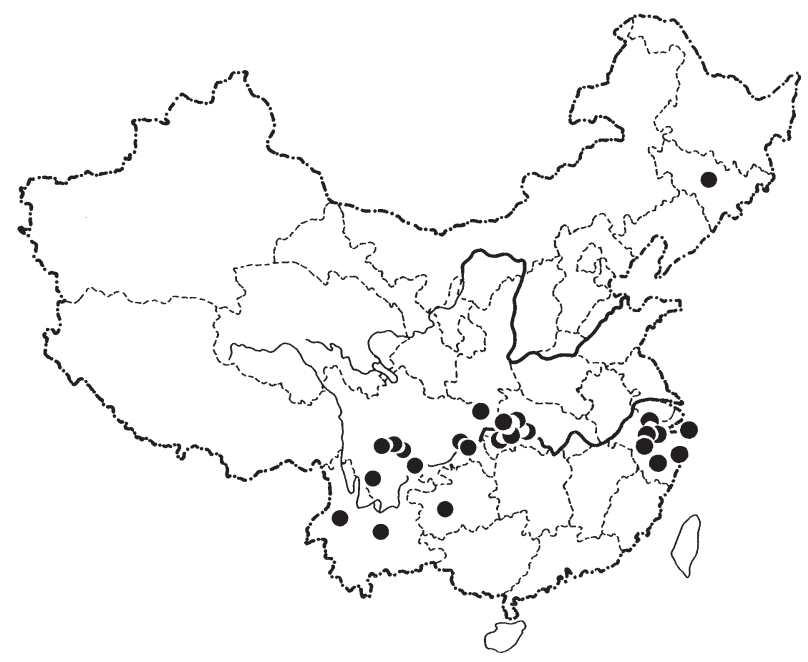

Map 3. Localities of Meghimatium bilineatum (Benson, 1842) in China 
is a widely distributed species, its range being identical with that of the genus (see above).

Comments. The slug is characterized by an enormous individual variability of coloration. Besides, juvenile specimens seem to be more contrastingly coloured and their body pattern is more distinct. The great number of synonyms is a result of describing species based solely on coloration; other characters provide evidence that the forms thus distinguished are conspecific. As a result of his detailed study, HOFFMANN (1924) synonymized most of the names, providing a sound justification. His arguments seem convincing, though we have not examined the types preserved.

So far the knowledge of the whole genus has been too fragmentary for us to decide about the taxonomic value of particular characters. For instance, when distinguishing between M. bilineatum and M. striatum, HOFFMANN (1924) paid much attention to the features of the kidney. According to this author, in some slugs the kidney wholly encirles the heart, whereas in others it only partly surrounds it, assuming the shape of a horse-shoe. HOFFMANN (1924) probably viewed the kidney only from the dorsal side (as indicated by his drawings, in which the ureter is situated on the right). All specimens examined by us have a kidney in the shape of a closed ring, which is a character typical not only of the whole family Philomycidae but of all the arionoid slugs. In dorsal view the heart often covers the narrowed section of the kidney which may give a wrong impression that the kidney does not make a closed circle.

Philomycus laoshanensis seems to be merely a colour form of Meghimatium bilineatum.

\section{Meghimatium cf. pictum (Stoliczka, 1873)}

Philomycus pictus STOLICZKA 1873: 30, Pl. III: Figs 9-14. Locus typicus: Penang hill, Penang Isl. (=Pinang) (Malaysia). Typus: no information.

Synonyms: Philomycus tonkinensis Simroth, 1902;

?Philomycus melachlorus Simroth, 1902; Philomycus fruhstorferi var. picta Collinge, 1901.

Body length $35 \mathrm{~mm}$. General coloration of alcohol-preserved specimens pale creamy; on this background a dark, much contrasting (more so than in the other two discussed species) irregular reticulate pattern composed of relatively large, irregularly shaped spots. Dorsally between the lateral streaks, the arrangement of spots often yields an irregular series of V-letters, which may produce a pine-stripe pattern as the "letters" are connected by an irregular streak running medially along the back (Figs 14-16).

Genitalia (Fig. 17). Vas deferens short, only slightly longer than penis. Penis in the shape of a crooked club, short, slightly longer than atrium. Spermatheca nearly spherical, its duct thin. Atrium large, barrel-shaped.

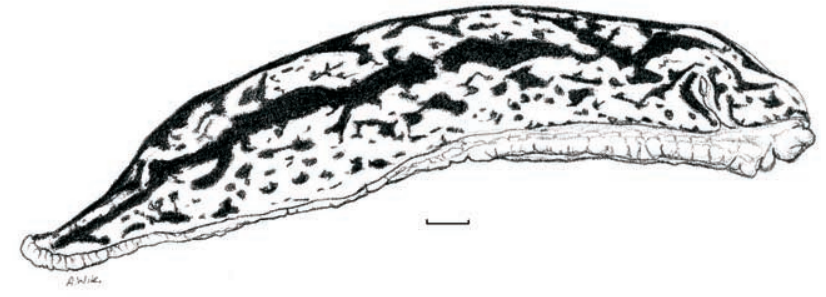

Fig. 14. Meghimatium cf. pictum (Stoliczka, 1873) - lateral view of a specimen from Xingyi (Guizhou Prov.) (orig.)

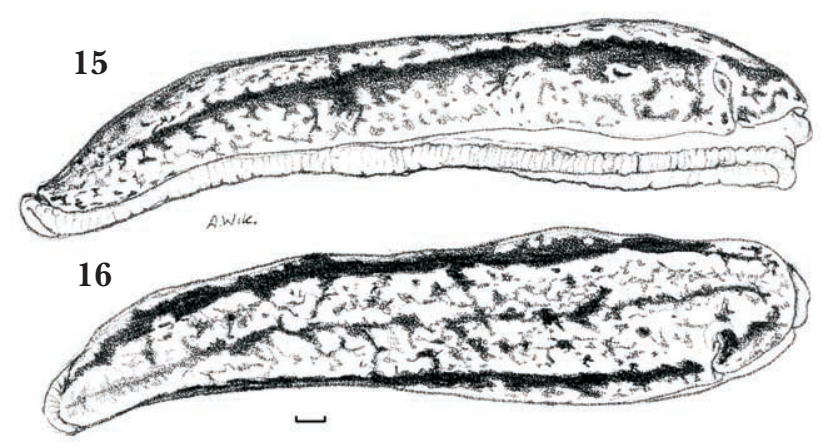

Figs 15-16. Meghimatium cf. pictum (Stoliczka, 1873) - lateral and dorsal view of a specimen from the Qinghe forestry station (Gansu Prov.) (orig.)

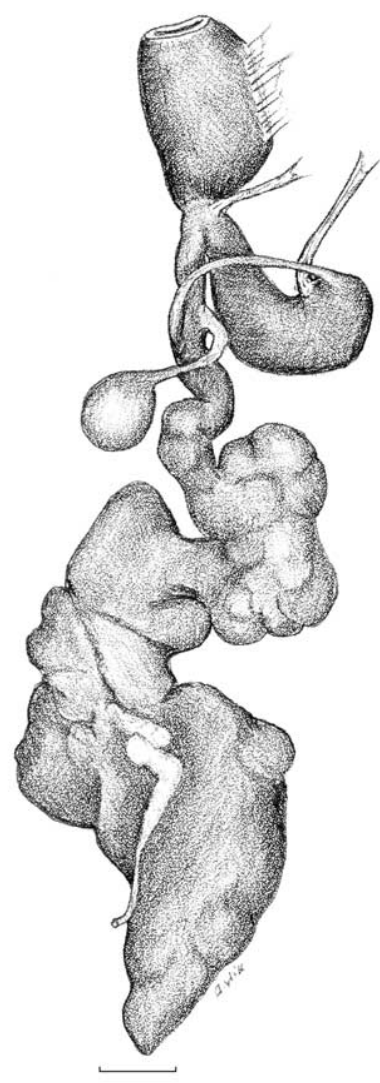

Fig. 17. Reproductive organs of Meghimatium cf. pictum (Stoliczka, 1873) - the same specimen as in Figs 15-16 (orig.) 
Bionomics unknown.

Material examined. Gansu Prov.: Qinghe forestry station, Kang County, Gansu Prov., 1400 m a.s.1., 1998-VII-15, 1 spec., leg. CHEN Jun; Shaanxi Prov.: Nanwutaishan Mt., Chang'an County, 1957-V-20, 2 spec., leg. CHEN DE-NIU; Zhangliangmiao, Liuba County; Nvwashan Mt., Pingli County, 1992-III-30, 1 spec.; Hongmiaoqu, Nanzhen County, Shaanxi Prov., 1957-IV-21, 2 spec., leg. ZHANG XI; Yunnan Prov.: Weixi County, 1981-VII-16, 1 spec.; Zhejiang Prov.: Annan, Qingyuan County, 1978-VI-27, 17 spec., leg. Chen De-NiU; Guangdong Prov.: Maozifeng, Nanxiong County, 1985-IX-22, 1 spec., leg. CHEN DE-NIU; Yilecun, Guangzhou, 1964-I-3, 3 spec., leg. CHEN DE-NIU.

Distribution in China (for localities where the material was collected see Map 4) unknown; it probably covers China and India.

Comments. According to Hoffmann (1924), besides the small size, the reticulate pattern on the body and relatively straight penis, the slug is distinct in the shape of its kidney which does not form a ring (see Comments to M. bilineatum).

The specimens identified here as $M$. cf. pictum do not differ clearly from M. bilineatum. They are smaller and have a more contrasting colour pattern, which is composed of larger spots arranged in "pine-stripes". With respect to genitalia, $M$. cf. pictum is distinguishable by a clavate penis roughly equalling atrium in size. The distribution ranges of $M$. cf. pictum and M. bilineatum seem to overlap partly. We are not sure whether the former slug is a distinct species or just a form of the latter. Considering the similarity of a few characters of the slug discussed to those of M. pictumuntil Philomycidae have been revised - we have decided with some reservations to treat the one concerned as $M$. (cf.) pictum, although this species was described from Malaysia which is quite distant from the Chinese localities.

\section{Meghimatium rugosum (Chen et Gao, 1982)}

Philomycus rugosus CHEN \& GAO 1982: 119, Figs 1-5. Locus typicus: Lishui, Zhejiang Province (China), ca. $500 \mathrm{~m}$ a.s.l. Holotypus: ZIAS (Map 5).

A crawling slug is up to $131 \mathrm{~mm}$ long. Body size of preserved specimens: length up to $62 \mathrm{~mm}$, width up to $12 \mathrm{~mm}$. Coloration yellowish-brown or deep brown, after preservation creamy brown with brown-black irregular narrow streaks. Besides, there is a considerably paler, complex, grey pattern both on back and sides, as well as a few nearly black spots (Figs 18-19).

Genitalia (Fig. 20). All parts of copulatory organs are strongly elongated except for atrium and spermoviduct, the latter being clearly short. Vas deferens thin and very long. Penis very long, simple, vermiform, convoluted, only at the end somewhat broader. Spermatheca ovally spherical, its duct nearly

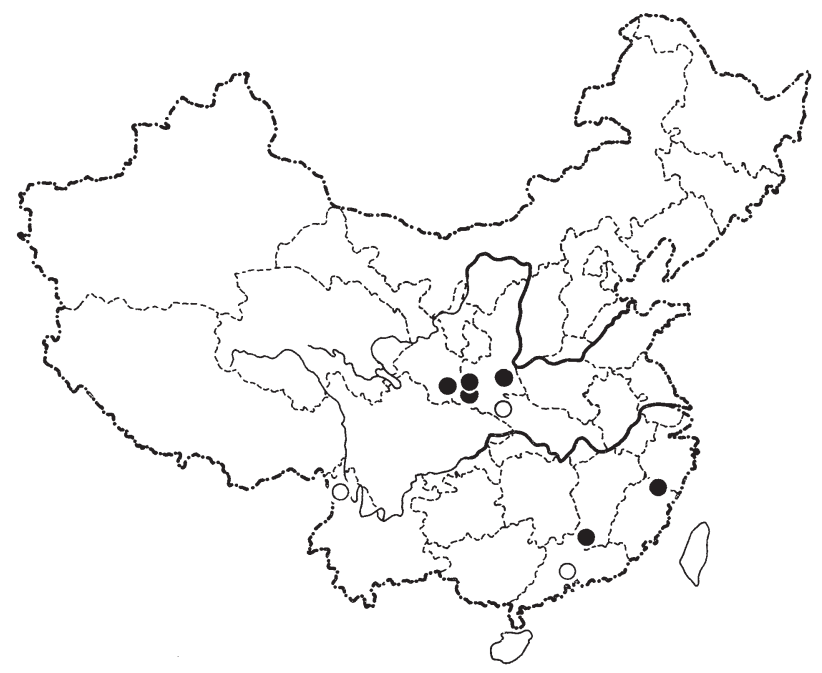

Map 4. Localities of Meghimatium cf. pictum (Stoliczka, 1873) in China. Hollow circles denote doubtful localities.

twice as long as spermatheca. Before joining spermatheca duct, oviduct is thick and short, farther assuming the shape of a long tube somewhat broader both posteriorly and anteriorly. This anterior section of oviduct from the connection with spermatheca duct is also referred to as vagina. It is joined by numerous membraneous strands of retentor muscles. Atrium very short.

Bionomics unknown.

Material examined. Zhejiang Prov.: Fengyangshan Mt., $1600 \mathrm{~m}$ a.s.1., 1984-VIII, 1 spec., leg. CHEN DE-NIU; Hongkou Forest Station, ca $500 \mathrm{~m}$ a.s.l., Lishui County, 1978-VI-14, types - 2 spec., leg. CHEN DE-NIU; Anhui Prov.: Qiyunshan, 1984-V, 1 spec., leg. Chen DE-NIU; Guangdong Prov.: Pingyuan County, 1985-IX, 1 spec., leg. PAN LIN-XIANG.

Distribution (Map 5). M. rugosum inhabits SE China, reaching south to the Yangtse River.

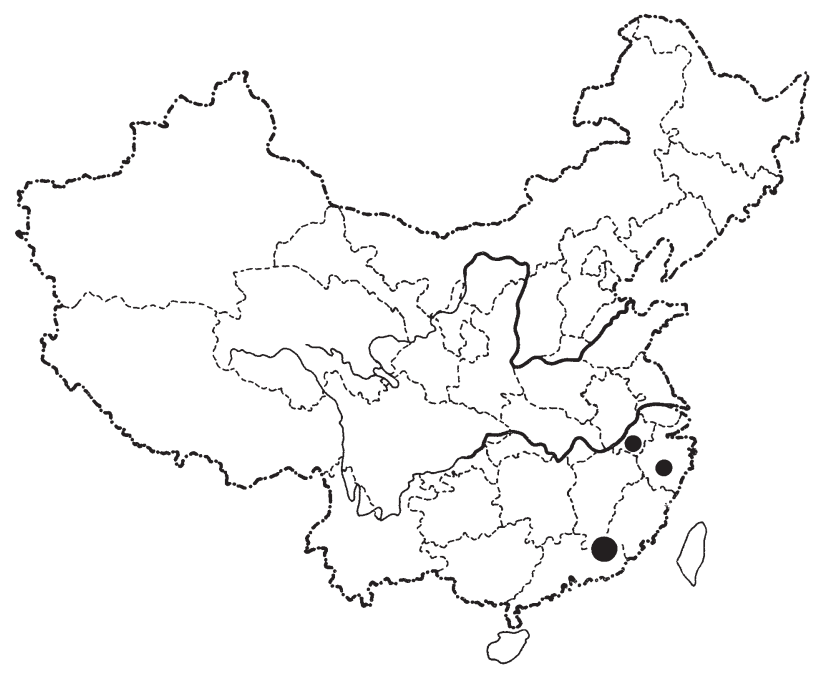

Map 5. Localities of Meghimatium rugosum (Chen et Gao, 1982) in China; type locality denoted by a large circle 

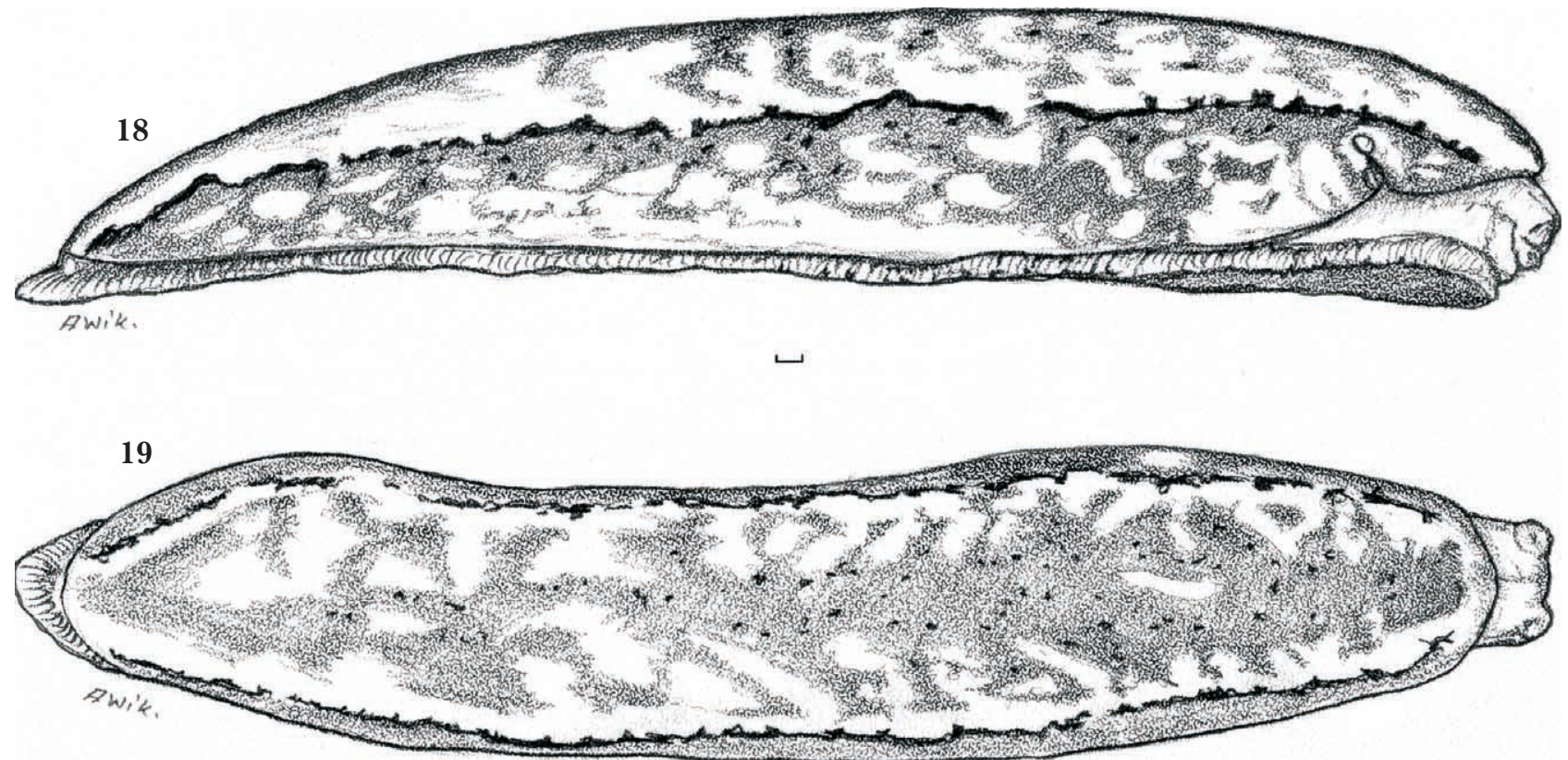

Figs 18-19. Meghimatium rugosum (Chen et Gao, 1982) - lateral and dorsal view of a specimen from Fengyang Mt. (Zhejiang Prov.) (orig.)

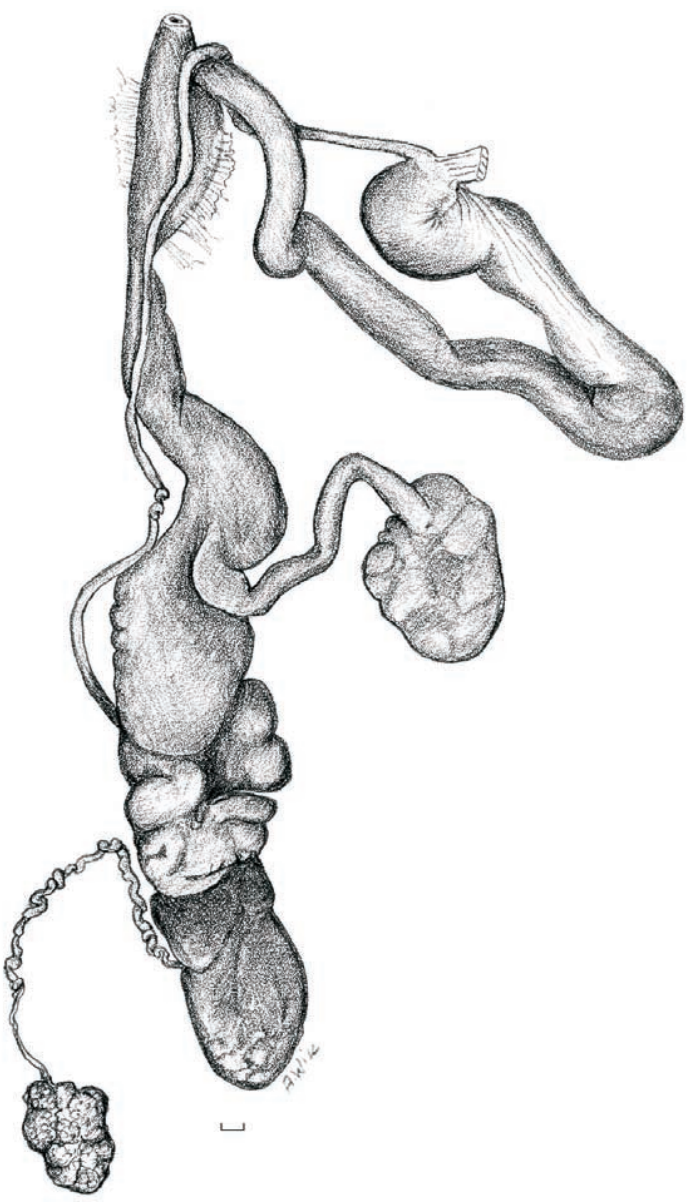

Fig. 20. Reproductive organs of Meghimatium rugosum (Chen et Gao, 1982) - the same specimen as in Figs 18-19
Comments. The following characters distinguish this species from all other Asian Philomycidae: body size; poorly distinct dark pattern; short spermoviduct; very long vas deferens, penis and oviduct; tiny atrium.

\section{Family Anadenidae Pilsbry, 1948 (Fig. 1)}

Anadeninae PILSBRY 1948: 676 (as a subfamily within Arionidae).

Mantle oval, covering ca. 1/3 body length, situated anteriorly, its surface covered by a granular sculpture. Pneumostome antemedial. Back rounded (posteriorly without a keel). No caudal gland. Inside mantle a flat, oval, inconspicuously asymmetrical vestigial shell. The second loop of intestine shifted posterad relative to the first one. Body unicolour or with a pattern on mantle and sides. Mantle median section usually the palest, surrounded by dark streaks. Behind mantle, on body sides, a series of almost vertical lines or blots producing a kind of broken streak may occur. Vas deferens long, the thinnest in the region of atrium, then gradually broadening and passing into a thicker epiphallus which apically opens to penis. Penial retractor inserted at posterior end of penis. Inside penis a papilla, ligula or numerous hard spines may occur. Spermatheca large, thin-walled; its duct thick-walled, often distended. Spermatophore, resembling a coiled wire, ends with a capillary section equipped with a tiny hook.

About a dozen species are known, described mainly on the basis of external appearance. The fam- 
ily requires a revision. Its range covers the Himalayas in broad sense.

Comments. We raise this group to the family rank, although treating it unlike PILSBRY (1948). According to this author, Anadenidae should also include the North American genera Prophysaon Bland et Binney, 1873 and Anadenulus Cockerell, 1890. This approach does not seem justifiable, considering not only different ranges of these genera but also morphological characters of the slugs concerned (WIKTOR in preparation). In our opinion the family Anadenidae comprises exclusively Asian species of the genus Anadenus, and the above diagnosis has been constructed accordingly.

\section{Genus Anadenus Heynemann, 1862}

Anadenus HeYNEMANN 1862: 138. Species typica: Anadenus giganteus Heynemann, 1862 (?Anadenus altivagus (Theobald, 1862)): 138.

For diagnosis see family Anadenidae.

\section{Subgenus Anadenus s. str.}

A feature distinguishing this subgenus is the lack of an additional, vesicular organ on penis (cf. diagnosis of Neoanadenus n. subgen.).

\section{Anadenus (?Anadenus) dautzenbergi Collinge, 1900 (nomen dubium)}

Anadenus dautzenbergi COLLINGE 1900: 134, Pl. 4: Figs 1-8. Locus typicus: Qua Toun Mts, SE of Fo Kien, Fujian Prov., China. Typus: probably not preserved (COLLINGE stated that it was in his collection but now the fate of the specimen is unknown; as we have kindly been informed by the curator of The Natural History Museum collection in London, FRED NAGGS, it cannot be found there).

The taxonomic status of this species is unclear, since the structure of its genitalia remains unknown. COLLINGE (1900) described it on the basis of characters that are of minor taxonomic value, i.e. external appearance, shell, jaw, radula, alimentary system and a few other features, all of which are shared by most known members of Anadenidae. Below we briefly quote more important characters mentioned by COLlinge (1900).

Body size. Length $37.5 \mathrm{~mm}$, mantle length 14.5 $\mathrm{mm}$, sole width $11.5 \mathrm{~mm}$. Coloration "yellowish-gray with yellowish-brown dorsum, which is bounded laterally by a dark line with short lateral branches". "Mantle reddish-brown with irregular, brownish-black matting". ColLINGE (1900) failed to describe the genitalia since, as he stated, they had got crumbled.

Comments. We give information on this slug for the sake of completeness. It seems, however, that its systematic position may never be clarified. The reason for this is the lack of any data on the structure of its genitalia; externally the slug bears resemblance to at least several other species, including the ones described in this paper.

\section{Anadenus (Anadenus) parvipenis n. sp.}

Holotypus. Gonggashan Mts., ca. 3,000 m a.s.l., Luding County, Sichuan Province, China; leg. CHEN DE-NIU, 1982-IX-20; ZIAS (Map 6).

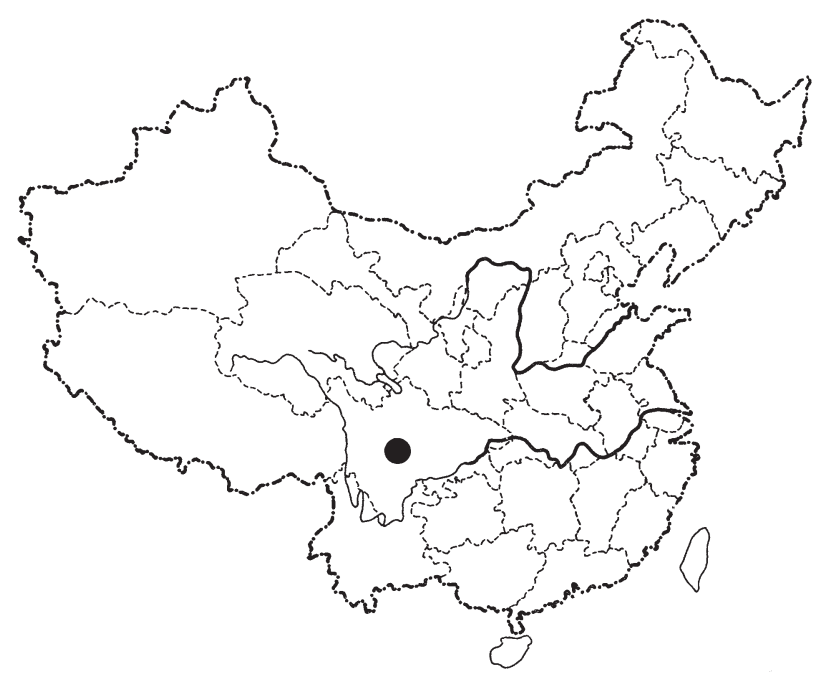

Map 6. Localities of Anadenus (Anadenus) parvipenis n. sp. in China

Etymology. The name refers to the size of the slug's penis which is exceptionally small for an anadenid.

Measurements: body length $41 \mathrm{~mm}$, mantle length $23 \mathrm{~mm}$, the largest sole width $18 \mathrm{~mm}$. General coloration olive brown (Figs 21-24). On mantle slightly darker, indistinct spotting which on sides grows intensified into barely visible streaks. Behind mantle poorly marked broken lateral streaks. Median section of back with few nearly black irregular spots. Sole of the

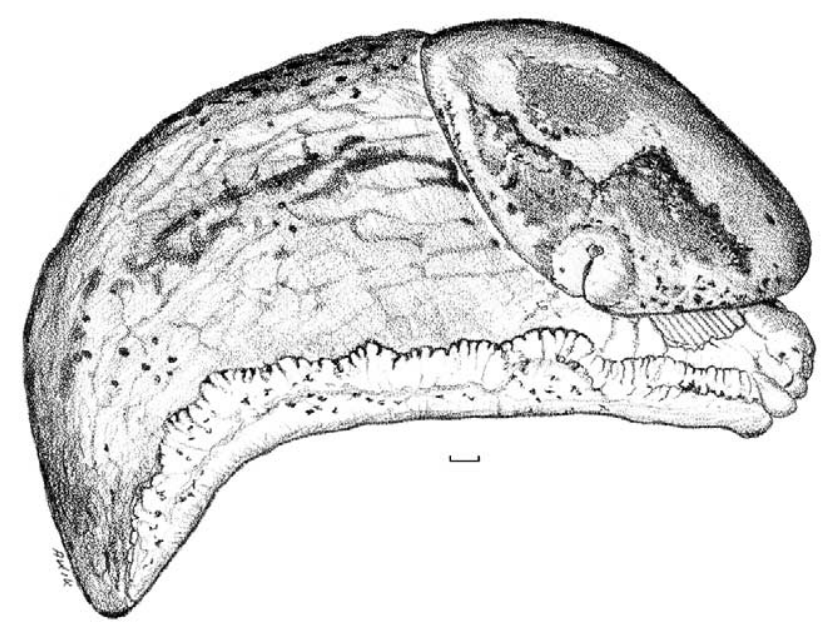

Fig. 21. Anadenus (Anadenus) parvipenis n. sp. - lateral view of the holotype (orig.) 


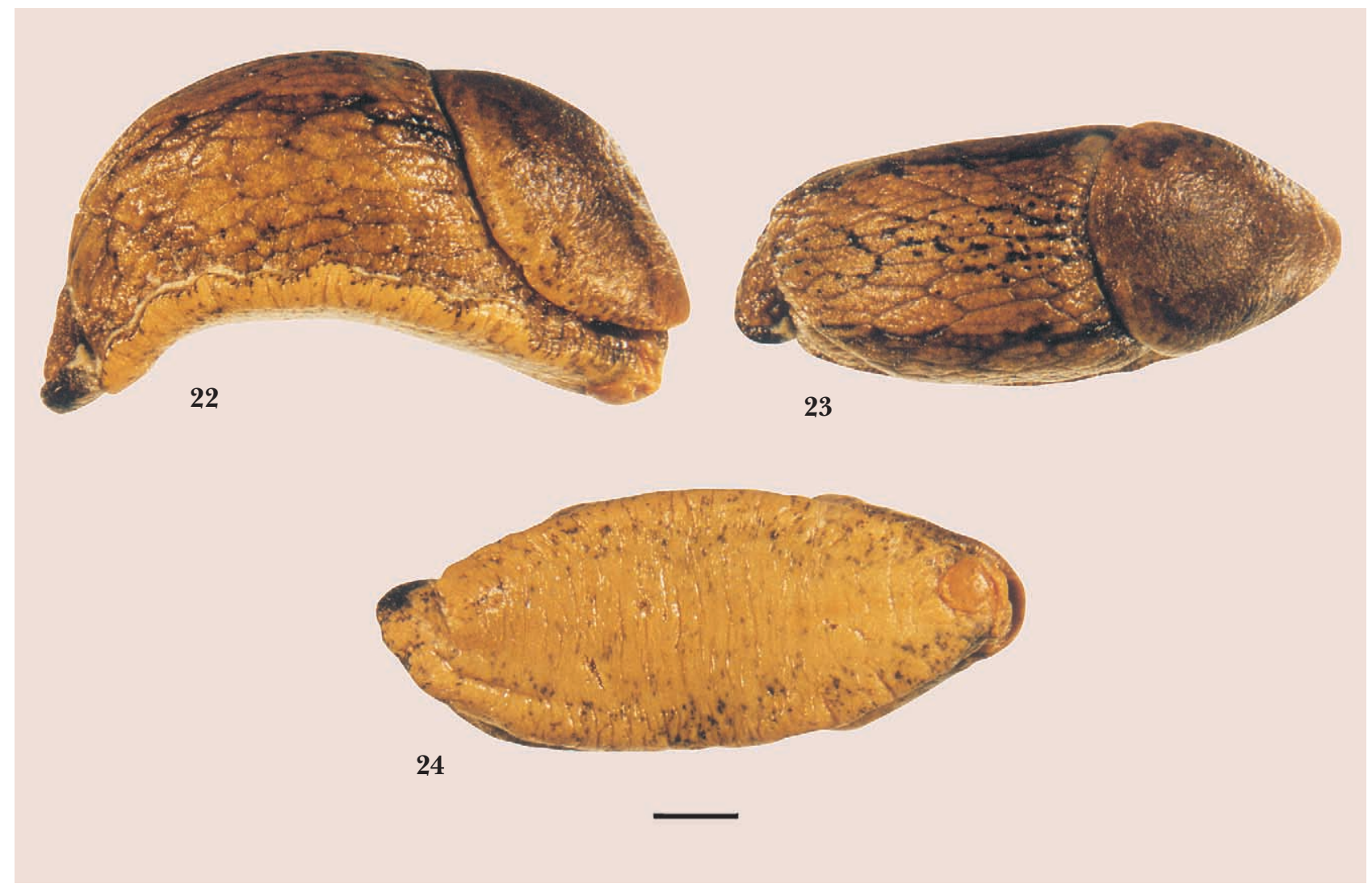

Figs 22-24. Anadenus (Anadenus) parvipenis n. sp. - holotype viewed from three different sides (photo J. MACIĄŻEK) (orig.)

same colour as the rest of the body, with additional black dotting mainly on lateral zones.

Genitalia (Fig. 25). Vas deferens thin, quite abruptly turning in a long, gradually broadening epiphallus. The latter opens to a small, more than ten times smaller, penis which is conical in shape. Immediately at the apical opening of epiphallus there is the insertion of a narrow but long penial retractor. Inside penis a tongue-shaped ligula. Compared to other organs, oviduct thick, tubular. Spermatheca duct broadened, nearly spherical; spermatheca strongly elongated, roughly twice as long as its duct (probably not expanded by a spermatophore).

Spermatophore unknown.

Bionomics unknown.

Comments. The slug differs from A. sechuenensis Collinge, 1899, known from the same province Sichuan - in its conical penis, a ligula inside penis and a broader, nearly spherical spermatheca duct. It differs from all other anadenids in its small conical penis and comparatively very long and thick epiphallus, as well as in a narrow penial retractor. With respect to external appearance, the slug is distinct in its black-dotted sole.

Until now, only two species have been recorded from Province Sichuan, namely A. sechuenensis, which is clearly different anatomically from $A$. parvipenis, and $A$. dautzenbergi of unclear taxonomic status (see p. 15).

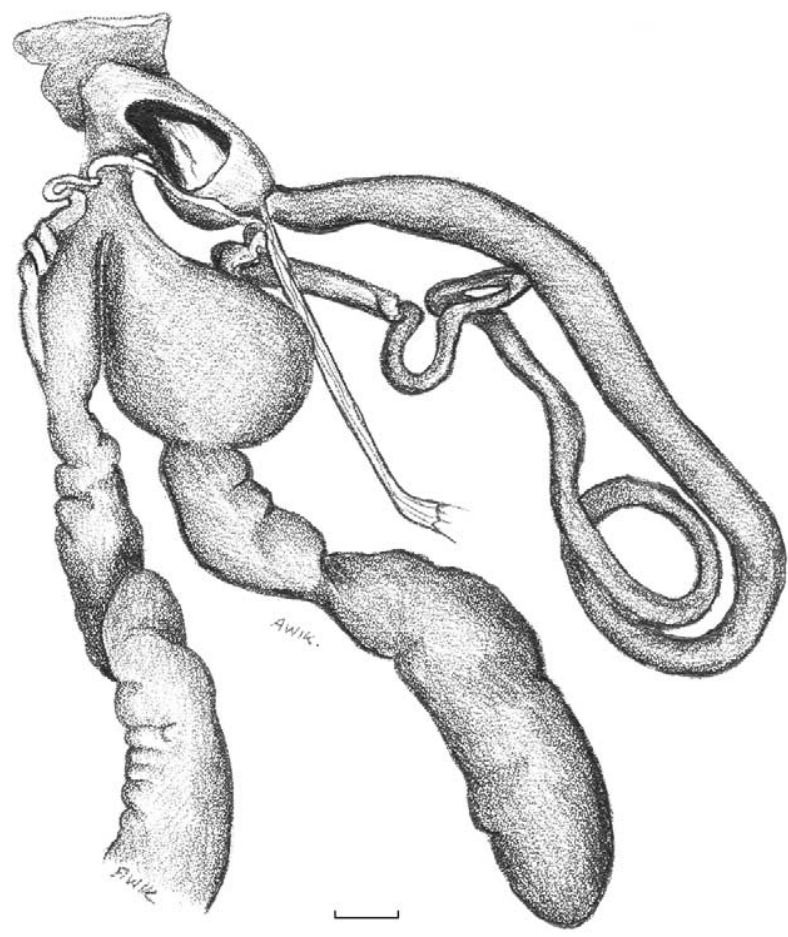

Fig. 25. Anadenus (Anadenus) parvipenis $\mathrm{n}$. sp. - copulatory organs of the holotype (orig.) 


\section{Anadenus (Anadenus) sechuenensis Collinge, 1899}

Anadenus (Anadenus) sechuenensis COLLINGE 1899: 78, Pl. IV: Figs 1-2, 6-7, Pl. V: Figs 8-13. Locus typicus: Sung pan, NW Sechuen (= Sichuan), China. Lectotypus and 1 paralectotypus: NHM, reg. no. 1899. 1.13. 71-72. Present designation.

References: SimRoth \& HOFFMANN 1928: 527, Fig. 172.

Lectotype measurements: body length $69 \mathrm{~mm}$, mantle length $35 \mathrm{~mm}$, the largest sole width $23 \mathrm{~mm}$; paralectotype: 55/28/19 mm, respectively. At present, the coloration is brown with traces of darker streaks. According to COLLINGE's (1899) description, the slug is "olive brown with a faint, dark mid-dorsum band and darker lateral bands". Mantle "with a posteromedian diamond-shaped, light space, with dark bordering, a few indistinct black spots laterally. Foot-fringe of the same colour as the body, lineoles almost black".

Genitalia (Figs 26-28). Vas deferens and epiphallus appoximately of the same length. Epiphallus gradually thickening, somewhat narrowing at its opening to penis. Next to this opening, which is apical, a wide penial retractor is attached, making a circle around vas deferens. Penis clavate due to posterior spherical swelling; inside the swollen section a papilla of corrugated surface (Figs 27-28), and more anterad the walls of penis are covered by longitudinal folds. Spermatheca and its duct combined slightly exceed penis in length; spermatheca

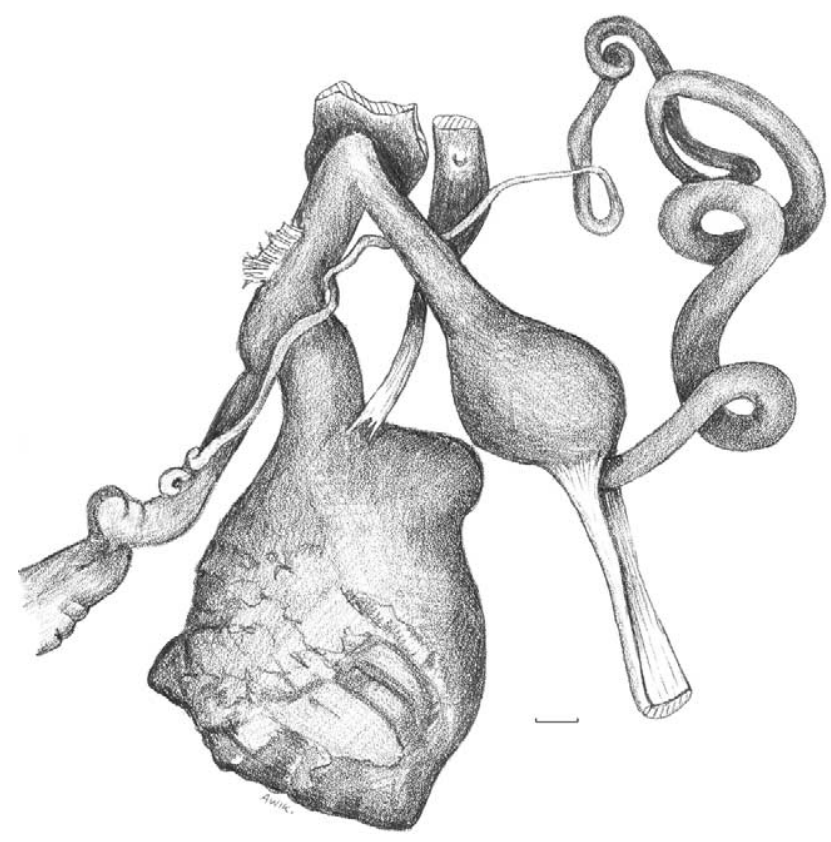

Fig. 26. Anadenus (Anadenus) sechuenensis Collinge, 1899 copulatory organs of the lectotype from Sungpan (orig.)
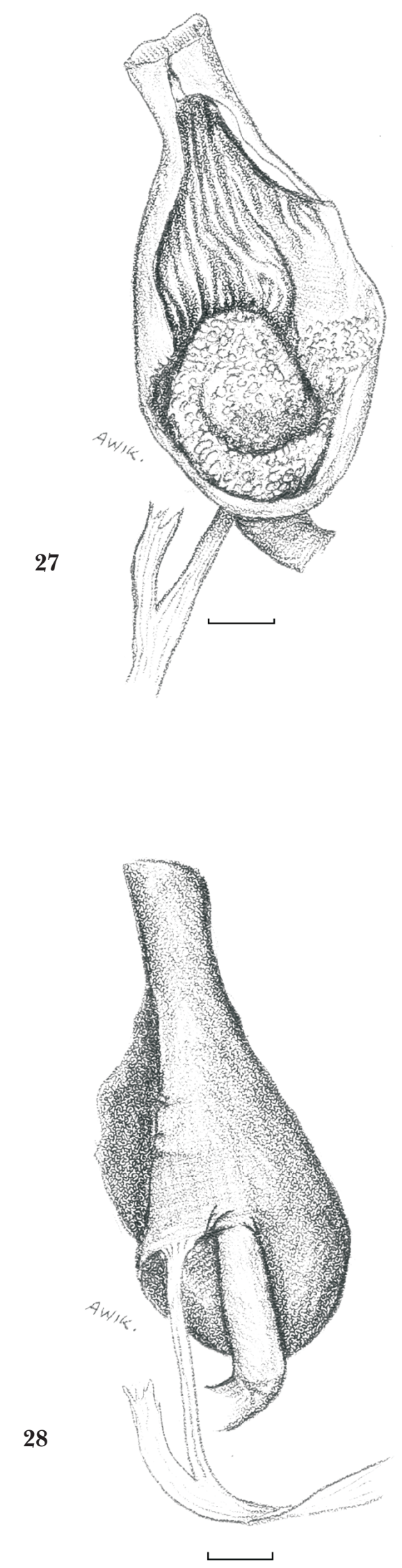

Figs 27-28. Anadenus (Anadenus) sechuenensis Collinge, 1899 - penis of a paralectotype from Sungpan (orig.) 
duct short and thick, roughly three times shorter than spermatheca. Vagina and oviduct bear no distinctive characters.

Spermatophore has no distinctive features compared with other species; perhaps it is slightly shorter than that in e.g. A. (N.) gonggashanensis.

Ecology and bionomics unknown.

Distribution. Known only from the type locality; we had at our disposal only two specimens from the London collection (Map 7).

Comments. The specimens deposited at The Natural History Museum in London are almost certainly syntypes, although this is not explicit from their labels. The older label reads "Anadenus sechuenensis. Cllge. Sung pan N.W. Sichuan. 1899”, the other one (apparently written later) includes the name, bibliographic data of the description and a footnote: "2 syntypes reg. no. 1899.1.13. 71-72". The collection

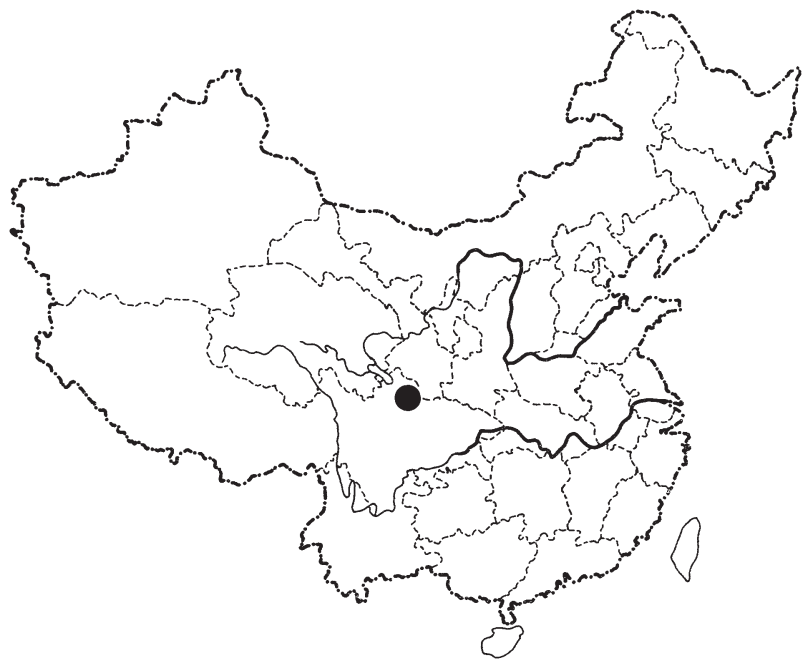

Map 7. Localities of Anadenus (Anadenus) sechuenensis Collinge, 1899 in China

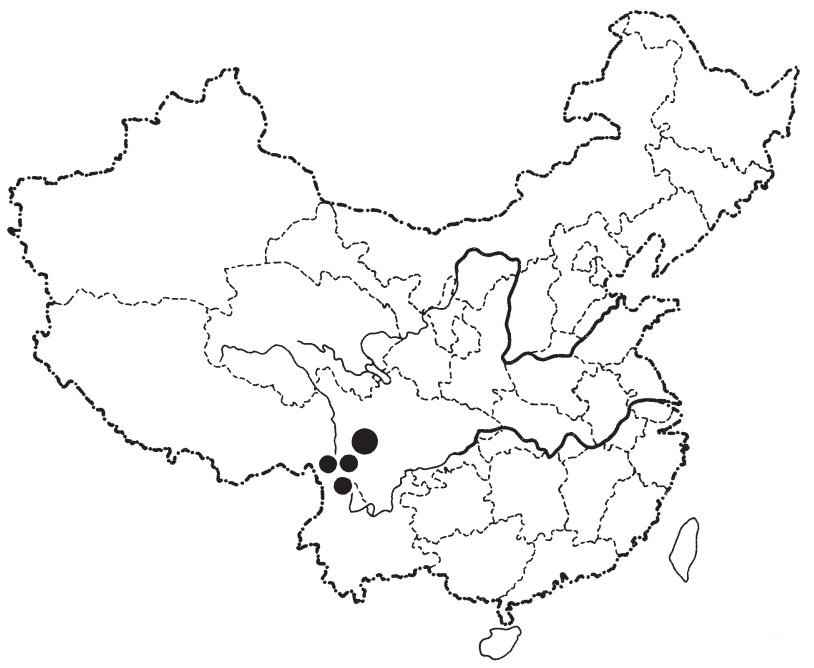

Map 8. Localities of Anadenus (Anadenus) yangtzeensis n. sp. in China; type locality indicated by a large circle curator has confirmed that the specimens are probably types (NAGGS in litt.).

A. sechuenensis differs from other species in its claviform penis, which has neither an appendix nor a vesicular, glandular structure opening at half its length (for the latter structure see Neoanadenus).

\section{?Anadenus (?Anadenus) sinensis Möllendorff, 1899 (nomen dubium)}

Anadenus (?Anadenus) sinensis MölLENDORFF 1899: 49. Locus typicus: village Tapa, Sytshuan (=Sichuan) Prov., China. Holotypus: in alcohol but totally dry; ZIN.

The description, based on a strongly dried (MÖLLENDORFF 1899: "sehr eingetrockneten") specimen kept in alcohol, includes characters of little taxonomic value, and therefore it seems impossible to establish whether A. sinensis is a distinct species or a synonym of some other, earlier described, slug. Besides, it is unclear what made MöLlENDORFF (1899) describe this slug as a new species since he did not mention any distinctive features.

For the sake of completeness, we quote after this author the following data: body length $40 \mathrm{~mm}$, mantle length $17 \mathrm{~mm}$, (?) width of the end of sole ("des Fussendes") $21 \mathrm{~mm}$. Coloration defined on the basis of a darkened specimen, as stated by the author: sides olive brown, back paler ("unten dunkel olivebraun, oben etwas heller").

Comments. At present it is impossible to decide what slug was concerned and what makes it different from other members of Anadenus. The characters given by MÖLLENDORFF are not helpful in distinguishing any other, obviously different, species, either. On the other hand, other members of the family, discussed in the present paper, occur in Sichuan Province as well.

\section{Anadenus (Anadenus) yangtzeensis n. sp.}

Holotypus. Army Station, Yajiang County, Sichuan Prov., China; leg. CHEN DE-NIU, 1982-VIII-26; ZIAS (Map 8).

Paratypi (Map 8). 1 specimen collected with the holotype (MNHW no. MP 705); Zhongwure, Xiangcheng County, Sichuan Prov., China; leg. CHEN DE-NIU 1982-VII-4, 1 specimen (ZIAS); Zhongwure, Xiangcheng County, Sichuan Prov., China, 3 specimens (2 spec. - ZIAS, 1 spec. - MNHW no. MP 705); Mt. Meilixueshan, Dequng County, Yunnan Prov., China; leg. CHEN DE-NIU 1982-VII-22, 9 specimens (5 spec. - ZIAS, 4 spec. - MNHW no. MP 705); Yakou of Dexueshan Mt., Zhongdian County, Yunnan Prov., China; leg. CHEN DE-NIU 1981-VIII-16, 7 juv. specimens (4 spec. - ZIAS, 3 spec. - MNHW) (all localities ca $3,500-4,000 \mathrm{~m}$ a.s.1.). 


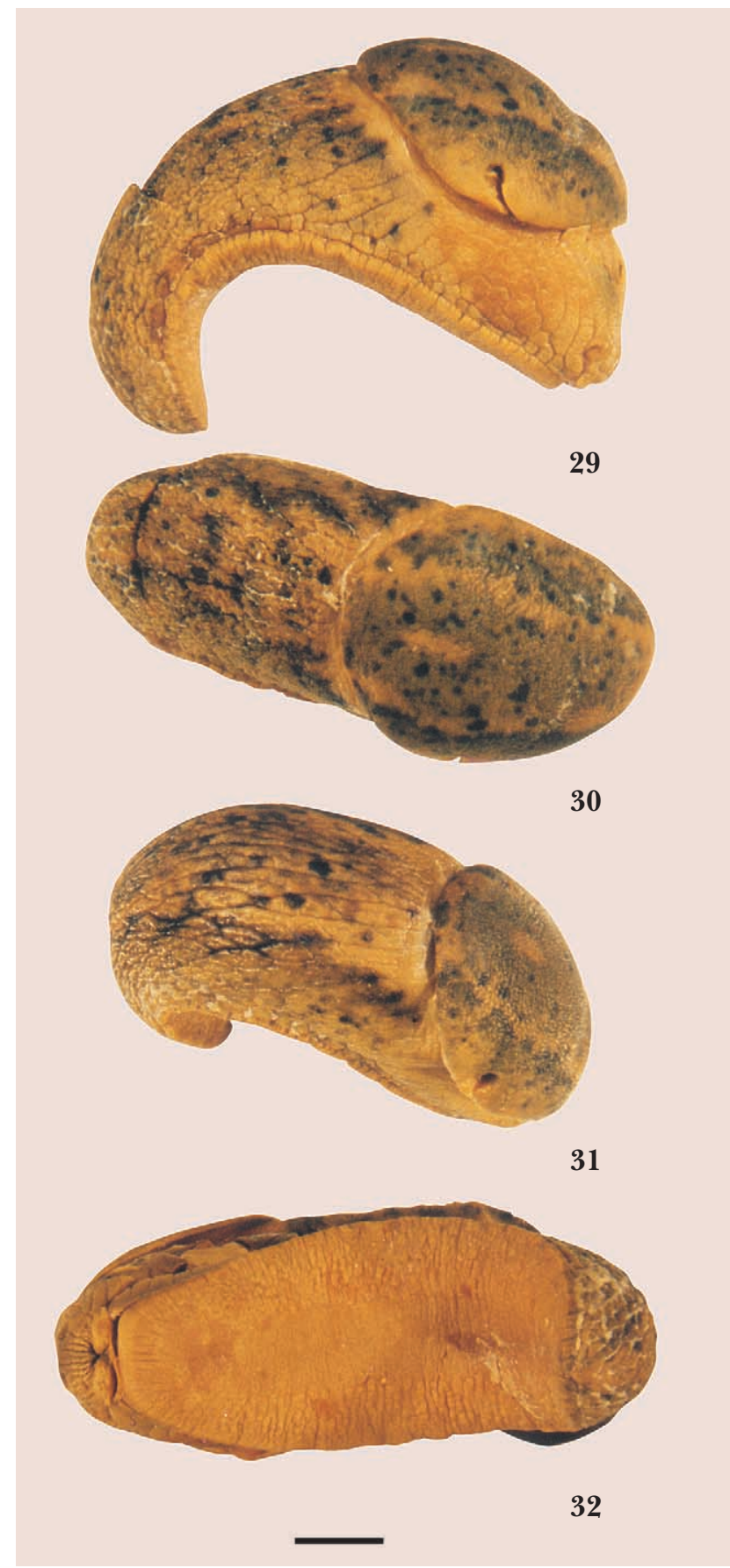

Fig 29-32. Anadenus (Anadenus) yangtzeensis n. sp. - a paratype from Meilixueshan Mt. viewed from various sides (photo J. MACIĄŻEK) (orig.)

Etymology. The name is derived from the Yangtze-Kiang (=Jangtse-Jiang) River, in whose upper basin the slug occurs.

Holotype measurements: length $63 \mathrm{~mm}$, mantle length $30 \mathrm{~mm}$, the largest sole width $17 \mathrm{~mm}$. Some paratypes are slightly larger, their respective measurements being ca. 68/30/20 mm.

General coloration (specimens at present alcohol-preserved) brown with a slight reddish tint. On this background, on mantle, back and sides, few irregular black spots ca $0.5 \mathrm{~mm}$ in diameter (Figs 29-32). Sole and its margin of the same colour as the rest of the body. Some specimens are darker brown, additionally having still darker streaks on mantle and broken streaks on sides behind it.

Genitalia (Fig. 33). Both vas deferens and epiphallus thin compared to these organs in other species. The border between the two is difficult to draw as vas deferens gradually thickens and passes into epiphallus. Penis posteriorly narrow, gradually broadening anterad. On the very end of this organ there is an inconspicuous appendix, usually bent or in the form of a transverse process. Vas deferens opens to penis slightly laterally but apically. Close to this junction and the base of appendix, penial retractor inserts. Inside penis a huge ligula, its surface covered by wrinkles (Figs 34-35). Oviduct long and tube-shaped. Spermatheca narrow, nearly as long as penis, its duct slightly shorter and thin. Probably the spermathecae of the examined specimens have never been filled with spermatophores.

Spermatophore unknown.

Alimentary tract - see Fig. 36.

Bionomics unknown.

Comments. The genitalia of this slug somewhat resemble those of Anadenus blanfordi Godwin-Austen,

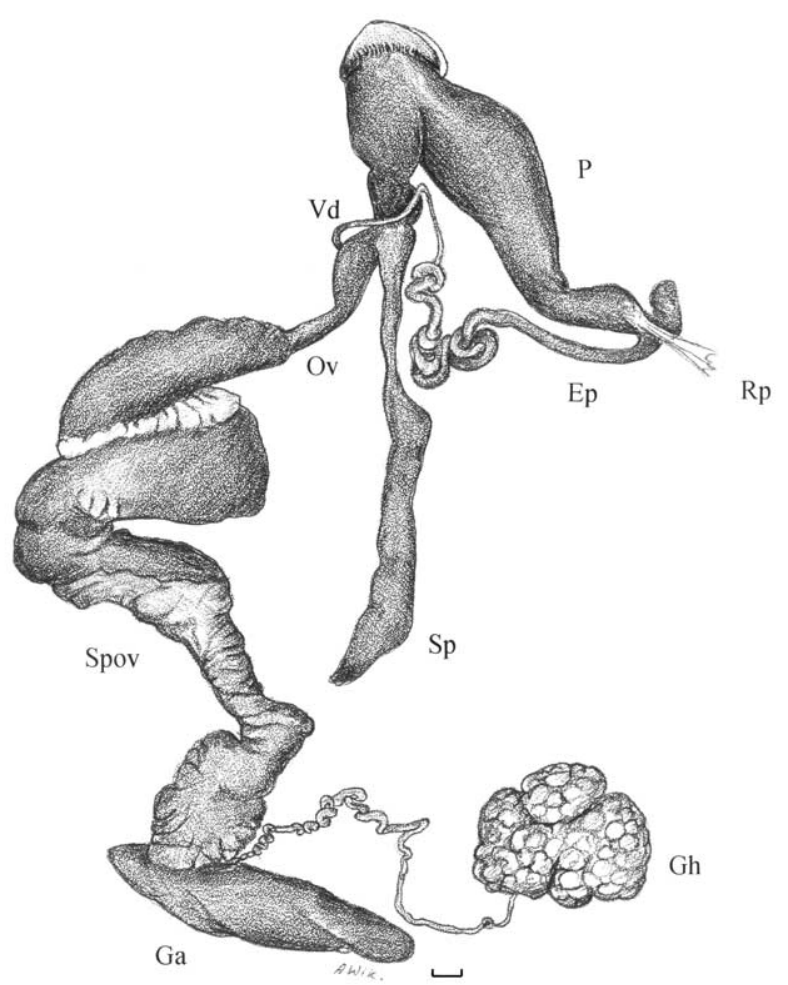

Fig. 33. Anadenus (Anadenus) yangtzeensis n. sp. - reproductive system of the holotype (orig.) Ep - epiphallus, $\mathrm{Ga}-$ glandula albuminalis, Gh - glandula hermaphroditica, Ov - oviductus, $\mathrm{P}$ - penis, $\mathrm{Rp}$ - retractor penis, $\mathrm{Sp}-$ spermatheca, Spov - spermoviductus, Vd - vas deferens 


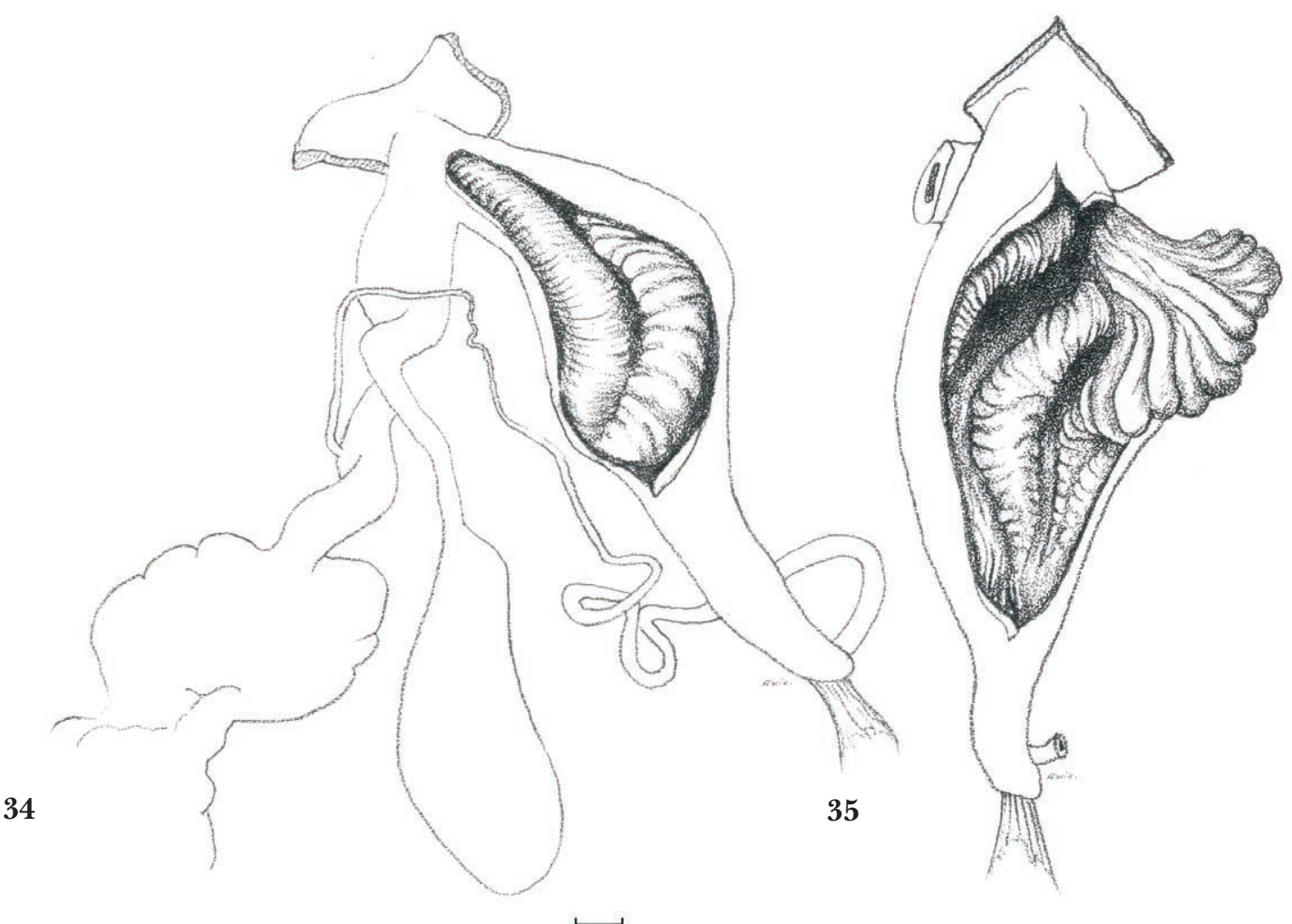

Figs 34-35. Anadenus (Anadenus) yangtzeensis n. sp. - copulatory organs with a ligula visible inside penis (a paratype from Yaijing) (orig.)

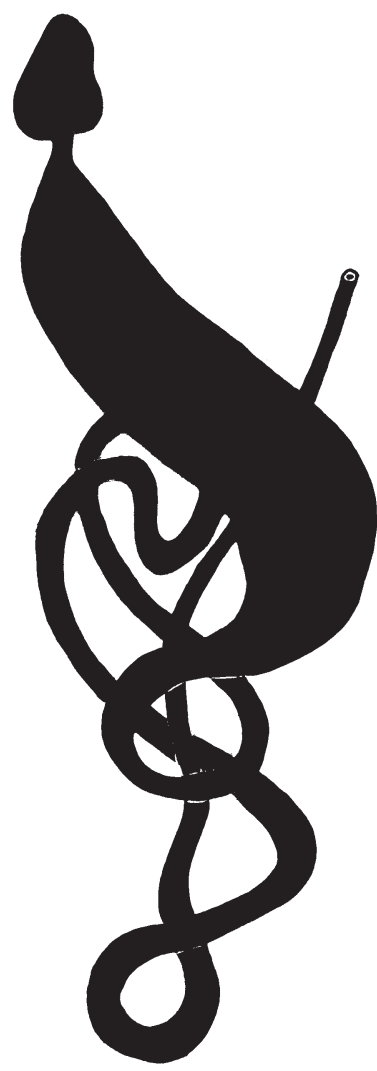

Fig. 36. Anadenus (Anadenus) yangtzeensis n. sp. - alimentary tract of a paratype from Yaijing (orig.); diagrammatic
1882 from Darjeeling (India) (WIKTOR in preparation). The slug itself (the examined holotype) is considerably smaller and has completely different, much more pronounced, skin wrinkles.

The specimens collected on Mt. Meilixueshan differ somewhat in being denser spotted. The rear end of their penis lacks a distinct appendix, which may be a result of the whole body having been strongly contracted. These specimens were probably ill-preserved, as suggested by eversion of ligula in some of them.

The slug differs from A. sechuenensis Collinge, 1899, recorded from the same province, Sichuan, among other characters in posteriorly narrowing penis, the presence of an inconspicuous appendix at the posterior end of penis of most specimens, and a huge, wrinkle-covered ligula inside the penis.

The characters distinguishing A. yangtzeensis from other anadenids include: fine black spots on the body, thin vas deferens and epiphallus, a huge wide ligula inside penis, and - in most specimens - presence of appendix on posterior end of penis.

\section{Anadenus (?Anadenus) yunnanensis n. sp.}

Holotypus. Mt. Zhibengshan, ca. 2,000 m a.s.1., Yunlong County, Yunnan Prov., China; leg. CHEN DE-NIU, 1981-VI-23; ZIAS (Map 9).

Etymology. The name has been coined from the name of Province Yunnan, where the slug occurs. 


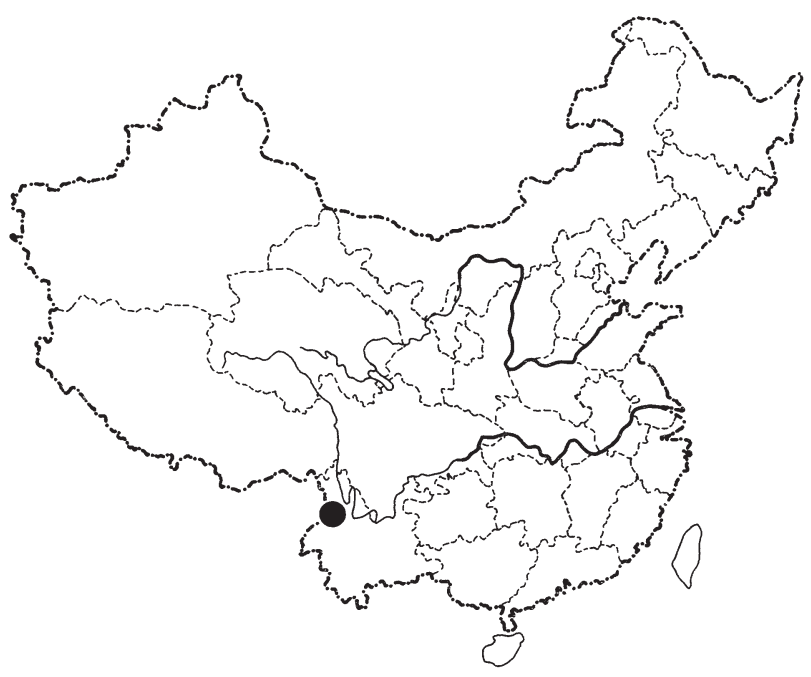

Map 9. Localities of Anadenus (Anadenus) yunnanensis n. sp. in China

Measurements: body length $93 \mathrm{~mm}$, mantle length $37 \mathrm{~mm}$, the largest sole width $30 \mathrm{~mm}$. The most distinctive character in the external appearance is skin sculpture of the section behind mantle (Figs 37-39). The wrinkles are exceptionally large and markedly pronounced, contrary to those in all other known species. The largest wrinkles are $17 \mathrm{~mm}$ long (!) and 3.5 $\mathrm{mm}$ wide. Those occurring on sides are shorter and thinner, and also less pronounced. The shape of wrinkles is also different from that in other Anadenus: in cross-section the most pronounced ones are simply triangular, whereas those on sides are semicircular, like in other species. General coloration after preservation in alcohol evenly black, only sides anteriorly and sole being somewhat paler, i.e. blackish brown.

Genitalia (Fig. 40). Unfortunately, the only specimen at our disposal has its penis - or its internal structures that almost certainly include a ligula - partly everted. The specimen is at an early phase of sexual activity, which is evidenced by a large gonad and a smallish albumen gland. In comparison with this organ in other species, vas deferens is relatively short. Epiphallus, also short, broadens gradually. It opens into penis somewhat asymmetrically at its posterior end. In the examined specimen the penis is nearly spherical but this is probably an effect of the organ having been partially everted; it is likely that before eversion the penis was cylindrical or elongatedly oval. Penial retractor wide, apically attached to penis. Oviduct very short and thin. Spermatheca duct thick, almost cylindrical; spermatheca elongated, probably never contained spermatophores and thus not expanded.

Spermatophore unknown.

Ecology, bionomics and distribution unknown.

Comments. The unique external appearance of this slug makes it distinguishable from all other members of Anadenidae recorded from China and India.
In our opinion, its being so characteristic externally is a sufficient basis for description of a new species, even based on a single specimen.

The slug differs from all other members of Anadenus, including A. sechuenensis Collinge, 1899, in huge skin wrinkles, additionally diversified on back and sides, and a relatively short epiphallus. The genitalia seem to exhibit all characters specific to Anadenus s. str. However, some doubts arise with respect to the uniqueness of skin wrinkles: we do not know if the character is species-specific and what is its taxonomic value, for which reason we place this slug within Anadenus s. str. but provided with a question mark.

\section{Subgenus Neoanadenus n. subgen.}

Species typica: Anadenus gonggashanensis n. sp.

Etymology. The name refers to its being a new, previously unknown, kind of Anadenus.

The new subgenus differes from Anadenus s. str. in the presence of an additional organ in the form of a vesicle, which laterally adheres to the anterior part of penis and opens through a duct (directed posterad) to the median portion of penis (Figs 42-44). The role of this organ is unknown. It is likely to be filled with sperm, which is later injected into a spermatophore, or else it may perform some glandular function. Until now there has been no mention of such an organ in descriptions and it is absent in other species of Anadenidae. In our opinion, this unique character justifies distinguishing a new taxon of subgeneric, or even generic, rank.

\section{Anadenus (Neoanadenus) gonggashanensis n. sp.}

Holotypus. Moxi, E slope of the Gonggashan Mts, ca. 2,500 m a.s.l., Luding County, Sichuan Prov., China; leg. CHEN DE-NIU 1982-IX-14; ZIAS (Map 10).

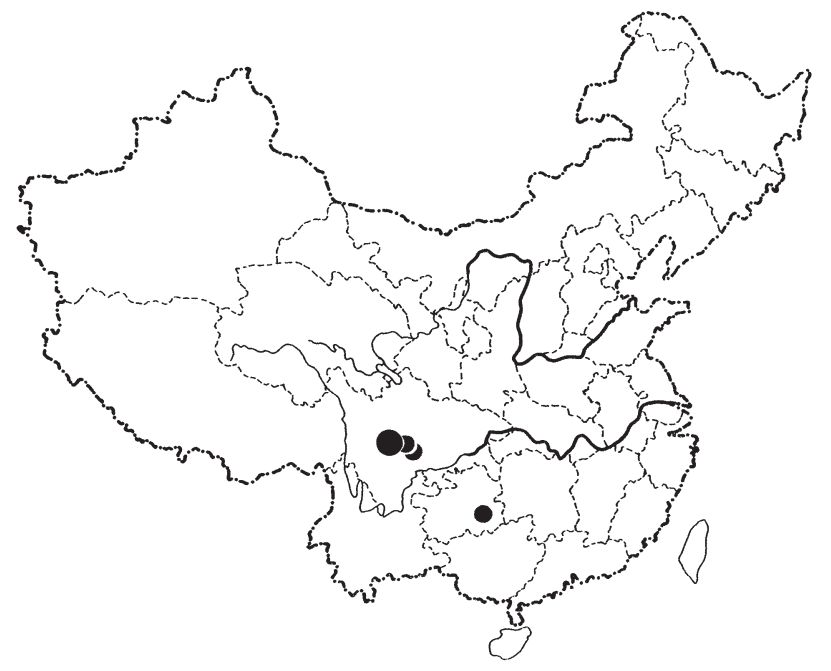

Map 10. Localities of Anadenus (Neoanadenus) gonggashanensis n. sp. in China; type locality indicated by a large circle 


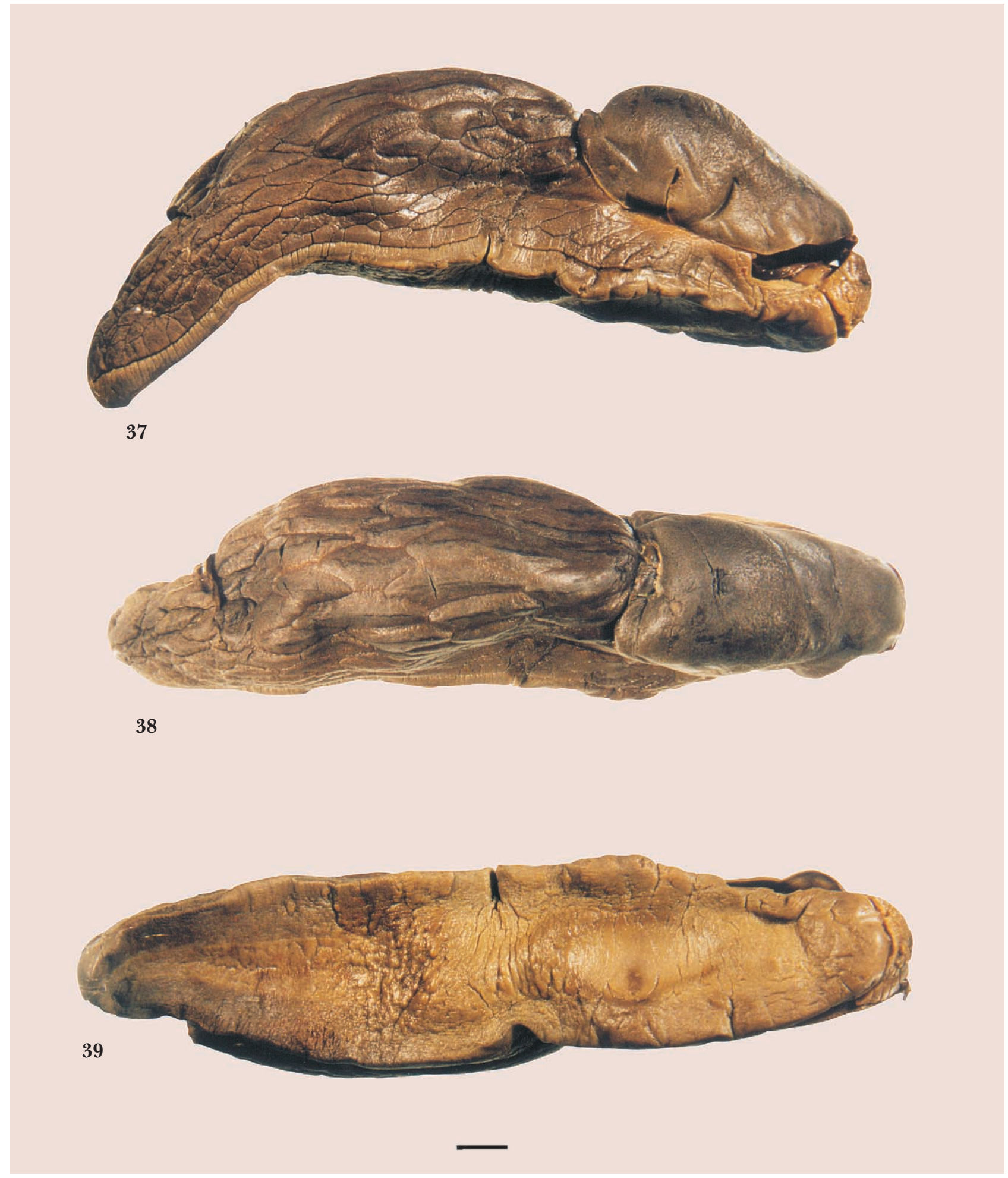

Figs 37-39. Anadenus (Anadenus) yunnanensis n. sp. - external appearance of the holotype (photo J. MACIĄŻEK)

Paratypi (Map 10). Yanzigou, E slope of the Gonggashan Mts, ca. 2,500 m a.s.l., Luding County, Sichuan Prov., China; leg. CHEN DE-NIU 1982-IX-17, 3 specimens ( 1 spec - MNHW - no. MP 704; $1+1$ juv. spec. - ZIAS); Jiulaondong, Mt. Emei, ca. 2,000 m a.s.l., Sichuan Prov., China; leg. Chen De-NIU 1964-VIII-9, 2 specimens (1 spec. - ZIAS; 1 spec. MNHW no. MP 704); (?) Leigongshan Mt., Guizhou Prov., China; leg. ChEN DE-NIU 1988-IV-23, 1 juv. specimen (No. 1 leg. CHEN DE-NIU). 


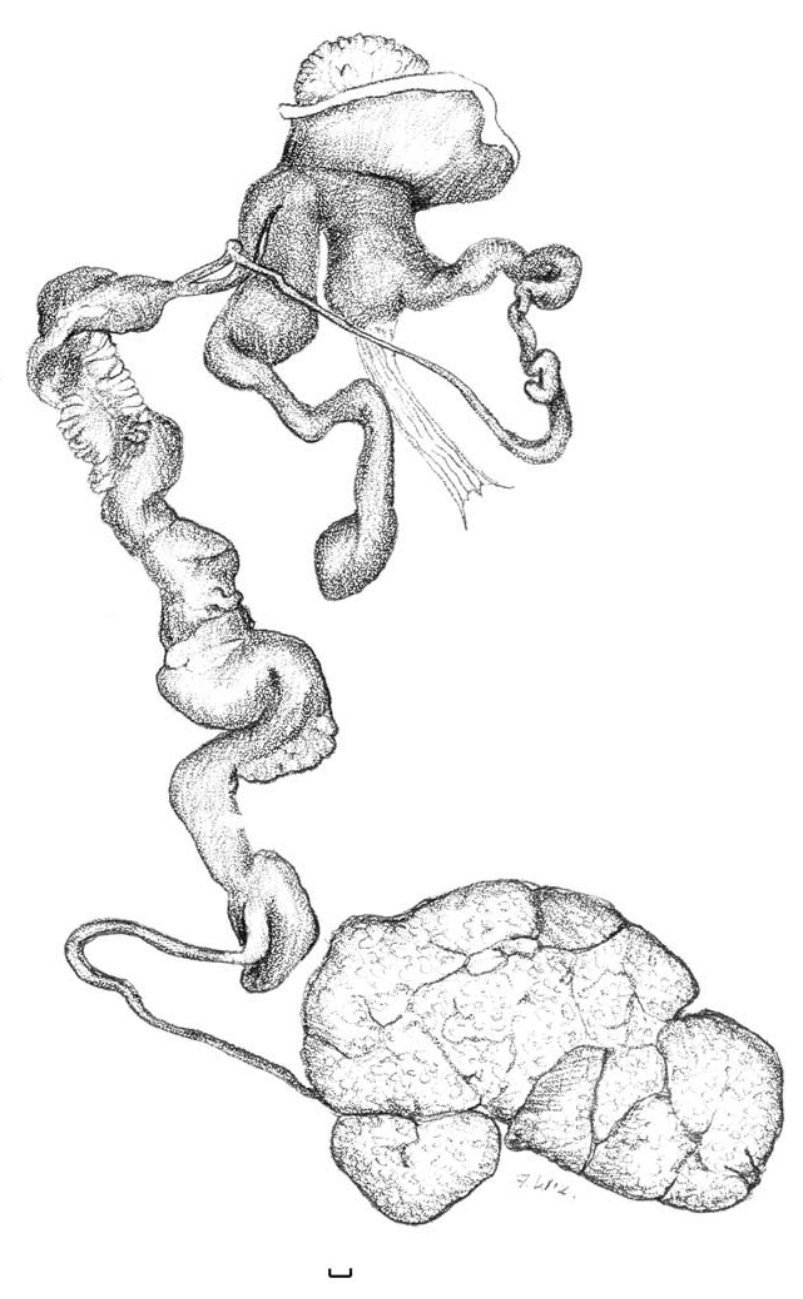

Fig. 40. Anadenus (Anadenus) yunnanensis n. sp. - reproductive system of the holotype; penis and its papilla partly everted (orig.)

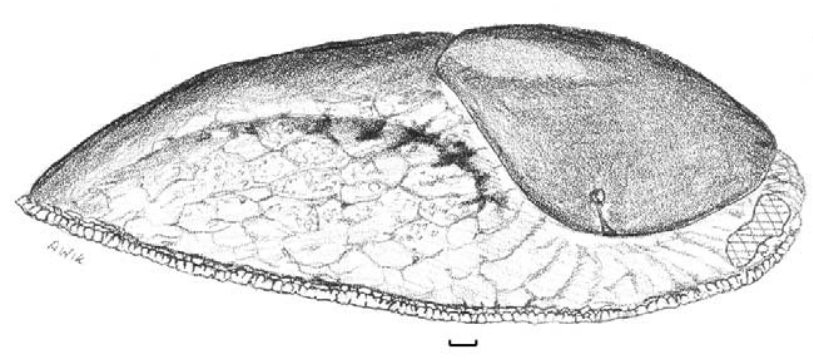

Fig. 41. Anadenus (Neoanadenus) gonggashanensis n. sp. - lateral view of the holotype (orig.)

Etymology. The name of the species is derived from the Gonggashan Mts, where the holotype was found.

Holotype measurements (alcohol-preserved): body length $42 \mathrm{~mm}$, mantle length $19 \mathrm{~mm}$, the largest sole width $15.5 \mathrm{~mm}$. The largest paratype: body length $52 \mathrm{~mm}$, mantle length $22 \mathrm{~mm}$, the largest width of

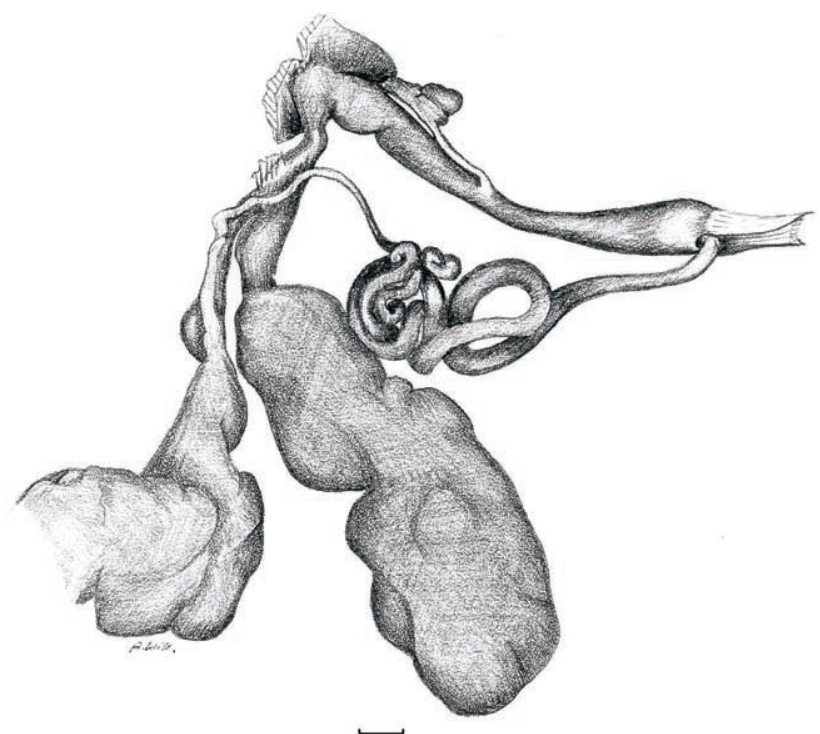

Fig. 42. Anadenus (Neoanadenus) gonggashanensis $\mathrm{n} . \mathrm{sp} .-\mathrm{co}-$ pulatory organs of the holotype (orig.)

sole $17 \mathrm{~mm}$. Coloration of alcohol-preserved specimens: mantle unicoloured except for a paler blot in the middle. On sides there are two nearly continuous streaks (Fig. 41).

Genitalia (Figs 42-44). Vas deferens comparatively long. Like in all other anadenids, it is the thinnest near atrium, then gently broadening into a very long and coiled epiphallus. The latter opens apically to penis, where it is encircled by the inserting penial retractor. Penis narrow in general, both anteriorly and posteriorly distended. Roughly at its half-length a specific organ in the form of a vesicle opens through a narrow duct to its lateral wall. This organ is fairly varied in shape, usually, however, oval in outline. Inside the posterior, broadened, section of penis (Figs 43-44) there is a semi-spherical papilla, its surface covered by fine tubercles. In the remaining part of penis irregular longitudinal folds. Among them there is the outlet of the duct leading to the vesicular organ whose internal walls are also covered by longitudinal folds (Figs 43-44). Oviduct tubular and narrow, connected with a huge spermatheca which is a few times longer than its duct and slightly exceeding penis in length. Atrium very short.

Spermatophore (Figs 45-46) cylindrical, ca. 100 $\mathrm{mm}$ long, gradually narrowing at one end, whereas the other passes into a thin flagellum terminating with a tiny hook (Fig. 46). Except for the flagelliform section, the spermatophore surface is smooth. The flagellum is reinforced by three longitudinal ridges, which undoubtedly play a part of stiffening structures.

Distribution. So far the species has been recorded only from the type locality and the localities of paratypes; all the sites are situated in Province Sichuan (Map 10). The slug lives on rocks in high mountains at an altitude of 2,000-4,000 m a.s.l. 


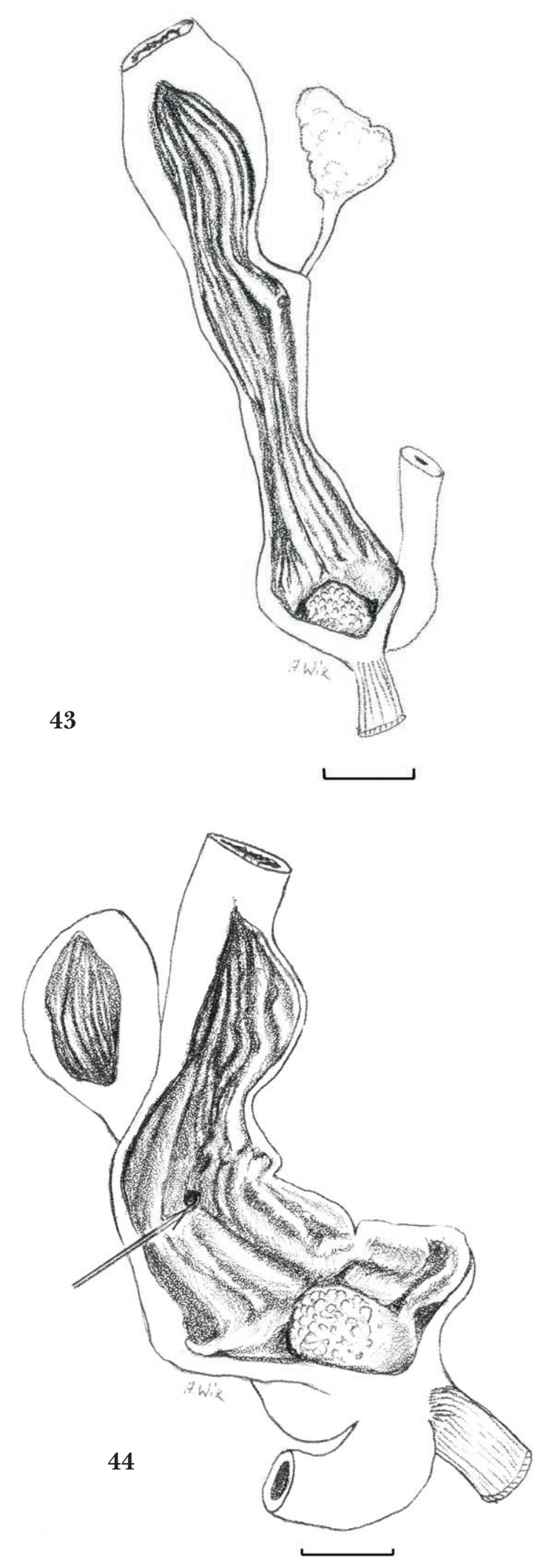

Figs 43-44. Anadenus (Neoanadenus) gonggashanensis n. sp. penises of two paratypes collected on the $\mathrm{E}$ slope of Gonggashan Mts but in different places and on different dates (Fig. 44 along with the holotype) (orig.)

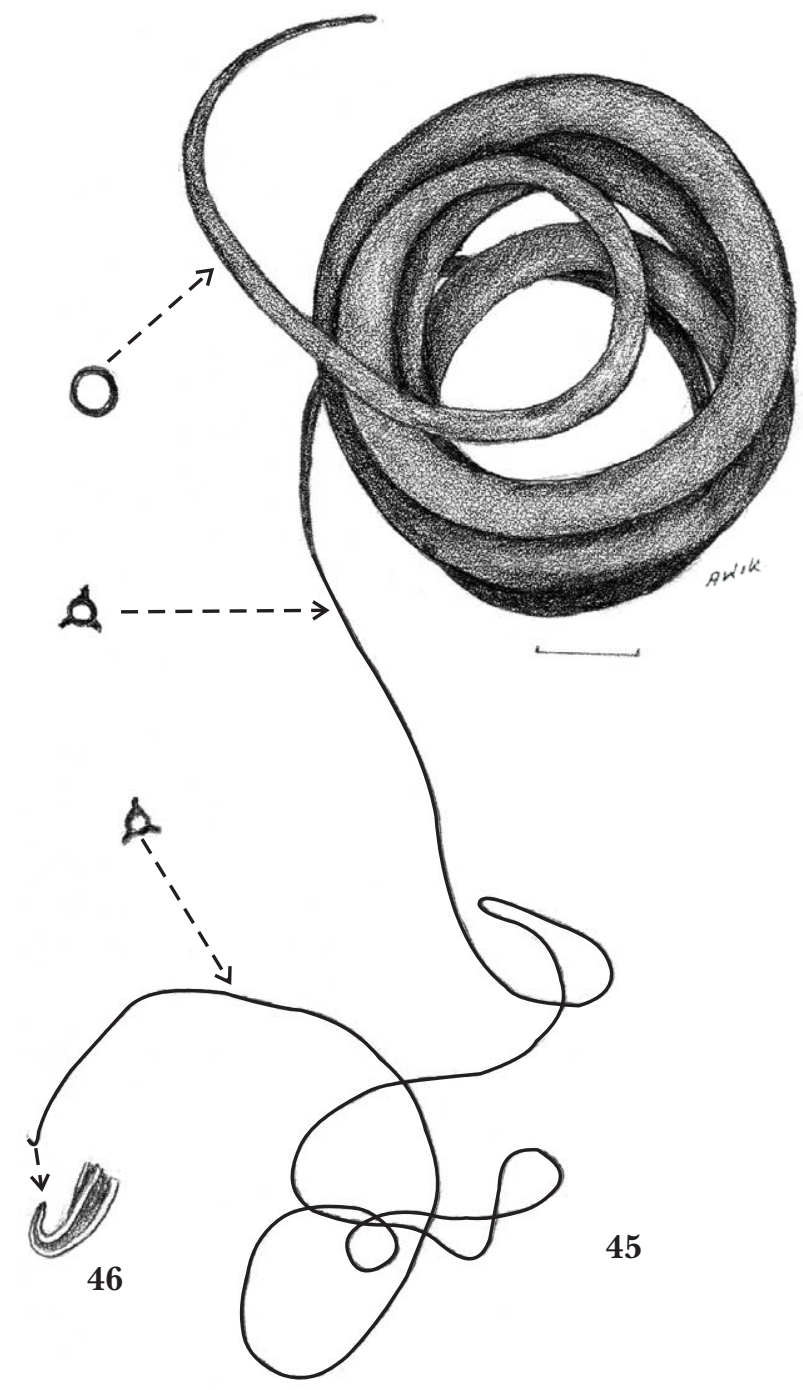

Figs 45-46. Anadenus (Neoanadenus) gonggashanensis $\mathrm{n}$. sp. - a spermatophore from a receiver - a paratype from Jiulaondong, Emali Mt. (orig.).

45 - a whole spermatophore and its cross-sections 46 - hook at the end of the flagellate part under a high magnification

Comments. The new species differs from all other members of Anadenus in the subgeneric characters, and besides, from A. sechuenensis Collinge, 1899 in the shape of penis which is narrow, both anteriorly and posteriorly distended, with longitudinal folds inside.

\section{SUPERFAMILY \\ LIMACOIDEA RAFINESQUE, 1815}

The origin of this superfamily is unclear. It is represented exclusively by slugs with a plate-like, reduced, asymmetrical shell, mostly phytophagous, and sometimes polyphagous. Mantle in live specimens covered by concentric wrinkles. Pneumostome situ- 
ated postmedially. Sole divided by longitudinal grooves in three zones. Jaw oxygnathic. Radular teeth narrow; marginal teeth high, sabre-shaped, with a small ectocone or devoid of it. Kidney arcuately surrounding heart from three sides; the heart axis tilted right relative to the body axis. Epiphallus absent, sperm being transmitted in the form of jelly (no spermatophore). The superfamily comprises the families Limacidae, Agriolimacidae and Boettgerillidae. Only representatives of the first two occur in China, all Limacidae being foreign and introduced there.

\section{Family Limacidae Rafinesque, 1815 (Fig. 1)}

Limacinae RAFINESQUE 1815: 141 (as family Limaxia).

References: LIKHAREV \& WIKTOR 1980: 219; WIKTOR 1989: 140.

Body up to $200 \mathrm{~mm}$ long, posteriorly pointedly narrowed. On back there is a keel which sometimes extends to mantle. Mantle oval, covering not more than $1 / 3$ body length. In live specimens its surface is covered by concentric wrinkles. Pneumostome usually postmedial (there are some exceptions). Like in other members of the superfamily, sole divided in three zones, a character typical of the family being transverse wrinkles on each of the zones. Coloration varied, often with longitudinal stripes or spots on a pale background. Alimentary canal consisting of three - less often two - loops, the first one always being the longest and reaching the most posterad. Heart axis tilted right by ca. $45^{\circ}$ relative to the body axis. Kidney bean-shaped, surrounding heart postero-laterally (no lobus). Bladder wedge-shaped. Shell flat, asymmetrical, with discernible growth lines. Retractors of the right and left side of head join into one muscle attached to diaphragm. Prostate and penis well-developed; penis often cylindrical. Epiphallus and stimulator absent but penial gland often present. Female genitalia simple, without accessory organs. The distribution range covers N Africa, Asia Minor, Europe, the Caucasus and Central Asia. Some species have been introduced almost worldwide. The family includes three subfamilies with 12 genera.

\section{Subfamily Limacinae Rafinesque, 1815}

Pneumostome postmedial. Intestine composed of 3 loops. Vas deferens opening to penis, the latter organ being cylindrical or sac-like.

\section{Genus Lehmannia Heynemann, 1862}

Lehmannia HEYNEMANN 1862: 211. Species typica: Limax marginatus O. F. Müller, 1774.

Synonyms: Simrothia Clessin, 1884; Ambigolimax Pollonera, 1887; Melitolimax Pollonera, 1891 (for more detailed data see HESSE 1926).
References: WALDÉN 1961: 85; LIKHAREV \& WIKTOR 1980: 261; WIKTOR \& LIKHAREV 1980: 424; WIKTOR 1989: 148.

Body length up to $65 \mathrm{~mm}$. Body slender, mantle covers at most $1 / 3$ body length, keel limited to posterior body end. Coloration varied but in most species there are two, or sometimes more, dark streaks on mantle. Posterior body part also striped or spotted. In some species body uniformly black. Mucus watery, colourless. Intestine built of 3 loops, on the third (shortest) a very long transparent caecum (not filling with faeces) reaching posterior end of the body. Kidney heart-shaped. Penis clavate, usually shorter than $1 / 3$ body length, crossed with right ommatophore retractor. On posterior end of penis a single, undivided, conical, lobular or flagellate penial gland. Inside penis a V-shaped fold.

The natural distribution range covers exclusively Europe and N Africa. A total of 16 species are known, of which two have been introduced in various parts of the globe, where, as synanthropes, they live in glasshouses or cultivations, especially horticultural.

\section{Lehmannia valentiana (Férussac, 1823)}

Limax valentianus FÉRUSSAC 1823: 96, Pl. 8a: Figs 5-6. Terra typica: Spain (?).

Limax poirieri MABILLE 1883: 52. Terra typica: Spain. Deroceras (Agriolimax) bilineatus CHEN et al. 1995: 403,

Figs 1-5, Map 10. Locus typicus: Mianxian County $\left(33^{\circ} 04^{\prime} \mathrm{N}, 109^{\circ} 02^{\prime} \mathrm{E}\right)$, Shaanxi Province, China. Paratypes: ZIAS. Syn. nov.

Length ca $46 \mathrm{~mm}$. Coloration creamy with a varied brown pattern (Fig. 47). On mantle two lateral streaks, between them sometimes an additional one (or more). Behind mantle body unicoloured or with lateral stripes, or else a reticulate pattern produced by fusing dots. Sole creamy.

Genitalia (Fig. 48). Penis club-shaped, posteriorly irregularly broadened. A distinctive feature is its often flattened, lobular or thick, truncated penial gland, set in the immediate neighbourhood of vas deferens (in other species on the opposite side of posterior part of penis). Spermatheca roughly as long as penis. Its container ovate, roughly as long as spermatheca duct.

Habitat. A ground-dwelling species, in natural conditions sheltering under stones and wood pieces, occurring in moist places, preferably close to water in poplar thickets and among dense herbs. Herbivorous. Very often found in horticultural crops, especially in greenhouses, where it is a pest. Exhibiting clear predispositions to synanthropization.

Material examined (Map 11): Nei Mongol: Garden, Baotou, 1989-I-7, 2 spec., leg. LIU YoNG-JIANG; Xixia Park, Baotou, 1989-V-8, 12 spec., leg. LIU YONG-JIANG; Greenhouse of Teacher's College, Huhehaote, 1998-II, 1 spec., leg. LIU YonG-JIANG; Garden of Huhehaote, 1998-II-13, 25 spec., leg. LIU 


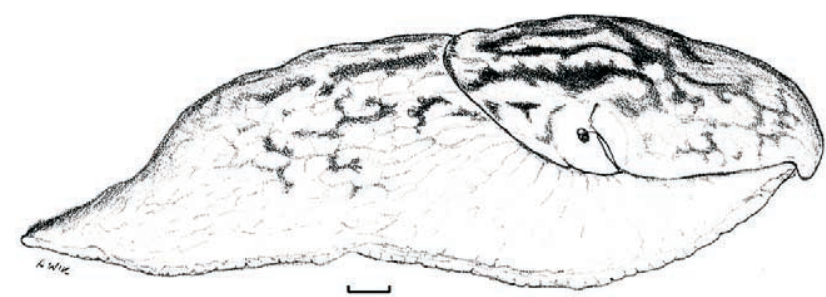

Fig. 47. Lehmannia valentiana (Férussac, 1823) - lateral view of a specimen collected in a greenhouse (Nanzhi) of Xiangshan, Beijing (orig.)

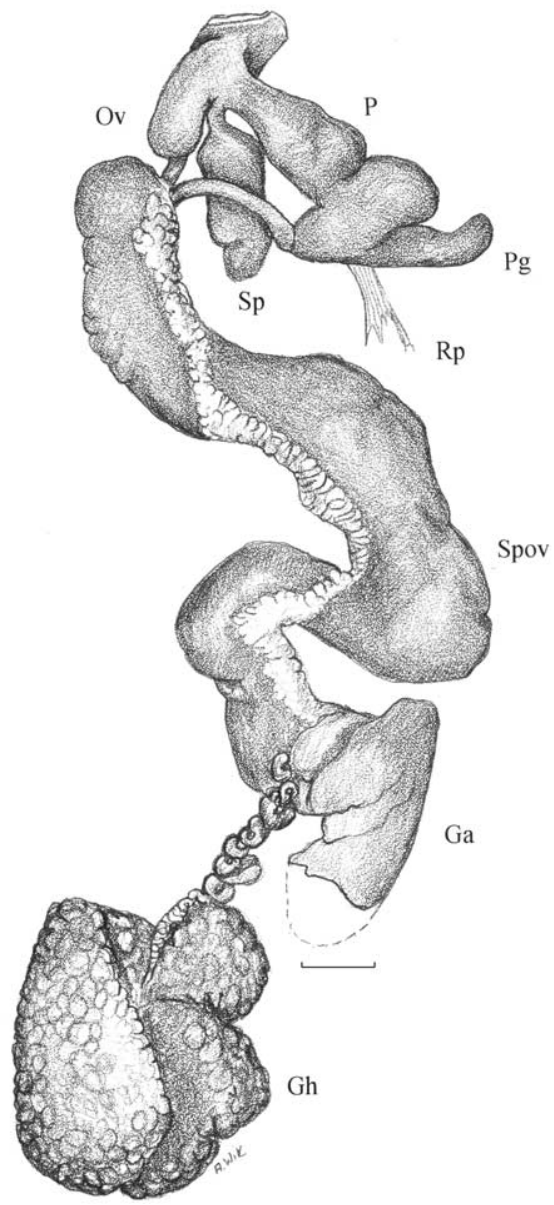

Fig. 48. Lehmannia valentiana (Férussac, 1823) - reproductive system of a specimen from a greenhouse (Nanzhi) of Xiangshan, Beijing (orig.). Ga - glandula albuminalis, $\mathrm{Gh}$ - glandula hermaphroditica, Ov - oviductus, P - penis, $\mathrm{Pg}$ - penial gland, $\mathrm{Rp}-$ musculus retractor penis, Sp - spermatheca, Spov - spermoviductus

YONG-JIANG; Garden Institute, Huhehaote, 1998-VII-16, 44 spec., leg. LIU YONG-JIANG; Garden of Biology Dept. of Neimenggu Univ., 1987-VII-18, 2 spec., leg. LIU Yong-JIANG; Beijing: Fragrant Hill, 1997-IX, 1 spec., leg. ZHANG GUO-QING; Greenhouse (Nanzhi) of Xiangshan Botanical Garden, 1998-VI, 61 spec., leg. ZHANG GUO-QING; Greenhouse of No. 621 Institute, Haidian, 1998-II, 5 spec., leg. CHEN DE-NIU; Greenhouse (Nanzhi) of Xiangshan, Botan-

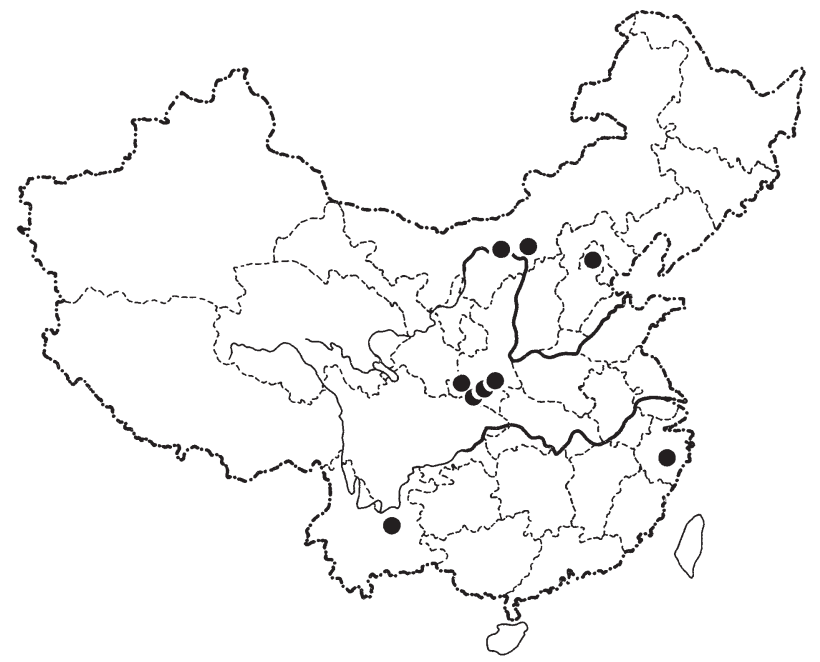

Map 11. Localities of Lehmannia valentiana (Férussac, 1823) in China

ical Garden, 1995-XI-20, 20 spec., leg. ZHANG GUO-QING; Shaanxi Prov.: Wuhouci, Mian County, 1992-IV-5, 12 spec., leg. CHEN DE-NIU; Chengguan, Zhenba County, 1992-IV-3, 1 spec., leg. CHEN DE-NIU; Hanying County, 1992-IV, 1 spec., leg. CHEN DE-NIU; Xihuacun, Yungaisiwan, Zhen'an County, 1992-III-27, 2 spec., leg. CHEN DE-NIU; Xiaomuling, Zhen'an County, 1992-III-28, 7 spec., leg. CHEN DE-NIU; Yungaisizhen, Zhen'an County, 1992-III-27, 6 spec., leg. Chen DE-NIU; Zhejiang Prov.: Huzhen, Jingyun County, 1978-VI-19, 1 spec., leg. CHEN DE-NIU; Yunnan Prov.: Kunming Medical College, Kunming, 1985-IV-15, 1 spec., leg. CHEN DE-NIU; Kunming Medical College, Kunming, 1998-VIII-4 10, 109 spec., leg. CHEN DE-NIU.

Distribution. The original distribution range of this slug is the Iberian Peninsula and probably northwestern Africa. It has been introduced in various parts of Europe, America and Asia; it also occurs on numerous islands of the Atlantic and Pacific Oceans. In China it is an introduced species (Map 11).

Comments. L. valentiana in China is undoubtedly an introduced species. No other representatives of the genus have been recorded from this country. The slug discussed differs from L. (L.) flavus in a smaller size, striped body, the presence of penial gland and a more liquid colourless mucus.

\section{Genus Limax Linnaeus, 1758}

Limax LINNAEUS 1758: 652. Species typica: Limax maximus Linnaeus, 1758.

Limacella BRARD 1815: 107 (non Blainville, 1826). Species typica: Limacella parma Brard, 1815 (= L. maximus Linnaeus, 1758).

References: HESSE 1926: 9; QUICK 1960: 180; WIKTOR 1973: 64; LIKHAREV \& WIKTOR 1980: 273. 
Body length often exceeding $100 \mathrm{~mm}$. Mantle covers less than $1 / 3$ body length. Coloration varied: body unicolour, spotted or striped. Intestine consisting of 3 loops, devoid of caecum or with long caecum (Fig. 49). Kidney rounded, gently oval. Bladder sac-like. Penis cylindrical, vermiform, long, sometimes considerably longer than body. Its posterior end without penial gland. Inside penis longitudinal folds. Spermatheca small and ovate, set on a short spermatheca duct, connected with penis or oviduct.

The natural distribution range covers the western Palaearctic, particularly the Mediterranean, including Asia Minor and N Africa. There are about 20 species included in two genera: Limaxs. str. and Limacus.

\section{Subgenus Limacus Lehmann, 1864}

Limacus LEHMANN 1864: 145. Species typica: Limax breckworthianus Lehmann, 1864 (= L. flavus Linnaeus, 1758).

Plepticolimax MALM 1868: 62. Species typica: Limax breckworthianus Lehmann, 1864.

Simrothia CLESSIN 1884: 62. Species typica: Limax breckworthianus Lehmann, 1864.

Body length up to $120 \mathrm{~mm}$. Body irregularly palerand darker-spotted; unicolour specimens rarely found. Last intestinal loop short, joined by a caecum

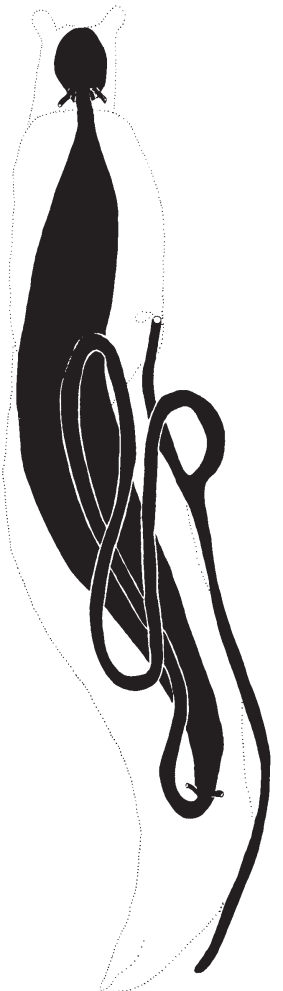

Fig. 49. Limax (Limacus) flavus Linnaeus, 1758 - alimentary canal of a specimen from Tainshengqiao (orig.); diagrammatic which reaches posterior body end. Prostate longer than oviduct. Two species known.

\section{Limax (Limacus) flavus Linnaeus, 1758}

Limax (Limacus) flavus LinNAEUs 1758: 652. Terra typica: Sweden (?).

Synonyms: The following synonyms may refer to either of two externally very similar species, namely L. (Limacus) flavus and L. (L.) maculatus (see Comments): Limax variegatus Draparnaud, 1801; Limacella unguicula Brard, 1815; Limax megalodontes Quoy et Gaimard, 1824; Limacellus unguiculus Turton, 1831; Limax umbrosus Philippi, 1844; Limax Ehrenbergii Bourguignat, 1853; Limax Deshayesi Bourguignat, 1861; Limax Companyoi Bourguignat, 1863; Limax eubalius Bourguignat, 1864; Limax breckworthianus Lehmann, 1864; Limax baeticus Mabille, 1968 (for more detailed data see HESSE 1926: 85 and WIKTOR 1989: 172).

Deroceras (Agriolimax) melasma CHEN et al. 1995: 403, Figs 6-9. Holotypus: ZIAS. Locus typicus: Hanzhong City $\left(33^{\circ} 03^{\prime} \mathrm{N}, 107^{\circ} 01^{\prime} \mathrm{E}\right)$, Shaanxi Province, China. Syn. nov.

References: YEN 1937: 306; WIKTOR 1973: 75, Figs 70-80, 101, 104, 108, 266-267; LIKHAREV \& WIKTOR 1980: 281, Figs 353-356; WIKTOR \& LIKHAREV 1980: 424, Fig. 25; WIKTOR 1989: 173, Figs 238-239, 244-245, 251-252; CHEN et al. 1995: 402, 406, Figs 6-9.

Length up to $120 \mathrm{~mm}$, but specimens considerably smaller, e.g. $45 \mathrm{~mm}$ in length, can already be sexually mature. Keel poorly marked, back arched. Both mantle and back, and partly sides, covered by darker and lighter dots (Fig. 50). The darker dots are grey-green, dirty cream or orange, whereas the paler ones are olive, cream or yellowish. The dark pigment does not extend to the sole margin (!). Mucus yellow or orange, watery and transparent.

Genitalia (Fig. 51). Penis vermiform, convoluted the bent sections joined together by a vascularized membrane - roughly equalling $1 / 6$ body length. Vas deferens opens apically but slightly laterally. Beside its junction with penis penial retractor is attached. Penis connected with atrium. Spermatheca small, oval; its duct joins oviduct (!), the resulting enlargement connected with atrium (!).

Habitat. Within its natural distribution range the slug is a forest species. It exhibits a unique predisposition towards synanthropization, in such a case living in glasshouses, dairies and vegetable warehouses, and - if the climate is favourable - also in gardens, cemeteries, parks etc. The slug feeds on various plant parts, especially tubers and fruit, in dairies probably on dairy products. In China, the species can be found in greenhouses where vegetables and flowers are cultivated. 


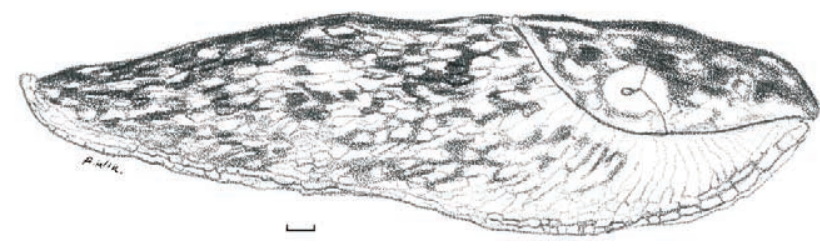

Fig. 50. Limax (Limacus) flavus Linnaeus, 1758 - a specimen from Tainshengqiao (orig.)

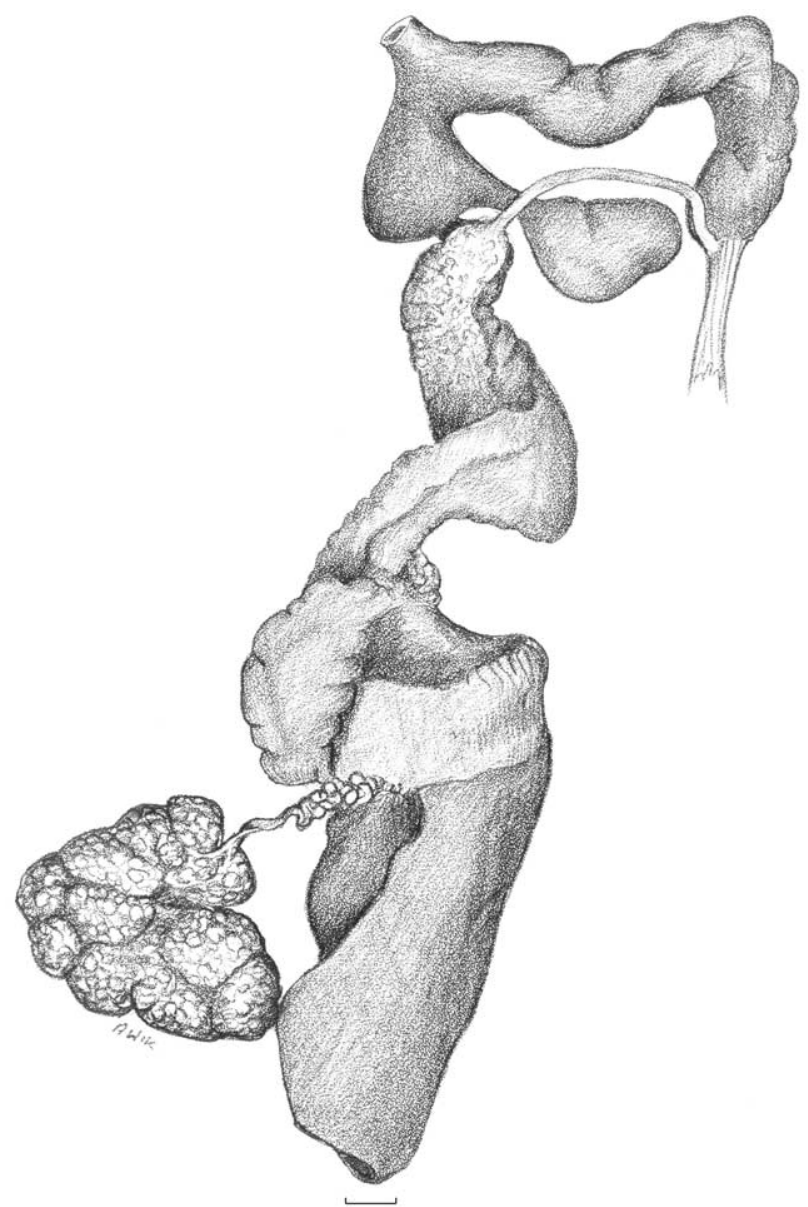

Fig. 51. Limax (Limacus) flavus Linnaeus, 1758 - reproductive system of a specimen from Tainshengqiao (orig.)

Material examined (Map 12): Heilongjiang Prov: Qiqiha'er, 1979-IV-20, 13 spec., leg. CHEN DE-NIU; Beijing: Chuanbanhutong, Chong wenmengwai, 1979-IV-10, 3 spec., leg. CHEN DE-NIU; 1973-VIII, 1 spec., leg. Chen DE-NIU; Hongmiao, Xidan, 1965-VI-17, 7 spec., leg. CHEN DE-NIU; Xidan, 1965-VIII, 1 spec., leg. CHEN DE-NIU; Shaanxi Prov.: Jingyanghe, Zhengba County, 1992-IV-3, 2 spec., leg. CHEN DE-NIU; Wuhouci, Mian County, 1992-IV-2, 1 spec., leg. CHEN DE-NIU; Ziyang County, 1992-III-31, 1 spec., leg. Chen DE-NIU; Hebei Prov.: Hejiaping, Changyang County, 1984-V-18, 2 spec., leg. CHEN DE-NIU; Guizhou Prov.: Yangguan, Guiyang, 1998-V, 25 spec., leg. Chen De-NiU; Yunnan Prov.:

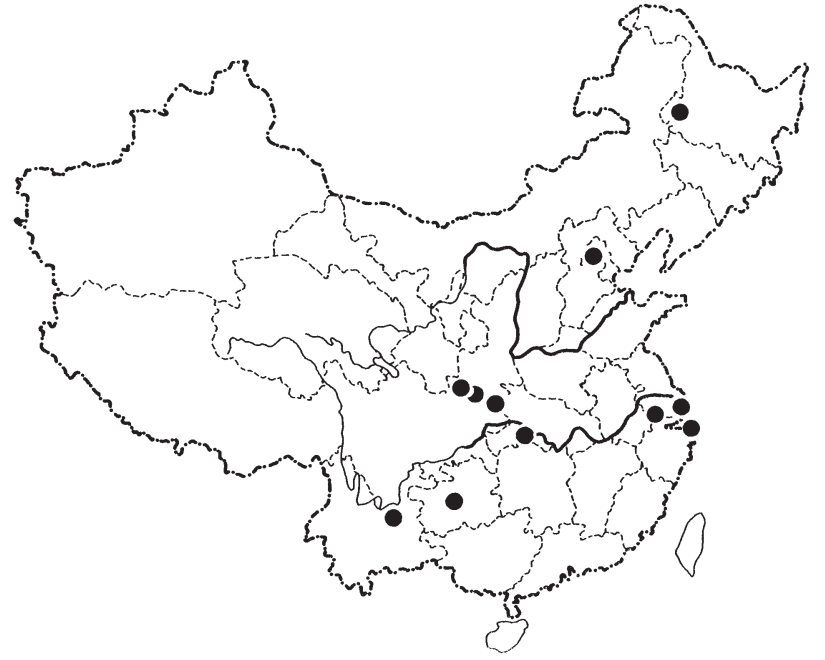

Map 12. Localities of Limax (Limacus) flavus Linnaeus, 1758 in China

Tianshengqiao, Xundian County, 1978-VIII-31, 19 spec., leg. CHEN DE-NIU.

Distribution. Its original distribution area is not precisely known. In natural habitats it occurs in south-eastern Europe and partly Asia Minor. Introduced worldwide, also in China (Map 12); recorded from Shanghai by YEN (1937).

Comments. A species bearing a close resemblance to L. (L.) flavus is Limax (Limacus) maculatus (Kaleniczenko, 1851) (synonyms: L. grossui Lupu, 1970; L. pseudoflavus Evans, 1972). Originally, L. maculatus inhabited the Black Sea coast and Transcaucasia but has been introduced in Ireland, Great Britain and some parts of Russia. As a synanthrope, it can be expected in various parts of the globe. L. maculatus differs from L. flavus in its darker coloration, the dark pigment reaching the sole margins (!) and the spermatheca being connected with the penis, not with the oviduct (!) (see LIKHAREV \& WIKTOR 1980: 284, Figs 357-358).

\section{Family Agriolimacidae Wagner, 1935 (Fig. 1)}

Agriolimacidae WAGNER 1935: 174.

Deroceratinae MAGNE 1952: 30.

Derocerasinae HUDEC 1972: 84.

Derocerasidae BODON et al. 1982: 53.

References: LIKHAREV \& WIKTOR 1980: 123; WIKTOR 1989: 100; HAUSDORF 1989: 35; WIKTOR 2000: 387.

Medium-sized and small slugs: up to $60 \mathrm{~mm}$ in length. Body posteriorly pointedly tapering. Mantle oval, often covering more than 1/3 body length, in live slugs its surface covered by concentric wrinkles. Pneumostome postmedial. Sole divided into 3 zones; in median zone wrinkles forming V-letters, in lateral zones they are transverse. General coloration uniform or the body is darker-spotted (never striped). Mar- 
ginal radular teeth sabre- or dagger-shaped. Alimentary canal coiled in two loops, the second reaching more posterad. Heart axis tilted by $45^{\circ}$ relative to long body axis. Kidney, equipped with lobus (Mesolimax being an exception), surrounds heart from back and sides. Bladder oval. Shell flat, asymmetrical, with concentric growth lines. Head retractors of right and left side join into a common trunk with posterior insertion. Penis short, sac-shaped, usually equipped with a penial gland and often with appendices. Female genitalia simple. Sperm transmitted in the form of jelly (no spermatophore is produced). The distribution range covers nearly the whole Holarctic and a fragment of Abyssinia in Africa. Some species have been introduced worldwide. The family is divided in two subfamilies comprising 6 genera with a total of ca. 120 species. Only two species have so far been recorded from China. Both seem to be indigenous to this country.

\section{Subfamily Agriolimacinae Wagner, 1935}

\section{Agriolimacinae WAGNER 1935: 174.}

Body length up to $50 \mathrm{~mm}$. Pneumostome clearly postmedian. Kidney equipped with lobus. Penis short, sac-like. The subfamily comprises 5 genera, with ca 110 species. The distribution range like that of the family.

\section{Genus Deroceras Rafinesque, 1820}

Deroceras RAFINESQUE 1820: 10. Species typica: Limax gracilis Rafinesque, 1820 [= Deroceras laeve (O. F. Müller, 1774)].

Synonyms: Agriolimax Mörch, 1865; Limax Linnaeus, 1758 (partim); Limacella Brard, 1815 (partim); Krynickia Kaleniczenko, 1839 (nomen nudum); Krynickillus Kaleniczenko, 1851 (partim); Megalopelta Mörch, 1857; Hydrolimax Malm, 1870; Krynichia Hazay, 1884; Chorolimax Westerlund, 1894 (for more data on synonymy see WIKTOR 2000: 388).

Body length less than $45 \mathrm{~mm}$. Mantle covers over $1 / 3$ body length. Coloration ranging from snowy white to deep black, the body being unicolour or spotted. Mucus colourless, but in many species a milky white secretion is also produced. On the terminal section of intestine, i.e. rectum, there is often (not always) a short or vestigial caecum. Kidney bears a large lobus. Penis short, nearly always equipped with penial gland, which is either branched or composed of many processes, and often having an appendix. Inside penis almost always a conical or flat stimulator.

Distribution range like that of the family. The genus comprises two subgenera: Deroceras s. str., represented by 98 species, and Liolytopelte Simroth, 1901 with only a few species. There are only two members of Deroceras s. str. occurring in China.

\section{Deroceras (Deroceras) altaicum (Simroth, 1886)}

Agriolimax altaicus SIMROTH 1886: 28, Pl. 1: Fig. 14. Terra typica: Altay Mts.

Agriolimax buchar var. coeciger SIMROTH 1910: 523, Pl. 7: Figs 19-21. Terra typica: Tian-Shan Mts. Syntypi: ZIN.

Agriolimax sibiriensis WALDÉN 1956: 363 - a new name for A. hyperboreus sensu Simroth, 1901 (non Westerlund, 1876). Locus typicus: Jakutsk (Siberia). Typus: ZIN.

Agriolimax altaicus transitorius WALDÉN 1956: 355, Figs 5-15, 18, Pl. 1: Fig. 28.

Deroceras (Agriolimax) stigmatoida CHEN \& GAO 1989: 408, Figs 1-5. Locus typicus: Minxian County, Gansu Prov. (341’N, $\left.104^{\circ} 25^{\prime} \mathrm{E}\right)$, China. Paratypus: ZIAS. Syn. nov.

References: UVALIEVA 1969: 53; LIKHAREV \& WIKTOR 1980: 146, Figs 92-102; WIKTOR 2000: 399, Figs 75-82.

Body length up to ca. $30 \mathrm{~mm}$. General coloration dirty cream, grey, yellow-brownish or blackish, sometimes darker-spotted. The dark pigment is usually concentrated in skin grooves of the posterior body section, which results in a reticulate pattern (Fig. 52).

Genitalia (Fig. 53). Gonad usually hidden beneath liver lobes and not reaching posterior end of viscera. Penis ovate, in older specimens elongated, sometimes convoluted and medially constricted. Penial gland small, finger-shaped or conical, rarely with an additional small lateral branch, and of smooth surface. Inside penis a stimulator in the form of a longitudinal fold. Spermatheca oval, not delimited from a short spermatheca duct.

Rectal caecum well-developed (Fig. 54).

Bionomics poorly known (UvaliEva 1969). The species seems to be euryoecious to a large degree. It is found both in the steppe and alpine zone, sheltering under stones and in leaf litter. In China, D. (D.) altaicum can be found in moist places in thickets near farms; sometimes it lives under cobbles in a similar environment. The slug reaches an altitude of up to 4,200 m a. s. 1 .

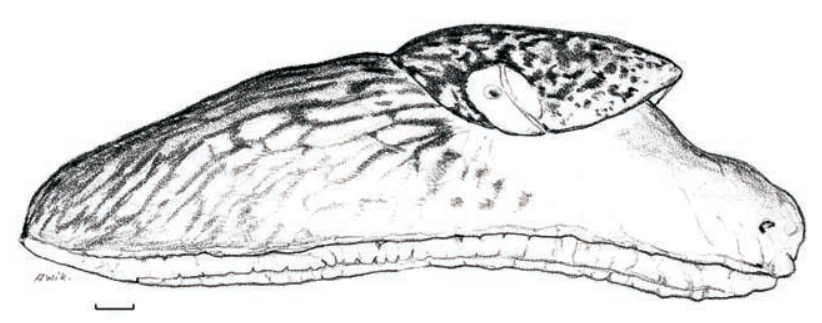

Fig. 52. Deroceras (Deroceras) altaicum (Simroth, 1886) - a specimen from the Kanhe River bank (orig.) 


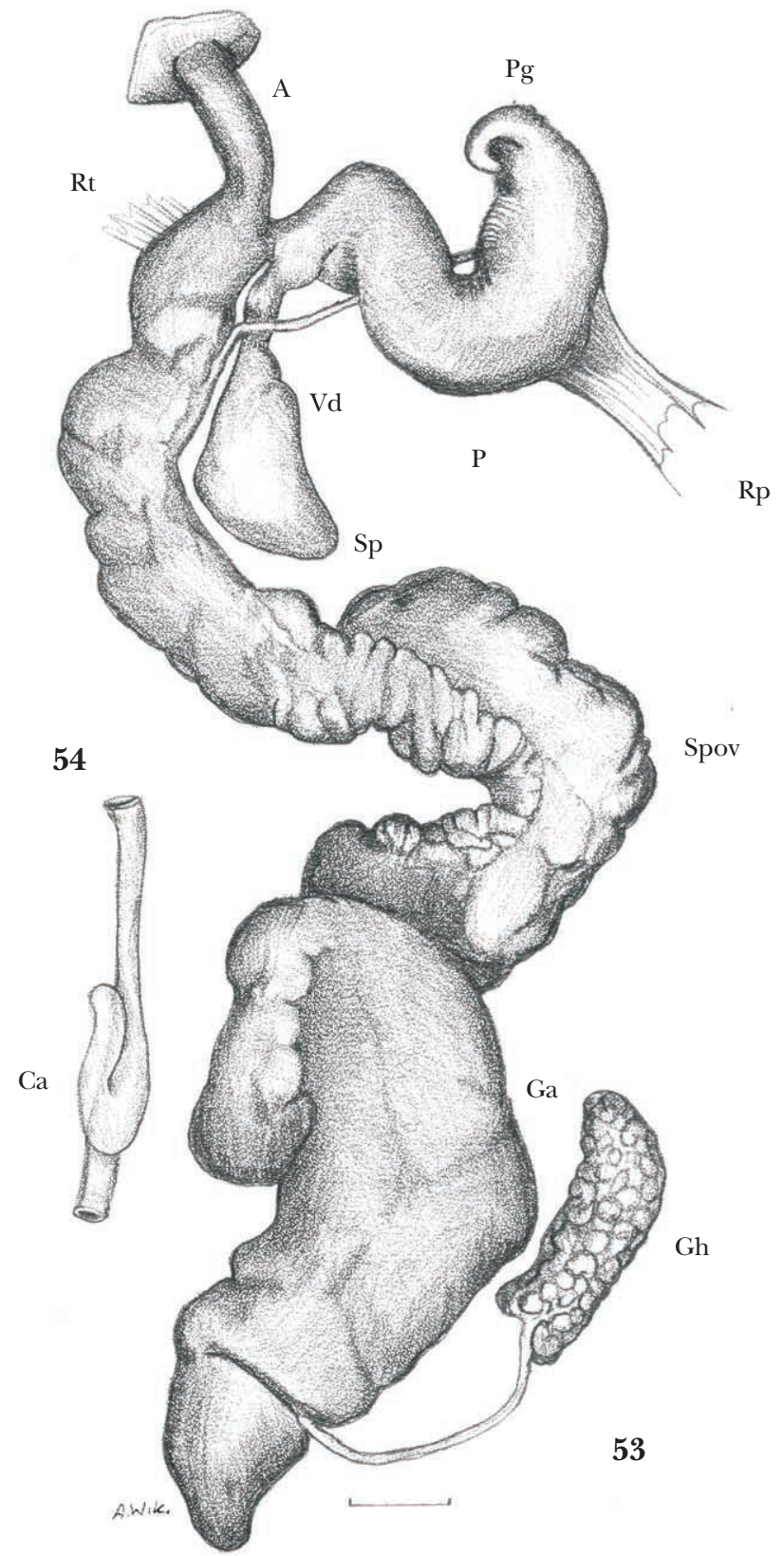

Figs 53-54. Deroceras (Deroceras) altaicum (Simroth, 1886) - a specimen from the Kanhe River bank. 53 - reproductive system. 54 - a fragment of rectum with caecum. A - atrium, Ca - caecum, Ga - glandula albuminalis, $\mathrm{Gh}$ - glandula hermaphroditica, $\mathrm{P}$ - penis, $\mathrm{Pg}$ - penial gland, Rp - musculus retractor penis, Rt - musculus retentor, Sp - spermatheca, Spov - spermoviductus, $\mathrm{Vd}$ - vas deferens

Material examined (Map 13): Xingjiang: Aksu, 1975-VIII-20, 17 spec., leg. CHEN DE-NIU; Hebei Prov.: Maojingba forestry station, Longhua County, 6 spec., leg. CHEN DE-NIU; Wulingshan Mt., Xinglong County, 1998-IX-5, 2 spec., leg. CHEN DE-NIU \& ZHANG GUO-QING; Wulingshan Mt., Xinglong County, 1982-VIII-20, 14 spec., leg. CHEN DE-NIU; Gansu Prov.: Chengguan, Min County, 1987-VIII-20, 7 spec., leg. Chen De-NIU; Min County, 1986-X, 5

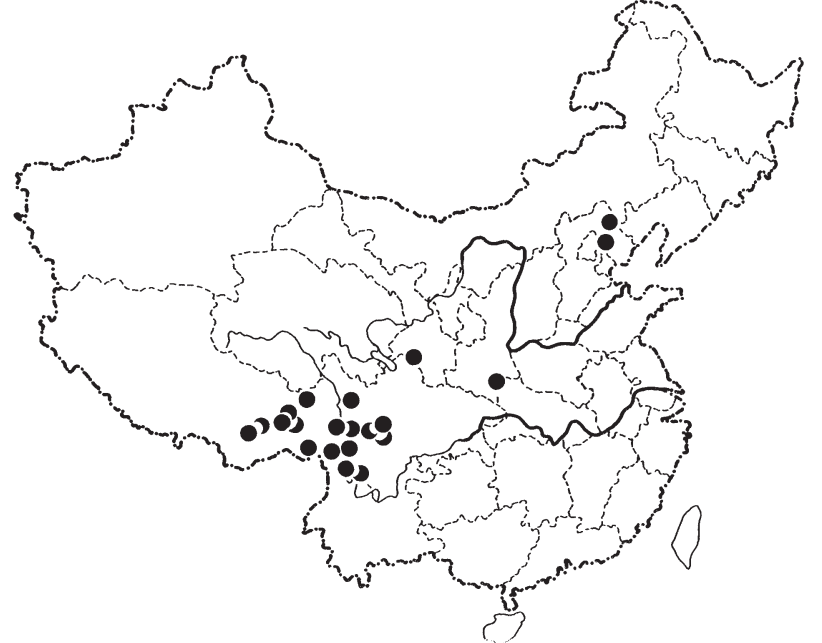

Map 13. Localities of Deroceras (Deroceras) altaicum (Simroth, 1886) in China

spec., leg. CHEN DE-NIU; Shaanxi Prov.: Bank of the Kanhe River, Xunyang County, 1984-X-23, 3 spec., leg. Chen De-NiU; Tibet: Tuobaxiang, Changdu County, under calcareous stones near a wheat farm, somewhat dry, 1997-VIII-9, 19 spec., leg. WU MING; Mainling County, Tibet, under a pile of broken bricks, near a house, humid environment, 1997-VII-3 4, 14 spec., leg. WU MING; Town of Linzhi County, near a house, in the neighbourhood of grassland and bushes, 1997-VII-8 9, 5 spec., leg. WU MING; Tongmai, Bomi County, under moist granite near a village, 2,900 m a.s.1., 1997-VI-11 15, 15 spec., leg. Wu MinG; Guyuxiang, Chayu County, under rotten wood in the shadow of a peach tree, dry, 1997-VIII-2 3, 9 spec., leg. WU MING; Sichuan Prov.: Ganzi State, 1997-IX, leg. WU MING; Yajiang County, 3,800 m a.s.1., 1981-VII-29, 10 spec., leg. CHEN DE-NIU; Tagongqu, Kangding County, 3,650 m a.s.l., 1981-VIII-8, 10 spec., leg. CHEN DE-NIU; Kangding County, 3,400 m a.s.l., 1981-VII-31, 6 spec., leg. CHEN DE-NIU; W slope of Gonggashan Mt., Kangding County, 1982-IX-6, 3 spec., leg. CHEN DE-NIU; Guanding, Kangding County, 3,700 m a.s.1., 1981-VIII-16, 8 spec., leg. CHEN DE-NIU; Zhuolaqu, Batang County, 1982-VIII-16, 5 spec., leg. CHEN DE-NIU; Army Station, Litang County, 1982-VIII-23, 11 spec., leg. CHEN DE-NIU; Army Station, Yajiang County, 1982-VIII-26, 1 spec., leg. CHEN DE-NIU; Kangding County, 1981-VIII-18, 6 spec., leg. CHEN DE-NIU; Yalong, Kangding County, 1981-VIII-19, 23 spec., leg. CHEN DE-NIU; W slope of Gonggashan Mt., Kangding County, 1982-IX-9, 12 spec., leg. CHEN DE-NIU; W slope of Gonggashan Mt., Luding County, 1982-IX-9, 68 spec., leg. CHEN DE-NIU; W slope of Gonggashan Mt., Luding County, 1982-IX-2, 68 spec., leg. CHEN DE-NIU; Daxueshan Mt., Xiangcheng County, 4,200 m a.s.1., 1981-VII-27, 1 spec., leg. CHEN DE-NIU; Daxueshan Mt., Daoban, Xiangcheng 
County, 4,100 m a.s.l., 1981-VII-27, 21 spec., leg. Chen De-NIU; Maintain Squad of Dakou Mt., Xiangcheng County, 4,100 m a.s.1., 1981-VII-27, 82 spec., leg. CHEN DE-NIU; Gonggashan Mts, Luding County, 1982-IX-20, 2 spec., leg. CHEN DE-NIU; Yunnan Prov.: Wenshuixiacun, Zhongdian County, 1982-VII-10, 7 spec., leg. CHEN DE-NIU; Zhongdian County, 1981-VIII-3, 32 spec., leg. CHEN DE-NIU; E slope of Baimangxueshan Mt., Deqing County, 1981-VIII-26, 28 spec., leg. CHEN DE-NIU; Zhongdian County, 4,200 m a.s.1., 1981-VII-20, 1 spec., leg. CHEN DE-NIU; Deqing County, 1984-VIII-20, 1 spec., leg. CHEN DE-NIU; S slope of Daxueshan Mt., Zhongdian County, 1981-VIII-18, 5 spec.; Yakou, Daxueshan Mt., 1981-VIII-16, 6 spec., leg. CHEN DE-NIU; Shuoduoganghe, Xiaozhongdian, Zhongdian County, 1984-IX-1, 3 spec., leg. CHEN DE-NIU; Zangeqianjing, Zhongdian County, 1981-VIII-8, 21 spec., leg. CHEN DE-NIU.

Distribution. An Asian species, distributed from Kamchatka, Sakhalin, the Kuril Islands and Primorskiy Kray to Mongolia, Lake Baikal, the Sayan Mts, Altay Mts, Dshungarski Khrebet Mts and the West Tyan-Shan Mts; in China to the Yangtse-Jiang River (Map 13).

Comments. The widely distributed $D$. agreste (Linnaeus, 1758) is very similar to D. altaicum. The distribution ranges of these two species probably partly overlap. D. agreste attains a larger size, while its body is neither spotted nor reticulated. Its penis, which is usually shorter, has a deeper lateral constriction; stimulator conical (WIKTOR 2000: 397, Figs 63-74).

\section{Deroceras (Deroceras) laeve (O.F. Müller, 1774)}

Limax laevis O. F. MülleR 1774: 1. Locus typicus: Frideriksdal (near Copenhagen, Denmark). Holotypus: probably non-existent.

Synonyms: Limax brunnaeus Draparnaud, 1801; Limax gracilis Rafinesque, 1820; Limax campestris Binney, 1842; Limax parvulus Normand, 1852; Limax weinlandii Heynemann, 1862; Limax araneus Gassies, 1867; Krynickillus (Malino) brunneus Mabille, 1868; Limax montanus Ingersoll, 1875; Limax ingersolli Binney, 1875; Limax hyperboreus Westerlund, 1876; ?Krynickillus mentonicus Nevill, 1880; Limax Hemphili Binney, 1890; Agriolimax globosus Collinge, 1896; Agriolimax Perkinsi Collinge, 1896; Agriolimax Bovenoti Collinge, 1897; Limax berendti var. pictus Cockerell, 1897; Agriolimax pseudodioicus Velichkovskiy, 1910; Agriolimax renschi Wagner, 1934; Deroceras monentolophus Pilsbry, 1944; Agriolimax schulzi Cvetkov, 1940 (for more detailed data see WIKTOR 2000: 462).

Agriolimax pellucidus CHEN \& GAO 1979: 359, Figs 1-5. Locus typicus: Zhalaite Qi, Heilongjiang Province, China. Holotypus: ZIAS. Syn. nov.
?Agriolimax agrestis: CHEN et al. 1984: 362.

References: PILSBRY 1948: 539, Figs 289-290 a-c; WALDÉN 1956: 349, Figs 1-4, Pl. 1: Figs 23-27; QUICK 1960: 172, Figs 11 A, B, E, F, N, 19; WIKTOR 1973: 106, Figs 102, 105-106, 150-158, 238, 270-273, Map 14; LIKHAREV \& WIKTOR 1980: 129, Figs 47-54; WIKTOR 1989: 104, Figs 73-74, 77-87, Map 4; WIKTOR 2000: 462, Figs 332-349.

Body length not exceeding $22 \mathrm{~mm}$, and even smaller specimens are frequently sexually mature and reproduce. Body more or less cylindrical. Mantle large, its posterior edge extending to half body length. Live slugs are chocolate or light coffee, of roughly uniform coloration. After preservation the general coloration becomes paler, irregular fine darker spots appearing on mantle. Mucus colourless and watery.

Genitalia (Figs 55-56). A partial or entire reduction of male copulatory organs, particularly of penis and its appendages, and sometimes of the free section of oviduct, is a common phenomenon in this species. The aphallic form (completely devoid of penis) is usually larger and has an oval or spherical spermatheca set on a clearly delimited long spermatheca duct (Fig. 55). When the penis is fully developed (euphallic form - Fig. 56), it is worm-like elongated, anteriorly slightly distended, posteriorly convoluted or twisted; on its posterior end there may be some small papillae representing penial gland. Vas deferens opens to penis approximately at $2 / 3$ its length. Penial retractor delicate and thin, laterally attached to penis roughly at half-length. Inside penis there is a papilla-like conical stimulator. In the forms having the least reduced penis the posterior section of the organ is lacking and vas deferens opens apically. In the case of a more advanced reduction, only a rounded lateral distension of atrium, to which vas deferens opens, is preserved, or the latter organ is a blind loosely hanging canal, or else it is often lacking. Female genitalia in the euphallic forms are similar to those in the aphallic ones.

Rectal caecum absent (Fig. 57).

Bionomics. A definitely hygrophilous slug, living in various habitats if only of high subsoil moisture. Most often the species is found close to streams, channels and ditches, on lake shores, etc., both in forest and open areas, occurring in various climates from subpolar zones to the tropics. The slug is an agile animal. It perfectly well tolerates being submerged in water, particularly when the temperature is not high. Eggs do not suffer from submergence. D. laeve easily reproduces uniparentally. Its life cycle is very short, under favourable conditions completed within a month or two. The slug reproduces throughout the vegetation season, producing a few generations which co-exist. It is easily introduced. In China, the species is active in moist thickets and on farms where 

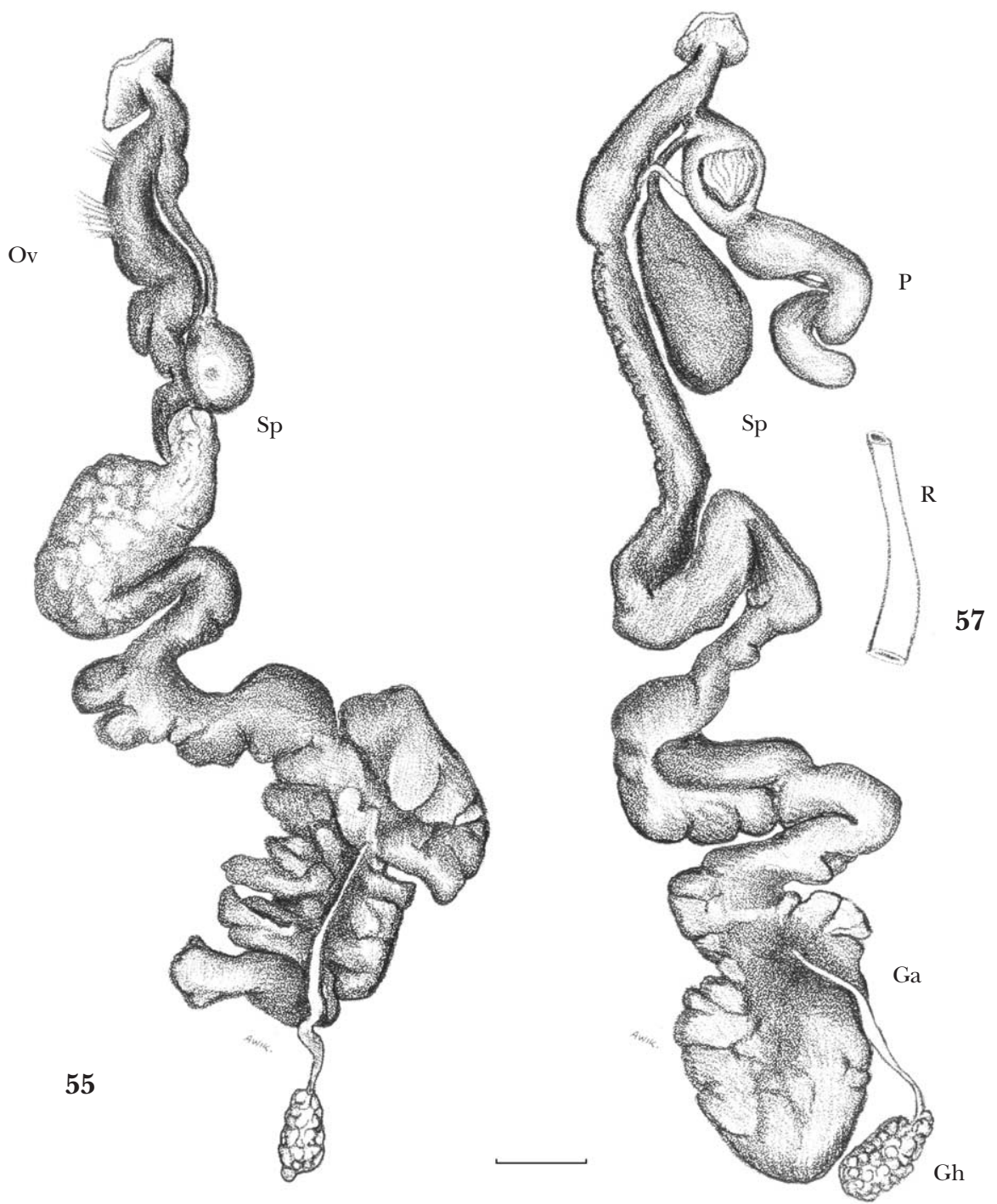

Figs 55-57. Deroceras (Deroceras) laeve (O.F. Müller, 1774) (orig.). 55 - reproductive system of an aphallic specimen from Wuhouci. 56 - reproductive system of a euphallic specimen from Hejiping. 57 - a fragment of rectum with caecum - the same specimen as in Fig. 56. Ga - glandula albuminalis, Gh - glandula hermaphroditica, Ov - oviductus, P - penis with stimulator visible inside, $\mathrm{R}$ - rectum, $\mathrm{Sp}$ - spermatheca

horsebean and cole are planted. It also lives on wet granite among lichens or moss.

Material examined (Map 14): (the altitude of localities ranges from $50 \mathrm{~m}$ a.s.l. - e.g. Hangzhou, Zhejiang Prov. - to 4,200 m a.s.l. - e.g. Zuogong, Tibet) Heilongjiang Prov.: Greenhouse of Teacher's School, Daqing, 1984-VI, 5 spec., leg. CHEN DE-NIU; Jilin Prov.: Greenhouse of Chinese Medical College Changchun, 1980-VII-12, 5 spec., leg. CHEN DE-NIU; Nei Mongol: Baihe, Erlian, 1979-VI-23, 2 spec., leg. CHEN DE-NIU; Greenhouse of Baotou Garden, Baotou, 1989-I-7, 10 spec., leg. Chen DE-NIU; Baotou, 1988-IV-26, 10 spec., leg. CHEN DE-NIU; Campus of Agr. \& Herb. College, Huhehaote, 1998-VII-17, 84 spec., leg. LIU YONG-JIANG; Campus of Agr. \& Herb. College, Huhehaote, 1998-VI, 84 spec., leg. LIU YONG-JIANG; Greenhouse of Teacher's
College, Huhehaote, 1998-II, 1 spec., leg. LiU YonG-JIANG; Hebei Prov.: Chende, 1983-V, 35 spec., leg. CHEN DE-NIU; Beijing: The Imperial Garden, Beijing, 1982-X, 20 spec., leg. CHEN DE-NIU; Gansu Prov.: Chengguan, Min County, 1987-VII-23, 16 spec., leg. Zhang GUANG-Xue; Shaanxi Prov.: Wuhouci, Mian County, 1992-IV-5, 3 spec., leg. CHEN DE-NIU; Zhangliangmiao, Liuba County, 1992-IV-7, 29 spec., leg. CHEN DE-NIU; Baimaxiang, Nanzhen County, 1992-IV-4, 5 spec., leg. CHEN DE-NIU; Zhengba County, 1992-IV-3, 13 spec., leg. CHEN DE-NIU; Wafang, Ziyang County, 1992-III-31, 5 spec., leg. CHEN DE-NIU; Xiaomuling, Zheng'an County, 1992-III-28, 2 spec., leg. CHEN DE-NIU; Yunzhenghe, Zheng'an County, 1992-III-27, 2 spec., leg. CHEN DE-NIU; Zhongbacun, Chang'ancun, Pingli County, 1992-III-30, 21 spec., leg. CHEN DE-NIU; Chengguan, 


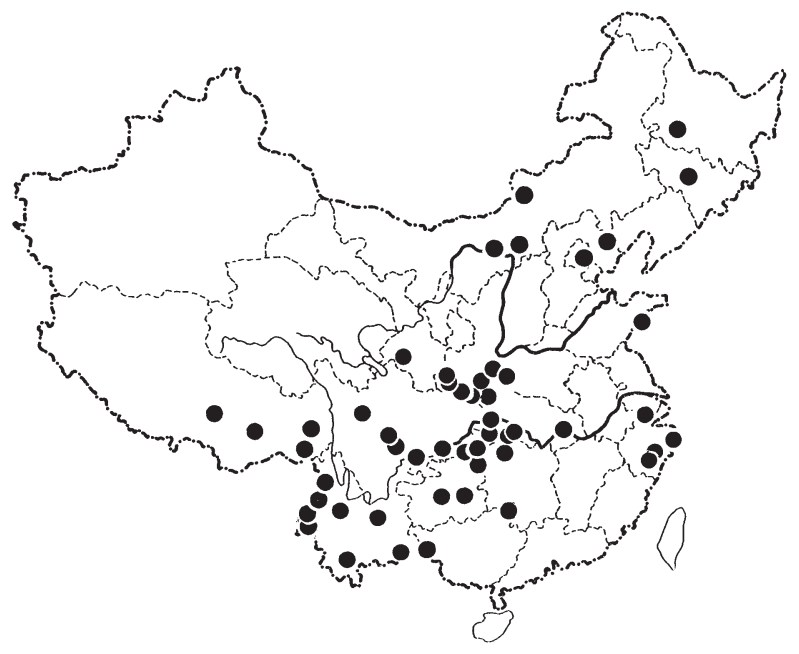

Map 14. Localities of Deroceras (Deroceras) laeve (O.F. Müller, 1774) in China

Pingli County, 1992-III-30, 6 spec., leg. CHEN DE-NIU; Jicun, Shangzhou, 1992-III-24, 1 spec., leg. CHEN DE-NIU; Sehe, Shanyang County, 1992-III-26, 5 spec., leg. CHEN DE-NIU; Shangnan County, Shaanxi Prov., 1992-IV, 5 spec., leg. CHEN DE-NIU; Sichuan Prov.: Moxi, E slope of Gonggashan Mt. Luding County, 1982-IX-14, 7 spec., leg. CHEN DE-NIU; Daofu County, 1982-VI-21, 4 spec., leg. CHEN DE-NIU; Chengguan, Ya'an County, 1964-VI-14, 15 spec., leg. Chen De-niu; Cangpingshan Mt., Ya'an County, 1964-VII-12, 5 spec., leg. CHEN DE-NIU; Lumbering Station, E slope of Gonggashan Mt., Luding County, 1982-IX-15, 1 spec., leg. CHEN DE-NIU; Fuhusi, Emei Mt., 1964-VIII-2, 1 spec., leg. Chen DE-NiU; Baoguosi, Emei Mt., 1964-VIII-3, 1 spec., leg. CHEN DE-NIU; Baoguosi, Emei Mt., 1964-VIII-3, 9 spec., leg. CHEN DE-NIU; Cuiping Hill, Yibin, 1964-VI-17, 4 spec., leg. CHEN DE-NIU; Beibei, Chongqing, 1980-VI-9, 17 spec., leg. CHEN DE-NIU; Youyang County, 1986-X, 1 spec., leg. CHEN DE-NIU; Shidi, Xiushan County, 1986-VI-16, 5 spec., leg. CHEN DE-NIU; Luojiayan, Jingxiqu, Qianjiang County, 1989-VII-23, 1 spec., leg. CHEN DE-NIU; Baidicheng, Fengjie County, 1986-VII-26, 1 spec., leg. CHEN DE-NIU; Shandong Prov.: Dalao \& Dalaoguan, Qingdao, 1963-VIII-5, 3 spec., leg. CHEN DE-NIU; Tibet: Lasah, 1980-V-27, 1 spec., leg. CHEN DE-NIU; Jiagecun, Mainling County, on/under rotten wood, rather humid environment, 1997-VI-30, 2 spec., leg. WU MinG; mountains of Xiachayu, Chayu County, 1,800 m a.s.1., 1980-VII-3, 1 spec., leg. CHEN DE-NIU; Jigongzhen, Chayu County, humid and near a house,
1997-VII-18 19, 2 spec., leg. WU MING; Zuogong, 4,200 m a.s.1., 1982-VIII-5, 1 spec., leg. CHEN DE-NIU; Hubei Prov.: Chengguan, Enshi, 1984-VI-1, 11 spec., leg. Chen DE-NIU; Hejiaping, Changyang County, 1984-V-18, 6 spec., leg. CHEN DE-NIU; Shizhushan Mt., Wufeng County, 1984-V-21, 1 spec., leg. CHEN DE-NIU; Vegetable Institute, Wuhan, 1992-VIII, 8 spec., leg. CHEN DE-NIU; Hunan Prov.: Qingyanshan Mt., Zhangjiajie, Dayong, 1988-VIII-19, 14 spec., leg. CHEN DE-NIU; Zhejiang Prov.: Hangzhou, 7 spec., leg. Chen De-NiU; Niutoushan, Changxing County, 1978-V-23, 36 spec., leg. CHEN DE-NIU; Niutoushan Mt., Changxing County, 1979-IX-14, 1 spec., leg. Chen De-NiU; Qingzu Farm, Ninghai County, 1979-V-21, 41 spec., leg. CHEN De-niu; Huzheng, Jingyun County, 1978-VI-24, 28 spec., leg. CHEN DE-NIU; Dashan Forestry Station, Lishui County, 1978-VI-17, 1 spec., leg. CHEN DE-NIU; Taishan Forestry Station, Lishui County, 1978-VI-23, 32 spec., leg. Chen DE-NIU; Shuiniuping, Fengyuan Forestry Station, Lishui County, 1978-VI-17, 2 spec., leg. CHEN DE-NIU; Yunnan Prov.: Pianma, Lushui County, Lujiangzhou, 1981-V-29, 1 spec., leg. CHEN DE-NIU; Pianma, Lushui County, Lujiangzhou, 1981-V-27, 2 spec., leg. CHEN DE-NIU; Yaojiaping, Lushui County, 1981-VI-5, 5 spec., leg. CHEN DE-NIU; Tengchong County, 1981-VI-22, 10 spec., leg. CHEN DE-NIU; Simao County, 1965-III-19, 83 spec., leg. CHEN DE-NIU; Heilongtan, Kunming, 1981-V-14, 10 spec., leg. CHEN DE-NIU; Mingzhuxiang, W suburb of Kunming, vegetable field, 1997-X-14, 116 spec., leg. CHEN De-niu; Liujiaying, Kunming, 1998-VIII-7 8, 241 spec., leg. CHEN DE-NIU; Chongka, Wenshan County, 1980-IX, 55 spec., leg. CHEN DE-NIU; Guizhou Prov.: Yangguan, Guiyang, 1998-V, 56 spec., leg. Chen De-NiU; Xishan Park, Guiyang, 1998-III-28, 28 spec., leg. CHEN DE-NIU; Tobacco station, Fuquan County, 3 spec.; Guangxi: Miao'ershan, Ziyuan County, 1984-X-25, 1 spec., leg. CHEN DE-NIU.

Distribution. D. laeve inhabits nearly the whole Holarctic from the Sahara in Africa to the eastern part of North America. It has been introduced worldwide as a synanthrope. Besides, the slug penetrates habitats which are almost natural. In China it is an indigenous species occurring in nearly whole country except for the Tibet (see Material and Map 14).

Comments. In all likelihood, the phenomenon of self-fertilization described by CHEN et al. (1984) with reference to Agriolimax agrestis actually concerned Deroceras laeve. 


\section{ACKNOWLEDGEMENTS}

We wish to thank the following persons for their assistance in preparing this paper: Prof. Dr. ILYA M. LIKHAREV from the Zoological Institute, Russian Academy of Sciences (Sankt Petersburg) and Mr. FrED NAGGS, The Natural History Museum (London), for the loan of slug material, including type specimens; Mrs. GRAŻYNA ZDUNEK-DUŚ for drawing the maps; RENATA BRASIŃSKA, M. A. for translating the text into English and Dr. hab. BEATA M. POKRYSZKO for proof-reading.

The project was financially supported by the National Natural Sciences Foundation of China (No. 39770095, No. 39970115) and the University of Wrocław, Poland.

\section{REFERENCES}

BACKELJAU T., DE BRUYN L. 1990. On the infrageneric systematics of the genus Arion Férussac, 1819 (Mollusca, Pulmonata). Bull. Inst. Royal Sci. Nat. Belgique 60: $35-68$.

BENSON W. H. 1842. Mollusca. In: General features of Chusan, with remarks on the flora and fauna of that island (CANTOR T., ed.), pp. 486-489. Ann. Mag. Nat. Hist. 9.

Bodon M., BoAto A., GiUsti F. 1982. On the genus Deroceras in western Liguria, with description of a new species (Gastropoda: Derocerasidae). Animalia, Catania 9: 53-71.

BRARD C. P. 1815. Histoire des coquilles terrestres et fluviatiles qui vivent aux environs de Paris. Paris.

CHEN DE-NIU, GAO JIA-XIANG 1979. On a new slug from China. Acta Zootaxonomica Sinica 4: 359-361 (in Chinese).

CHEN DE-NIU, GAO JIA-XIANG 1982. A new slug of the family Philomycidae from Zhejiang Province, China. Sinozoologia 2: 119-121 (in Chinese).

CHEN DE-NIU, GAO JIA-XIANG 1985. A new species of slug of the family Philomycidae from Shandong Province, China (Pulmonata, Stylommatophora). Acta Zootaxonomica Sinica 10: 24-26 (in Chinese).

CHEN DE-NIU, GAO JIA-XIANG 1988. A study on the land molluscs as the intermediate hosts of parasites of human and domestic animals from China. Sinozoologia 6: 55-65 (in Chinese).

Chen De-NIU, GaO JiA-XIANG 1989. A new species of slug from Gansu Province, China (Pulmonata: Stylommatophora). Acta Zootaxonomica Sinica 14: 408-410 (in Chinese).

CHEN DENIU, GAO JIAXIANG, SCHI JICHENG [= CHEN DE-NIU, GAO JIA-XIANG, SCHI JICHENG] 1984. Observations on the breeding of a single slug, Agriolimax agrestis. Acta Zoologica Sinica 30: 362-367 (in Chinese).

CHEN DE-NIU, XU WEN-XIAN, LIU YAN-HONG 1995. Zoogeographical analysis of the land molluscs from Shaanxi Province, China, with description of two new species (Gastropoda: Pulmonata: Stylommatophora). Acta Zootaxonomica Sinica 20: 398-410 (in Chinese).

Clessin S. 1884. Deutsche Excursions-Mollusken-Fauna. 2. Aufl., Nürnberg.

COLLINGE W. E. 1899. On the anatomy and systematic position of some recent additions to the British Museum collection of slugs. J. Malac. 7: 77-85.
COLLINGE W. E. 1900. Description of a new species of Anadenus from China. J. Malac. 7: 133-135.

DRAPARNAUD J. P. R. 1805. Histoire naturelle des Mollusques terrestres et fluviatiles de la France, Paris.

FÉRUSSAC J. B. L. D'Audebard DE 1819. Histoire naturelle génerale et particuliére des Mollusques terrestres et fluviatiles 2. Paris.

FÉRUSSAC J. B. L., D'AUdEBARD DE 1823. Histoire naturelle génerale et particuliére des Mollusques terrestres et fluviatiles. Nouvelle division des Pulmonés sans opercule 2: 96 a-z, $\alpha-\lambda$. Paris.

GRAY J. E. 1840 - see TURTON W.

GRAY J. E. 1847. A list of the genera of recent Mollusca, their synonymy and types. Proc. Zool. Soc. London 15: 129-206.

HASSELT J. C. VAN 1823. Uittreksel uit een' Brief van Dr. J. C. van HASSELT aan Professor VAN SWINDEREN. Algem. Konst- en Letterbode 2: 230-233.

HAUSDORF B. 1989. Phylogeny of the Limacoidea sensu lato (Gastropoda: Stylommatophora). J. Moll. Stud. 64: $35-66$.

HESSE P. 1926. Die Nacktschnecken der palaearktischer Region. Abh. Arch. Moll. 2: 1-152.

HeYnemann F. D. 1862. Die Nacktschnecken von Himalaya. Malak. Bl. 10: 137-143.

HoffmanN H. 1924. Zur Anatomie und Systematik der Philomyciden. Jenaische Zietschrift Naturwiss. 16: 363-391.

HudeC V. 1972. Poznamky k anatomii nikterých druhu plzu Krymu. Eas. Nár. Muz. (odd. Prirodovidný). Zoologie 141: 73-91.

LEHMANN R. 1864. Neue Nacktschnecken aus Australien. Malak. Bl. 11: 145-149.

LIKHAREV I. M., WIKTOR A. 1980. The fauna of slugs of the USSR and adjacent countries (Gastropoda terrestria nuda). Fauna SSSR. Mollyuski III(5). Nauka, Leningrad (in Russian).

LINNAEUS C. 1758. Systema naturae. Ed. X. reformata, Holmiae.

MABILLE J. 1883. Sur quelques espéces de mollusques terrestres. Bull. Soc. philos. Paris. 7: 39-53.

MAGNe A. 1952. Deroceratidae de la faune girondine. Proces verbaux Soc. sci. phys. natur. Bordeaux (1946-1948): 30-32. 
MALM A. W. 1868. Zoologiska observationer. V Häfted. Skandinaviska land sniglar, Limacidae etc. Reprinted: Göteborg, Kongl. Vetensk. Vitterh. Samh. Handlingar 1870, 10: 26-83.

MÖlLENDORFF O. 1899. Binnen-Mollusken aus Westchina und Centralasien. Ann. Mus. Zool. Acad. Imp. Sc. St. Pétersburg 4: 48-144.

MÜLLER O. F. 1774. Vermium terrestrium et fluviatilium, seu animalium infusoriorum, helminthicorum, et testaceorum, non marinorum, succincta historia. 2. Havniae et Lipsiae.

PILSBRY H. A. 1948. Land Mollusca of North America (North of Mexico). 3. II, part 2. Monogr. Acad. Natur. Philad.

QUICK H. E. 1960. British slugs (Pulmonata: Testacellidae, Arionidae, Limacidae). Bull. Brit. Mus. (Nat. Hist.), Zool. London 6: 103-226.

RAFINESQUE-SCHMALZ C. S. 1815. Analyse de la nature ou tableau de l'univers et des corps organisées. Palerme.

RAFINESQUE-SCHMALZ C. S. 1820. Annales of nature, or annual synopsis of new genera and species of animals, plants etc. discovered in North America. First Annual Number, for 1820. Lexington.

RIEDEL A., WIKTOR A. 1974. Arionacea. Ślimaki krążałkowate i ślinikowate (Gastropoda: Stylommatophora). Fauna Polski 2. PWN, Warszawa.

Simroth H. 1886. Weitere Mitteilungen über palaearktische Nacktschnecken. Jahrb. dtsch. malak. Ges. 13: 16-34.

SimrotH H. 1901. Die Nacktschnecken des Russischen Reiches. St. Petersburg.

SiMroTH H. 1902. Über einige kürzlich beschriebene neue Nacktschnecken, ein Wort zur Aufklärung systematischer Verwirrung. Zool. Anz. 25: 355-357.

Simroth H. 1910. Kaukasische und asiatische Limaciden und Raublungenschnecken. Ann. Mus. Petersburg 15: 499-560.

Simroth H., HofFmanN H. 1928. In: BronN H. G. (ed.). Klassen und Ordnungen des Tier-Reiches. Bd. 3. Mol- lusca II. Abt. Gastropoda. Buch 2. Pulmonata, Akademische Verlagsgesellschaft, Leipzig.

STOLICZKA F. 1873. On the land-shells of Penang Island, with descriptions of the animals and anatomical notes. Pt. 2 Helicacea. Journ. Asiat. Soc. Bengal. XLII: 11-38.

TURTON W. 1840. A manual of the land and freshwater shells of the British Islands, with figures of each of the kinds. Ed. 2 (J. E. GRAY, ed.). London.

UVALIEVA K. K. 1969. O rosprostranieni mollyuskov v vostochno-kazahanskoy oblasti. Izv. AN Kazakh. SSR., ser. biol. 3: 53-59.

WAGNER H. 1935. Die Nacktschnecken Ungarns, Croatiens und Dalmatiens. II. Ann. Mus. Nat. Hung. 29: 169-212.

WALDÉN H. W. 1956. Notes on some Siberian slugs, especially on the type of Limax hyperboreus Westerlund. Arkiv. zool., ser. 2, 10: 347-366.

WALDÉN H. W. 1961. On the variation, nomenclature, distribution and taxonomical position of Limax (Lehmannia) valentianus Férussac (Gastropoda, Pulmonata). Arkiv Zool., ser. 2, 15: 71-96.

WikTOR A. 1973. Die Nacktschnecken Polens. Arionidae, Milacidae, Limacidae (Gastropoda, Stylommatophora). Monogr. Fauny Polski 1. PWN, Kraków.

WikTOR A. 1989. Limacoidea et Zonitoidea nuda. Ślimaki pomrowiokształtne (Gastropoda: Stylommatophora). Fauna Polski 12. PWN, Warszawa.

WikTOR A. 2000. Agriolimacidae (Gastropoda, Pulmonata) - a systematic monograph. Ann. Zool. 49: 347-590.

WikTOR A., LiKHAREV I. M. 1980. The pallial complex of Holarctic terrestrial slugs (Pulmonata, Stylommatophora) and its importance for classification. Zool. Pol. 27: 409-448.

YEN T. C. 1937. Notes on some common slugs of Shanghai. Chinese J. Shanghai 27: 306-310 (in Chinese).

received: December 30th, 1999

accepted: February 20th, 2000 